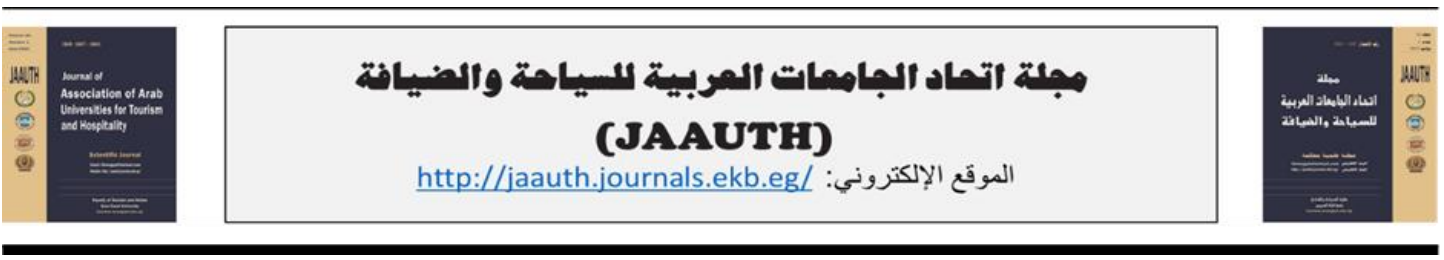

أثر السعادة الوظيفية والاستقرار الوظيفي على العاملين في شركات السياحة المصرية

بسام سمير الرميدي

هبة الله علي سيد محمد جعفر

قسم الدراسات السياحية - كلية السياحة والفنادق - جامعة مدينة السادات

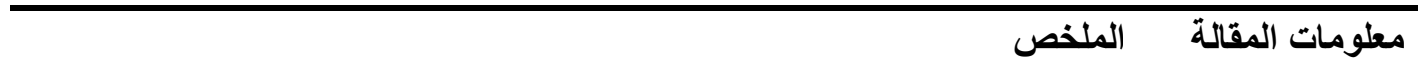

زاد اهتمام مختلف الشركات مؤخراً بالنواحي النفسية في العمل، مثل شعور العاملين الكلمات المفتاحية المفوماتة بالسعادة الوظيفية، والإحباط الوظيفي، بجانب اهتمام تلك الشركات بتوفير الإستقرار الوظيفي في بيئة العمل لضمان عدم حدوث إخلال وظيفي فيالعمل. حيث هدفت الدراسة إلي تقييم أثر السعادة الوظيفية والإستقرار الوظيفي والإحباط الوظيفي علي الإخلال الوظيفي في شركات السياحة، وتحديد إذا ما كان للسعادة الوظيفية دوراً وسيطاً في العلاقة بين الإستقرار الوظيفي والإخلال الوظيفي في تلك الشركات. كما هدفت الدراسة الى تحديد إذا ما كان هنالك فروق ذات دلالة إحصائية في استجابات

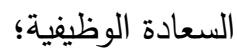

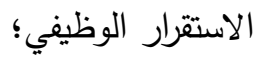

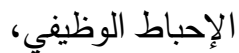

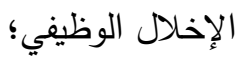
شركات السياحة المصرية. أفراد العينة لمتغيرات الدراسة المتمثلة فى السعادة الوظيفية، والإستقرار الوظيفي، والإحباط الوظيفي، والإخلال الوظيفي وذلك طبقاً للمتغيرات الديموغرافية. لتحقيق أهداف الدراسة؛ تم توزيع الوه استمارة على عينة من العاملين في شركات السياحة

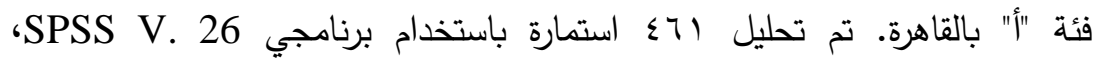
AMOS V.21

\section{(JAAUTH)}

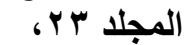

العدد 1)

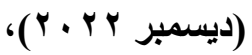

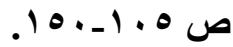
جزئياً في العلاقة بين الإستقرار الوظيفي والإخلال الوظيفي. كما أبرزت النتائج عدم وجود فروق ذات دلالة إحصائية في استجابات أفراد العينة للسعادة الوظيفية، والإستقرار الوظيفي، والإحباط الوظيفي، والإخلال الوظيفي تعزي للمتغيرات الديموغرافية والوظيفية. وقد أوصت الدراسة بأهمية تبني أنماط القيادة الداعمة المتمثلة في القيادة الخادمة والملهمة لتحقيق مستوى عالٍ من الاستقرار والسعادة الوظيفية لدى العاملين بشركات السياحة.

المقدمة ازداد الاهتمام بالظواهر الإيجابية داخل الثركات والمرتبطة بعلم النفسي الإيجابي، مثل زيادة الاهتمام بالرفاهية

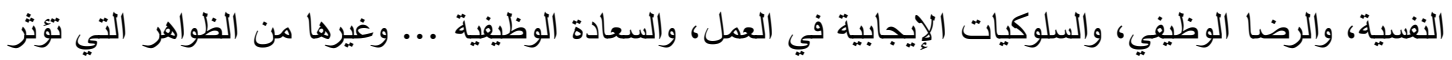
علي نجاح تلك الشركات أو فشلها (Al-Ali et al., 2019). وبناءً على ذلك؛ تلعب بيئة العمل دوراً هاماً في 


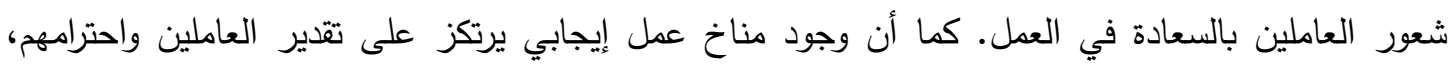

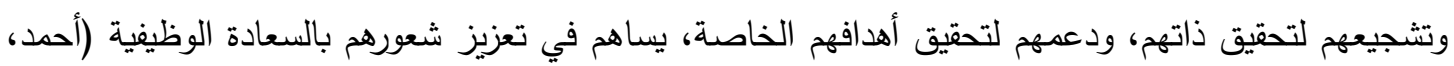

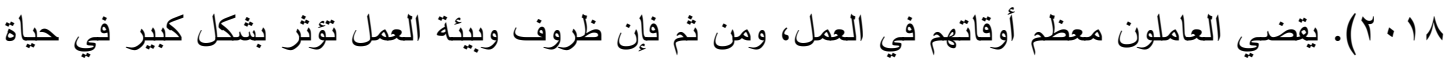

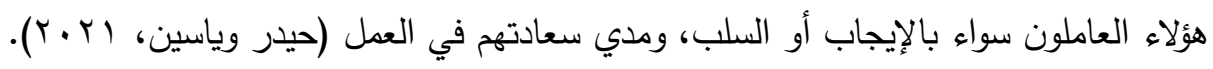
يعد مفهوم السعادة الوظيفية من الدفاهيم الحديثة في مجال العلوم الإدارية، وأصبح أكثر انتثاراً خلال السنوات

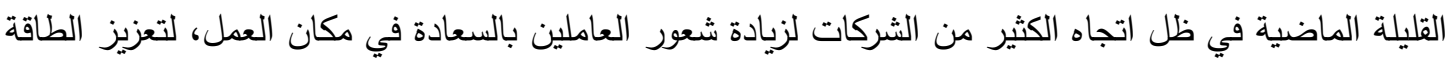

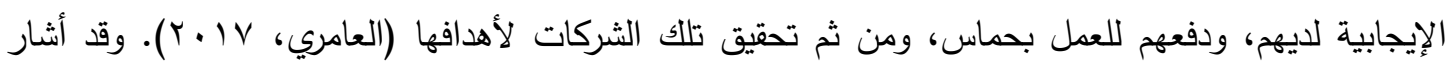

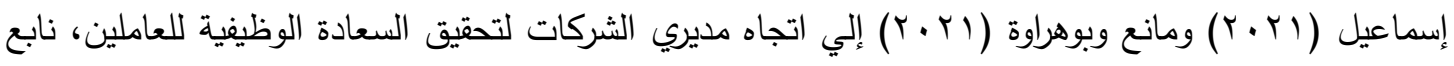

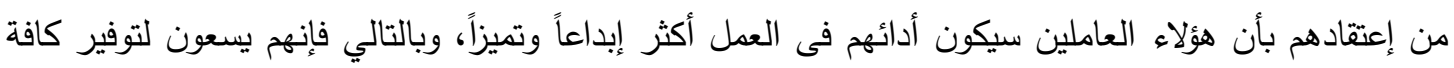

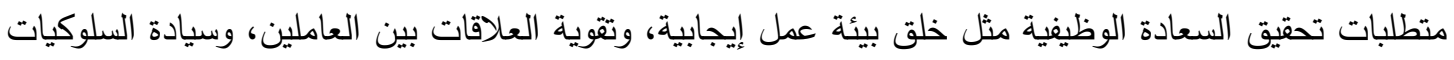

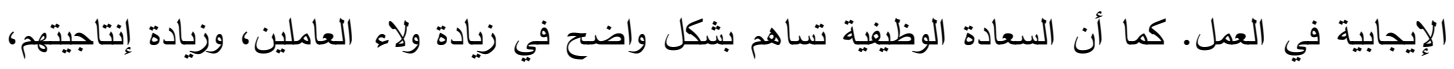

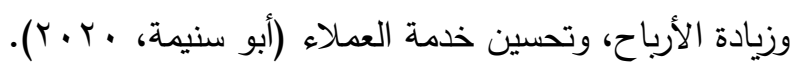

كما أصبح تحقيق الإستقرار الوظيفي متطلباً رئيسياً داخل مختلف الثركات، حيث أن شعور العاملين بالإستقرار

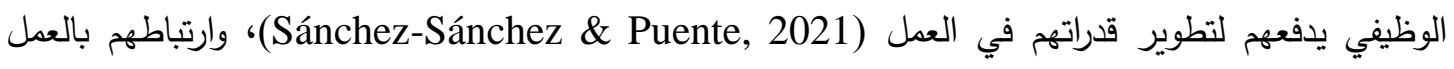

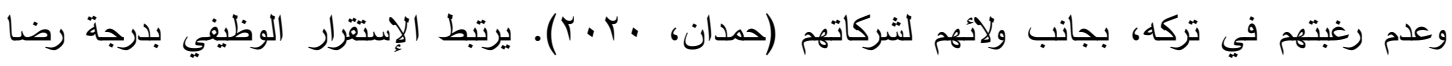

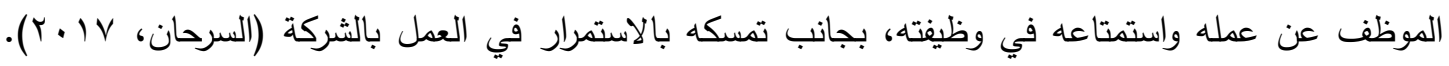

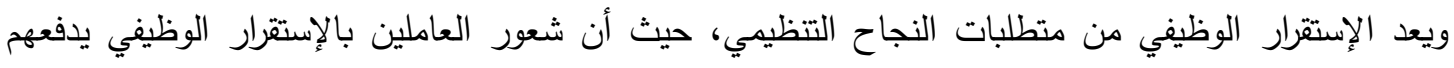

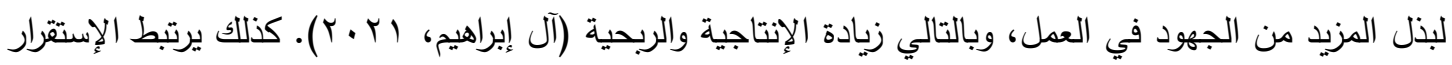

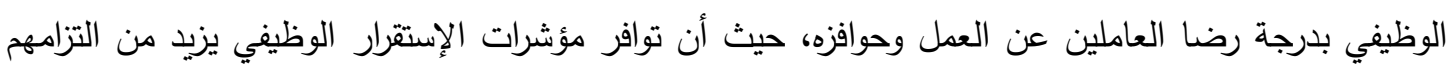

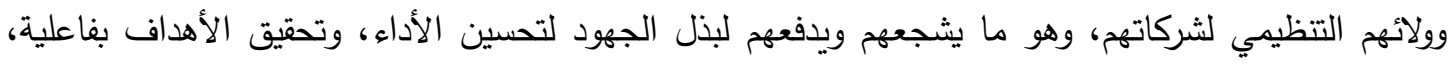

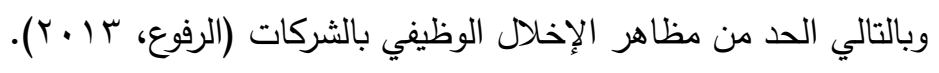

كذللك تتجه الشركات للتوسع والنمو في بيئة العمل السريعة التغيير وشديدة المنافسة، بجانب تزايد احتياجات

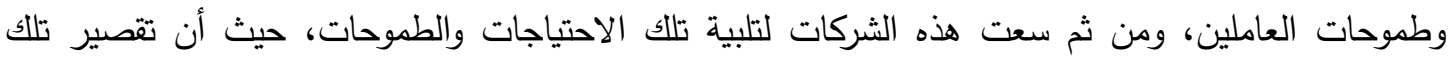

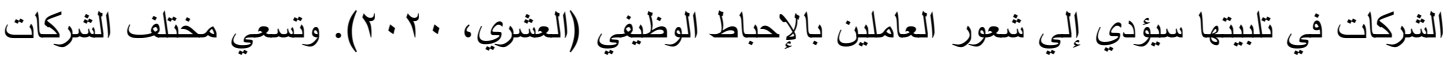

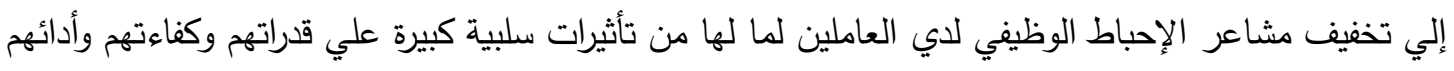

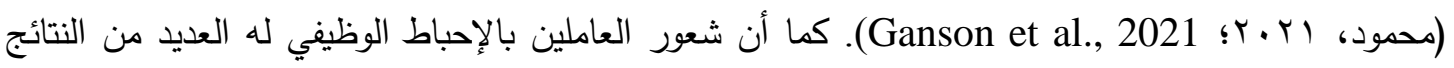

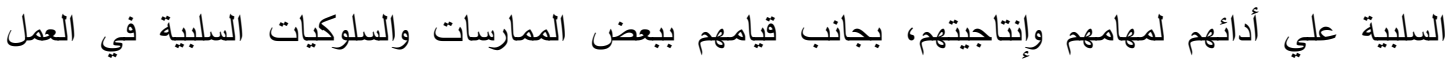

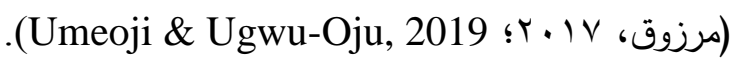

في ضوء ما سبق؛ تسعي الكثير من الشركات اليوم لتوفير متطلبات تحقيق الإستقرار الوظيفي والسعادة الوظيفية

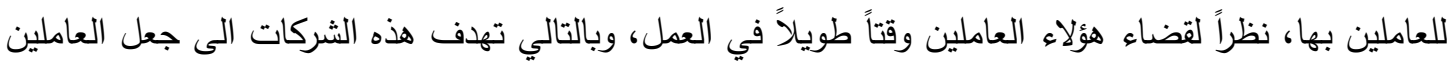


أكثر إقبالاً ودافعية للعمل. كما تسعي الكثير من الشركات للبحث عن أسباب الإحباط والإخلال الوظيفي لدي

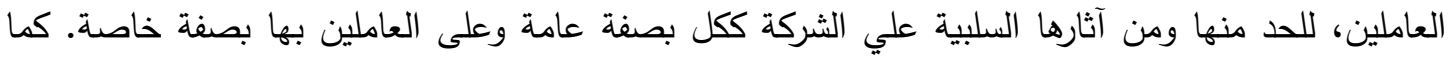

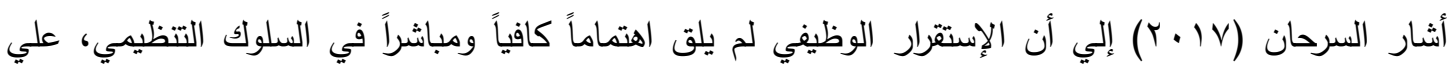

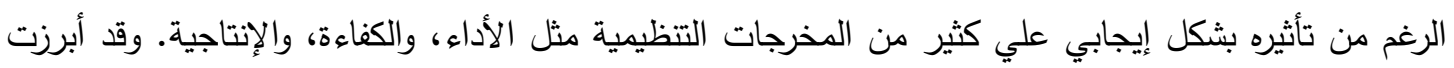

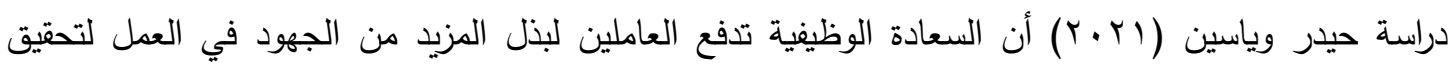

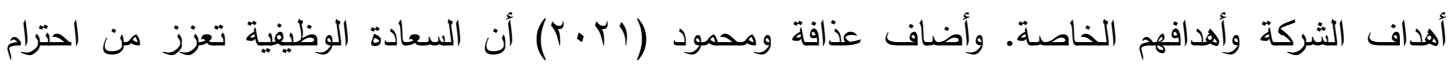

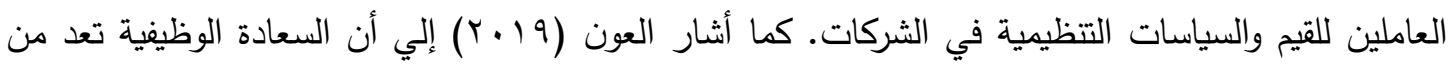

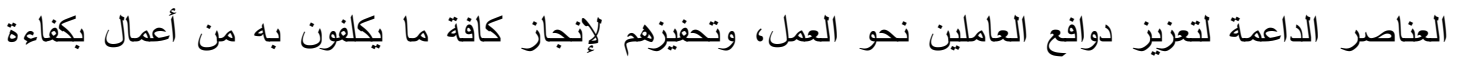

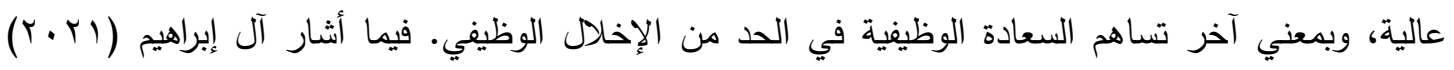

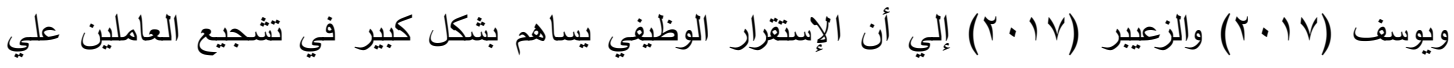

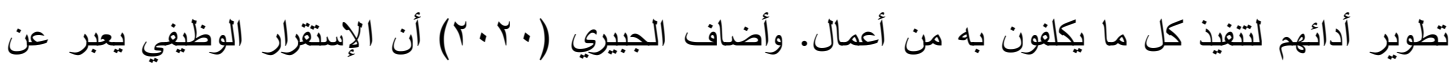

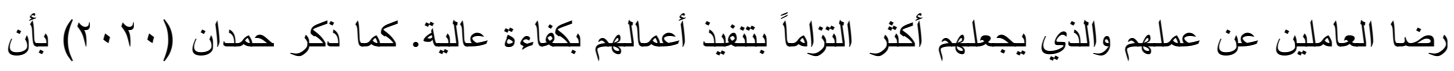
الإستقرار الوظيفي يعزز من الراحة النفسية للعاملين في العمل، ومن ثم شعورهم بالسعادة الوظيفية.

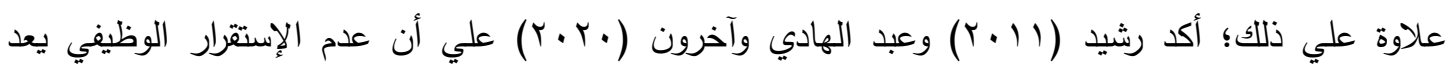

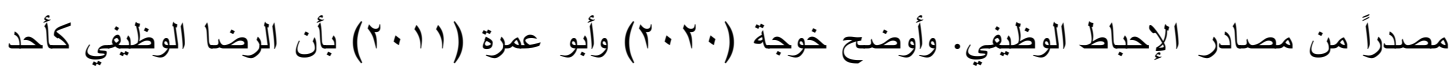

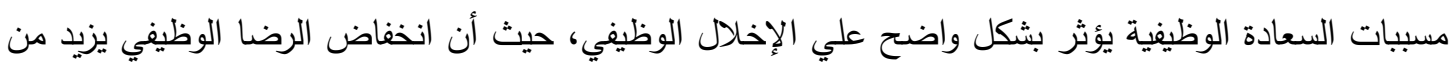

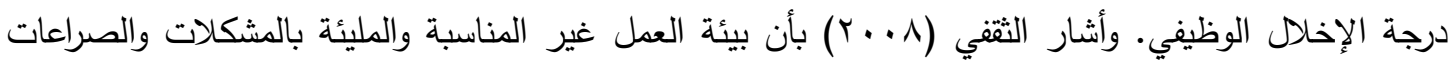

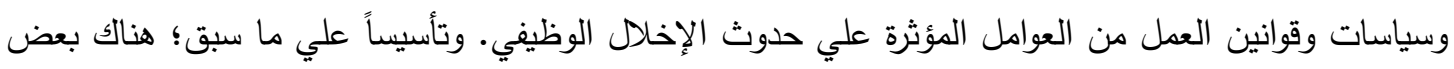

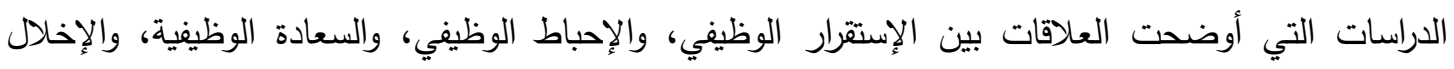

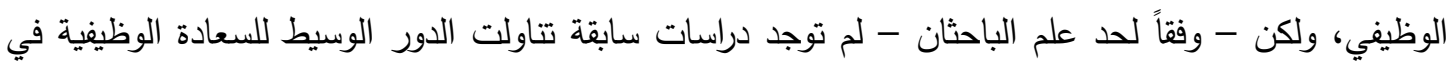

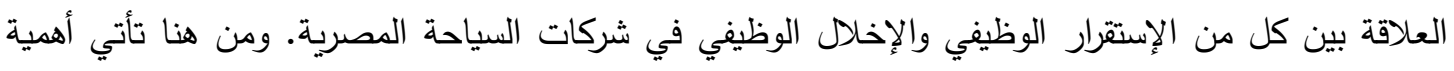

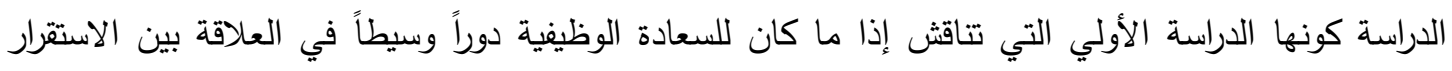

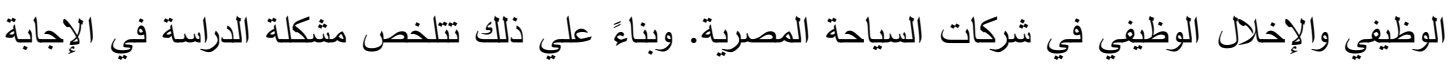

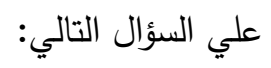

- - هل تلعب السعادة الوظيفية دوراً وسيطاً في العلاقة بين الإستقرار الوظيفي والإخلال الوظيفي في شركات السياحة؟

| - | (الإطار النظري

السعادة الوظيفية

هناك اختلاف واضح بين الكتاب والباحثين حول مفهوم السعادة الوظيفية، نظراً لكونه مفهوماً سلوكياً لا يظهر

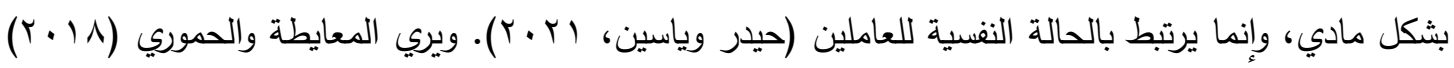


أن السعادة الوظيفية تشير إلي شعور الموظف بارتباط عاطفي قوي نحو مكان عمله، بجانب ارتباطه واندماجه عاطفياً وفكرياً في وظيفته، ويري بأنه مسئول عن تحقيق أهداف الشركة التي يعمل بها ونجاحها، وينبع هذا الثعور من خلال ما تطبقه الثركة من ممارسات وسياسات، وعلاقة الإدارة مع العاملين، فكلما اهتمت الثركة بسعادة العاملين، كلما زاد حماس هؤلاء العاملين، وحرصهم علي أداء وظائفهم بشكل فعال، والتزامهم وولائهم.

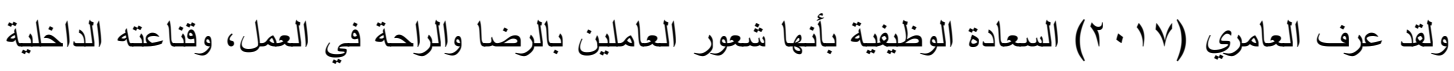
بأن ما يقوم به من أعمال أو يحققه من إنجاز في العمل يتتاسب مع أهدافه الخاصة وطموحه الوظيفي. بينما

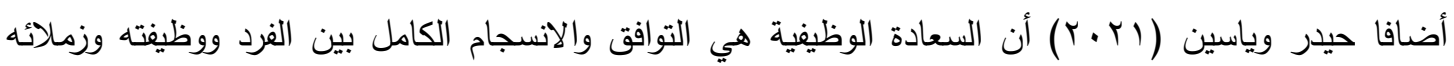
بشكل ينعكس علي تحقيق أهدافه وإشباع طموحه الوظيفي. وقد لخص حيدر وياسين (Y. (Y) السعادة الوظيفية في شعور العاملين بالرضا والإيجابية والتقدير في العمل، وارتباطهم بوظائفهم، واندماجهم في العمل، وتقوية علاقاتهم بالغير، والحرص علي تحقيق الإنجازات.

عندما يشعر العاملون بالسعادة الوظيفية؛ فإنهم يمتلكون الكثير من الخصائص والإتجاهات الإيجابية في العمل، تُهن والتي تميزهم عن غيرهم ممن لا يشعرون بتلك السعادة. وتشمل أهم تلك الخصائص نشاط العاملين وحيويتهم، وتقكيرهم في حاضرهم دون الانشغال بالماضي أو القلق من المستقبل، بجانب التفاؤل والأمل في المستقبل، وسعيهم المستمر لبناء علاقات قوية مع زملائهم في العمل، وسيطرتهم وتجنبهم للمشاعر والإتجاهات السلبية في العمل. وتشمل كذللك إدارة الذات، والتعاطف مع زملائهم في العمل، والإقبال علي العمل برغبة، وإنجازهم لعملهم، وتقديرهم وفخرهم بعمله، وعدم القيام بأعمال دون تخطيطها وتتظيمها بشكل مسبق، وأخيراً الاستقرار

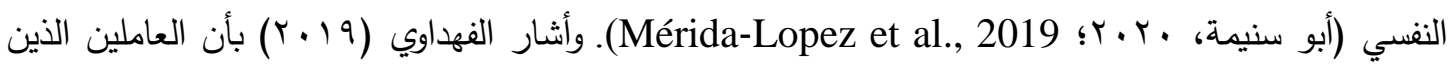
يشعرون بالسعادة الإيجابية يتسمون بعدد من الخصائص مثل الرضا الوظيفي، والاستقلالية، ومقاومة ضغوط لإناني

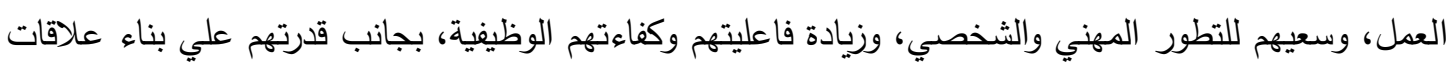
مع الآخرين بسهولة.

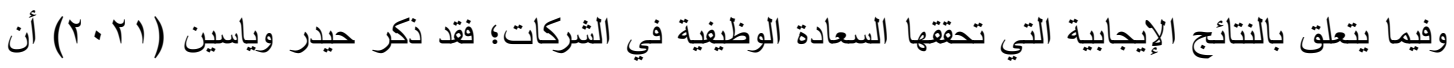
السعادة التظيمية تساهم في زيادة جهود العاملين، وبالتالي زيادة الإنتاجية، وخلق ممارسات وسلوكيات إيجابية

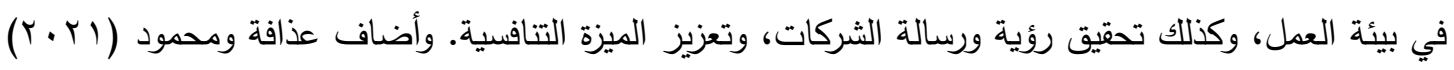
ومانع وبوهراوة (Y. · (Y) أن السعادة الوظيفية تساعد في انخفاض معدلات التأخر عن العمل والغياب، وزيادة الإلتزام التظيمي، ودعم وتشجيع العمل الجماعي، بجانب دفع العاملين للإبداع والابتكار في العمل، وتحقيق النجاح الوظيفي، وشعور العاملين بالرفاهية الوظيفية، واحترام القيم والسياسات التظظيمية في الثركات.

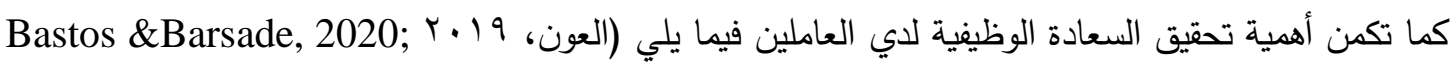
:(Alserhan et al., 2021; Buttet al., 2020 أ- - تحسين خدمة العملاء وشعور العملاء بالسعادة لتعاملهم مع الشركة؛ ب- تحقيق النجاح والتطور التنظيمي للشركة؛ 


$$
\begin{aligned}
& \text { ج- تحسين السمعة التظيمية للشركة؛ } \\
& \text { د- تحسين جودة الخدمات؛ } \\
& \text { هـ - انخفاض معدل دوران العمالة؛ } \\
& \text { و - الاستخدام الأمثل لكافة موارد وإمكانيات الشركة، وتخفيض التكاليف؛ } \\
& \text { ز - زيادة فاعلية الاتصالات الإدارية داخل الشركة؛ } \\
& \text { ح- زيادة قدرات التعلم التظيمي بالشركة؛ }
\end{aligned}
$$

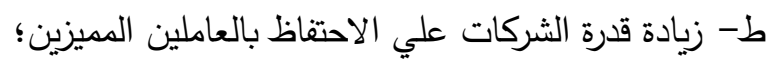

$$
\begin{aligned}
& \text { ي- تخفيض مستوي الإحباط الوظيفي. }
\end{aligned}
$$

وقد توصلت دراسة خلف (Y) (Y.Y) إلي أن السعادة الوظيفية ترتبط إيجابياً بتعزيز الثقة التنظيمية. فيما توصلت

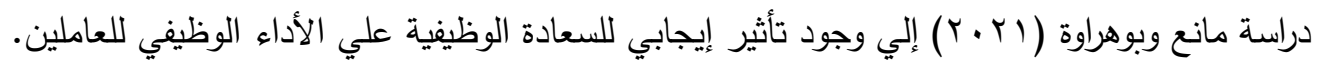

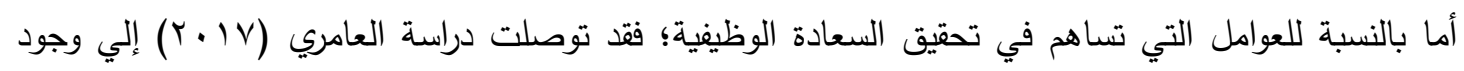
علاقة ارتباط إيجابية بين الرضا الوظيفي والسعادة الوظيفية. كما توصلت دراسة جمعة وآخرون (9 (19) إليأن تطبيقات الهندسة البشرية تؤثر إيجابياً في زيادة شعور العاملين بالسعادة الوظيفية. بينما أكدت نتائج دراسة أبو

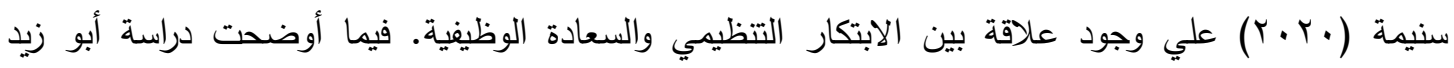

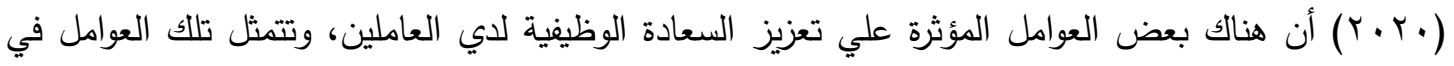
سلوكيات القيادة التحويلية، والإرهاق الوظيفي، وسلوكيات دعم الاستقللية في العمل، وسلوكيات تشديد الرقابة.

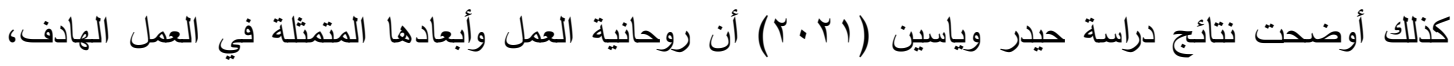
والإحساس بالعمل، والتفاني بالعمل، والملائمة بين قيم الفرد والوظيفة يؤثرون بشكل إيجابي في تعزيز شعور

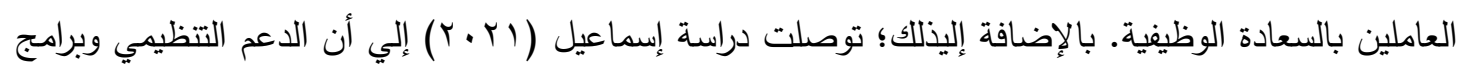

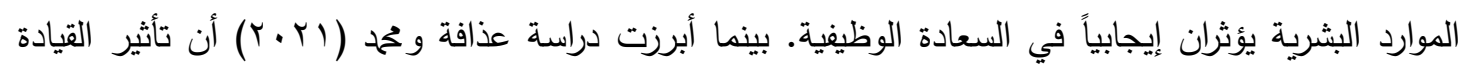
المستدامة في تحسين السعادة التنظيمية لدي العاملين.

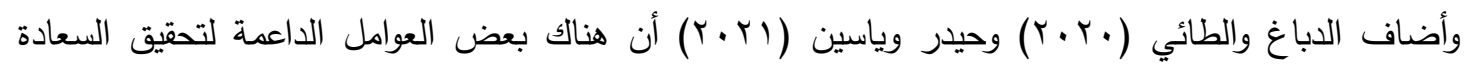
الوظيفية داخل الشركات، ومن بين هذه العوامل طبيعة ظروف العمل، وسياسة الأجور والمكافآت، والعلاقات

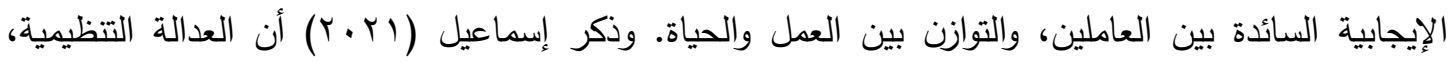
والدعم الإشرافى، والإثراء الوظيفي، والتمكين من العوامل الداعمة لتحقيق السعادة الوظيفية لدي العاملين.

\section{الاستقرار الوظيفي}

يعد الإستقرار الوظيفي أحد ركائز نجاح أي شركة، بجانب تحسين سمعة الشركات، وتعزيز قدرتها التتافسية في

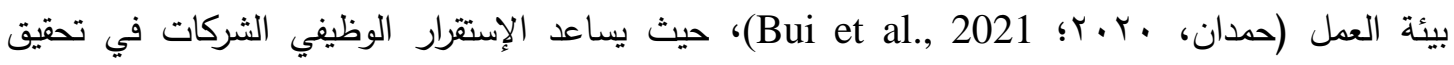
أهدافها، والاحتفاظ بالعاملين الموهوبين، وتخفيض تكاليف استقطاب عاملين جدد موهوبين (آل إبراهيم، (Y • ب). كما يساهم الإستقرار الوظيفي في تحقيق الأمان الوظيفي للعاملين، وتحقيق أهدافهم (Ali, 2020)، وزيادة 
ارتباطهم بالثركة، وتعزيز السلوكيات والإتجاهات الإيجابية نحو العمل، ودعم الثقافة التظظيمية للشركة (يوسف،

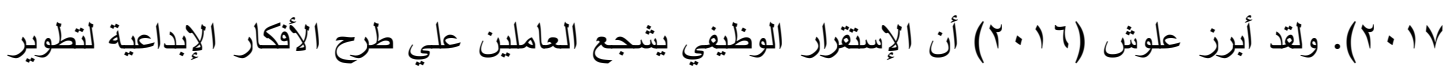

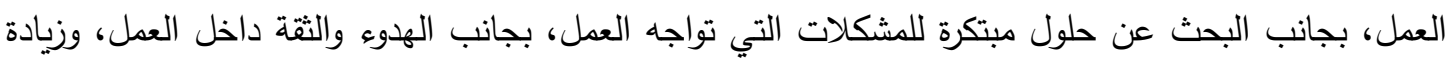
قدرتهم علي أداء وظائفهم باستقلالية. كما ذكر الزعيير (YlV) أن مفهوم الإستقرار الوظيفي يرتبط ببقاء الموظف في وظيفته داخل الثركة لفترة

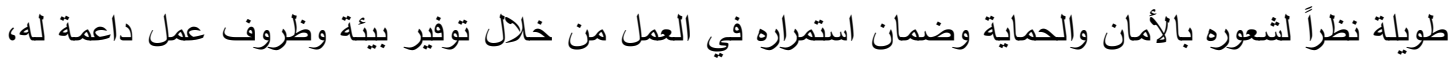

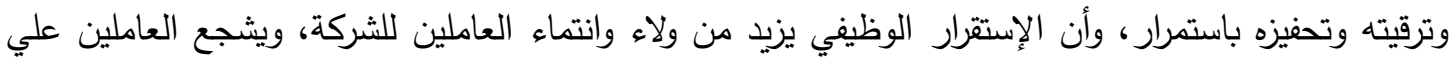

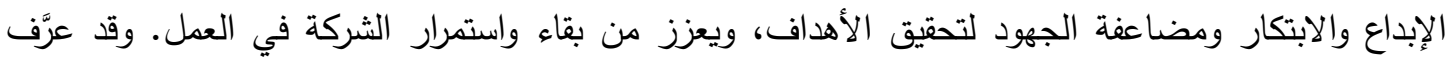

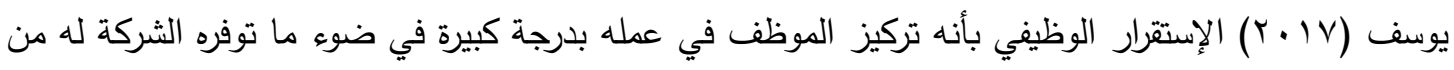

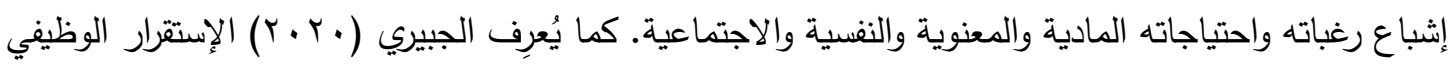

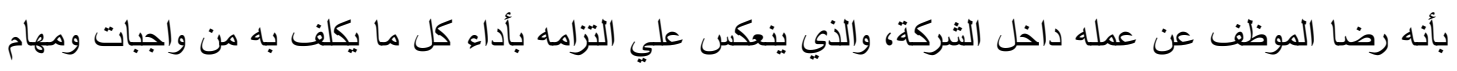

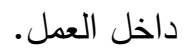

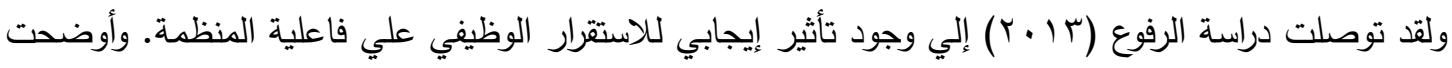

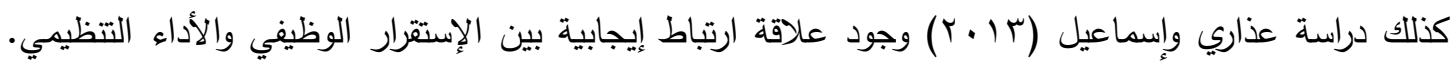

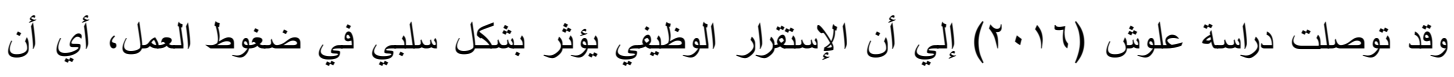

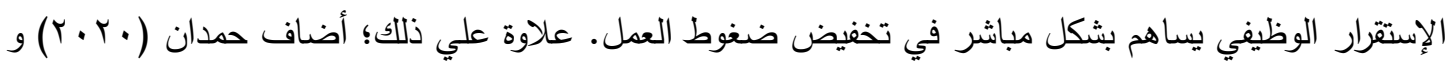
Kamau

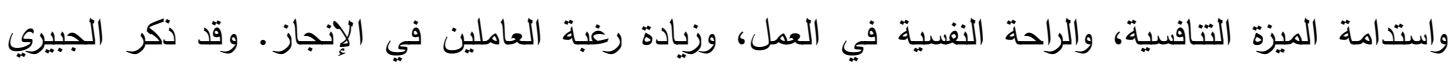

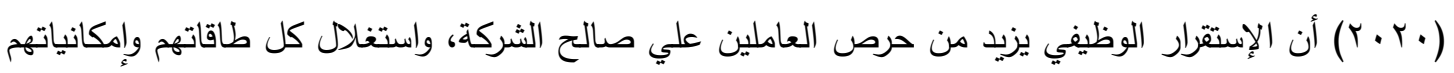
من أجل تحقيق الأهداف، وزيادة قدرة الثركة علي مواجهة تحديات بيئة العمل.

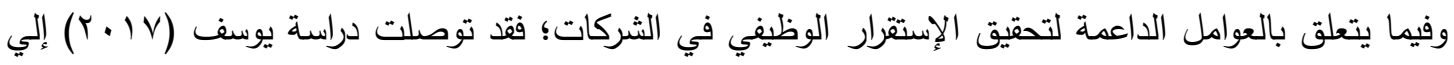

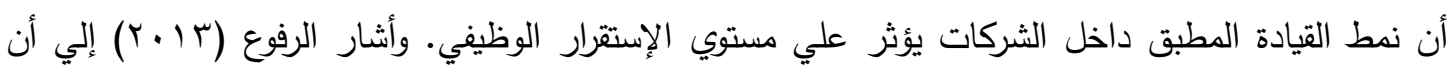

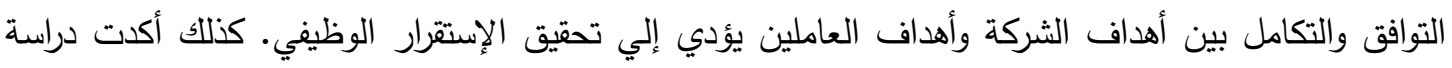

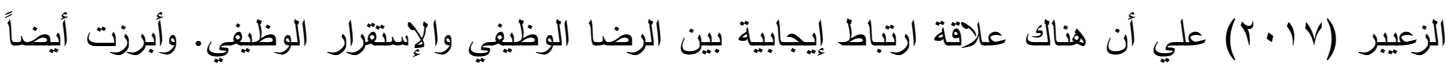

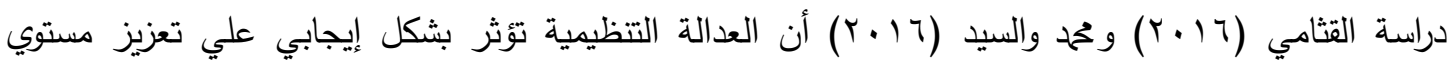

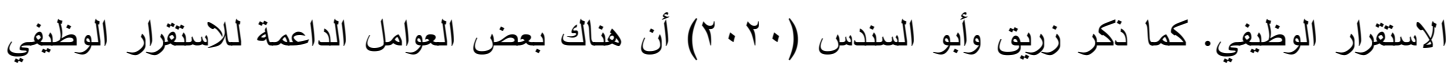

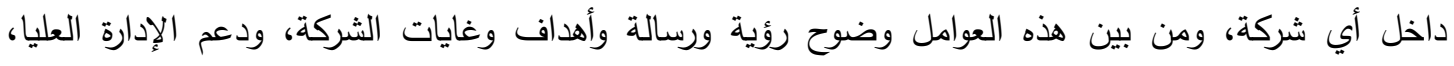

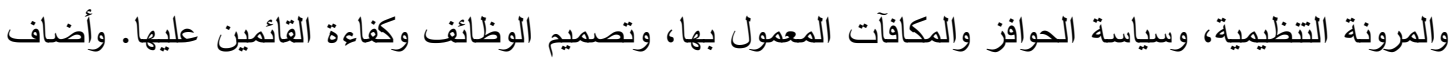

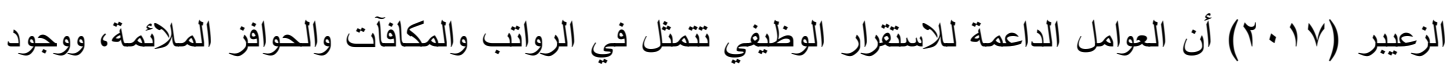
فرص للتطوير المهني، وجودة الحياة الوظيفية. 
وعلي الجانب الآخر؛ فهناك عدد من الأسباب التي تؤدي إلى اختلال أو عدم الإستقرار الوظيفي داخل

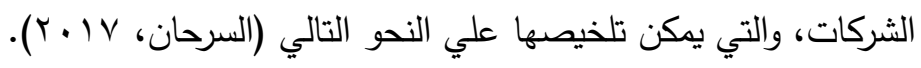

أ- التغيرات التي تحدث في البيئة الداخلية أو الخارجية للشركة، والتي تتطلب من الثركة ضرورة تغيير أو

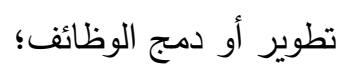

ب- ضعف الرواتب والمكافآت بالثركة مما يدفع العاملين للبحث عن وظائف توفر لهم رواتب ومكافآت

مناسبة؛

ج- كثرة تنقل الموظف بين الوظائف المختلفة داخل الشركة؛

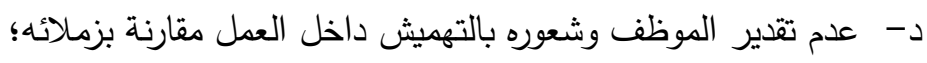
هـ - عدم توفير البرامج التدريبية والتطويرية؛

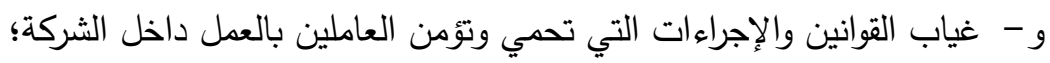
ز - عدم عدالة تقييم الأداء، والمساواة بين العاملين المميزين وغيرهم ممن هم أقل منهم في مستوي العين الأداء.

\section{الإحباط الوظيفي}

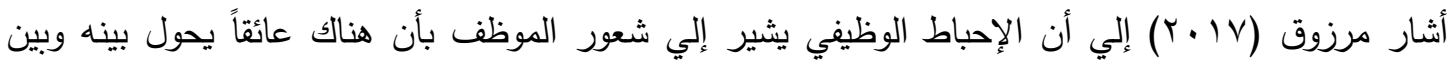

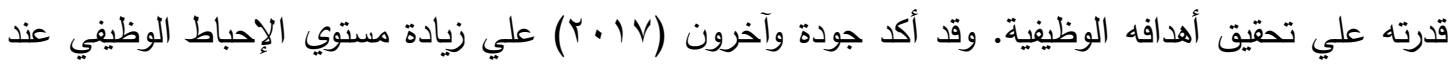

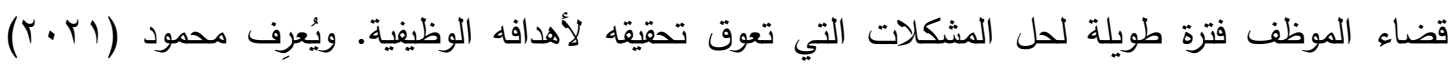

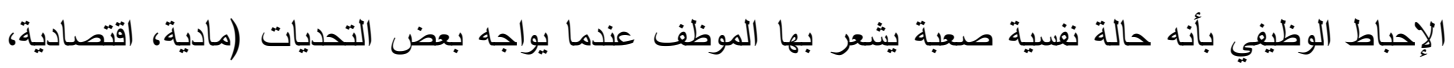

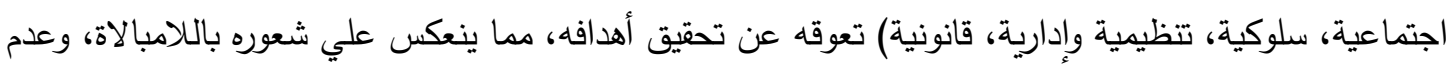

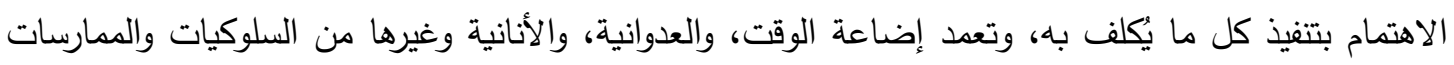

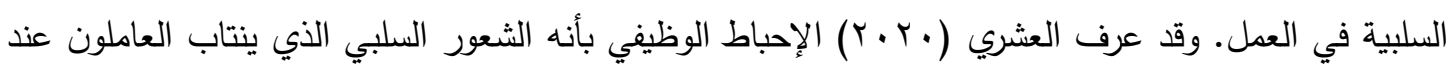

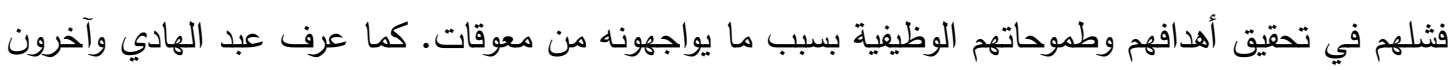

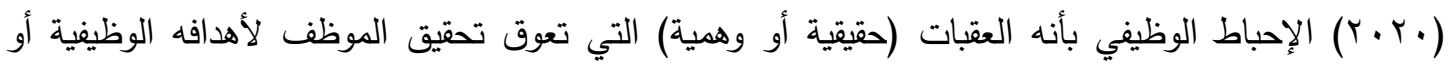
الثخصية في العمل، وقد تكون تلك العقبات شخصية خاصة بالموظف أو تتظيمية خاصة بالثركة. هناك العديد من المصادر التي يمكن أن تساهم في حدوث أو زيادة مستوي الإحباط الوظيفي لاي العاملين، مثل

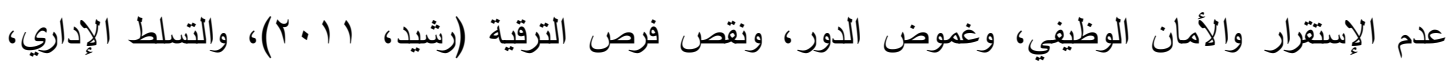

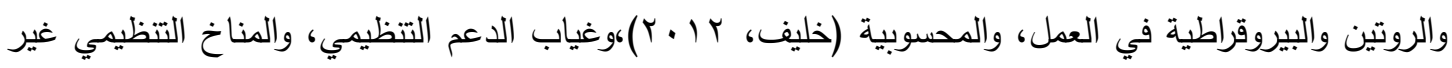

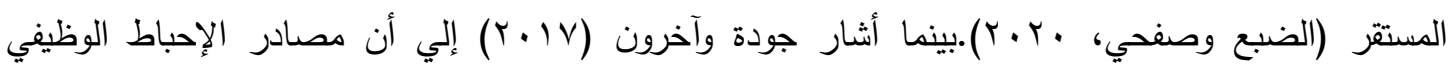

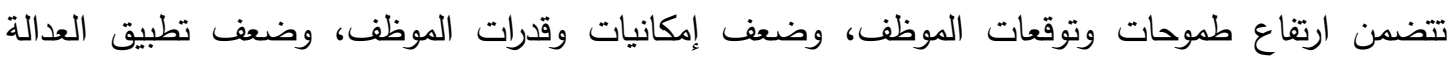

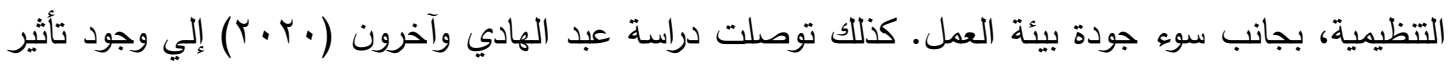
للتهكم التنظيمي في زيادة مستوي الإحباط الوظيفي لاي العاملين في شركات السياحة. 
فيما ذكر العشري (·.r.r) أن مصادر الإحباط الوظيفي تتمثل فيما يلي: أ- تكليف العاملين بمهام لا تتتاسب مع قدراتهم ومهاراتهم وإمكانياتهم؛

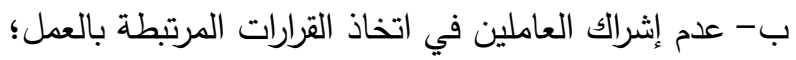
ت- عدم وجود سياسة عادلة للترقيات؛ ث- عدم الأخذ بمقترحات وآراء العاملين في تطوير الشركة؛ تصات ج- انخفاض الروح المعنوية للعاملين؛ ح- ضعف الثقافة التنظيمية السائدة بالثركة.

أما بالنسبة لأنواع الإحباط الوظيفي؛ فقد أبرز أبو المعاطي وفياض (19 ب r) الأنواع التالية للإحباط الوظيفي

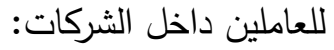

أ- الإحباط المرتبط بالعمل: يرتبط هذا النوع بالظروف المحبطة (بيئة العمل، وأدوات العمل، والفرص

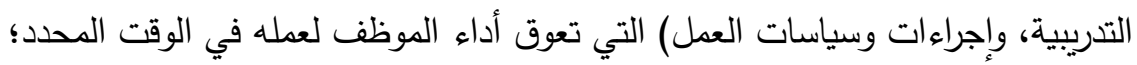

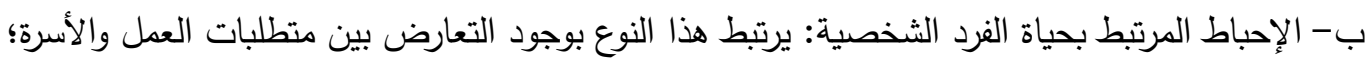

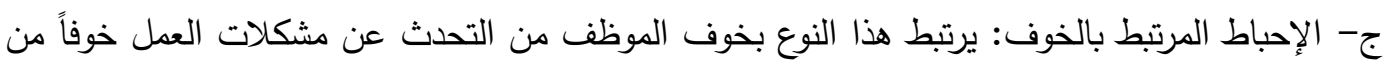

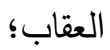

د- الإحباط المرتبط بالآخرين: يرتبط هذا النوع بالعلاقات والتعاملات المحبطة بين الموظف وزملائه في العمل؛ هـ - الإحباط المتزايد: يرتبط هذا النوع بعدم رضا الموظف عن عمله أو راتبه، وكذلك عدم رضاه عن سياسة الترقية والتدريب بالشركة. ومع حدوث أو زيادة مستوي الإحباط الوظيفي لاي العاملين داخل الشركات، فإنه سيترتب عليه العديد من النتائج

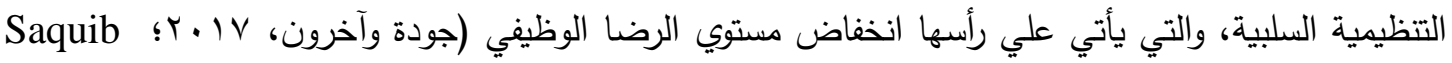

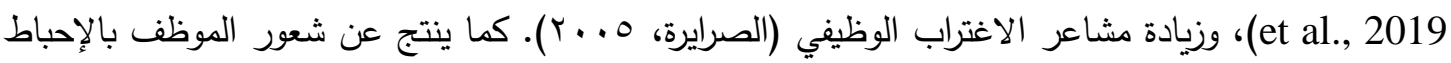

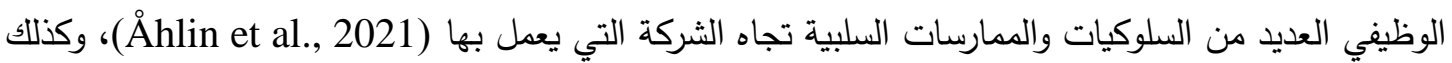
تجاه زملائه في العمل، ومن بين هذه السلوكيات، والعدوانية، والصراعات مع العاملين، وانخفاض الروح

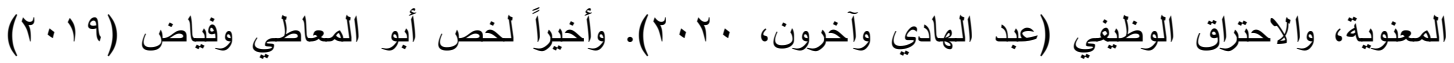

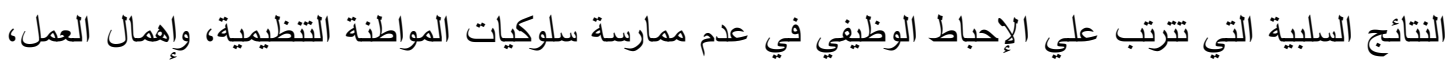

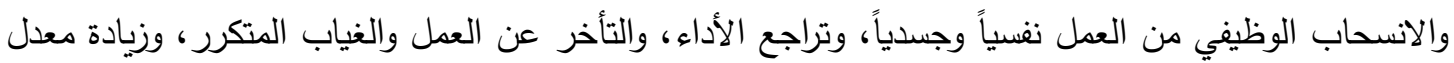
دوران العاملين.

\section{الإخلال الوظيفي}

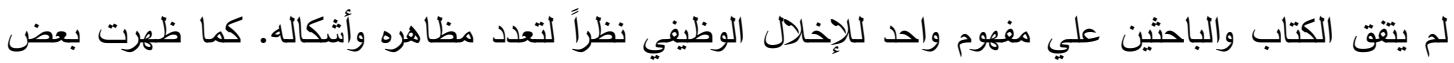

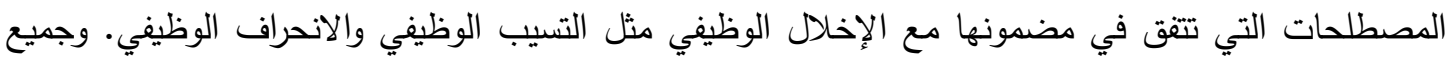


هذه المصطلحات تتفق في إخلال الموظف بعمله، ومخالفته لسياسات وإجراءات وقوانين العمل، وإلحاق الضرر

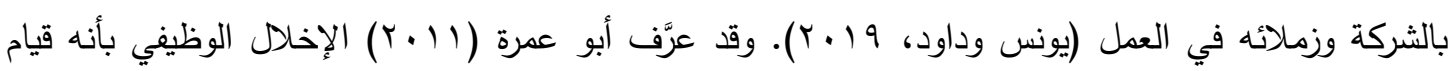
الموظف بمخالفة القوانين والإجراءات الإدارية المعدول بها داخل الثركة، والتي تتظم العمل عند قيامه بتنفيذ

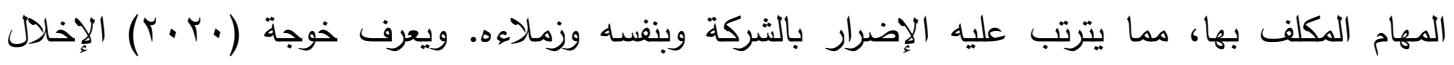
الوظيفي بأنه عدم الإلتزام بالسياسات والقوانين التنظيمية التي تحكم العلاقة بين الشركة والعاملين فيها أو بين العاملين وبعضهم البعض، وقد يشمل أيضاً عدم الإلتزام بالقيم والإتجاهات والسلوكيات التي تسود بيئة العمل.

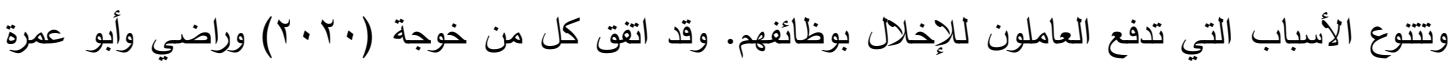

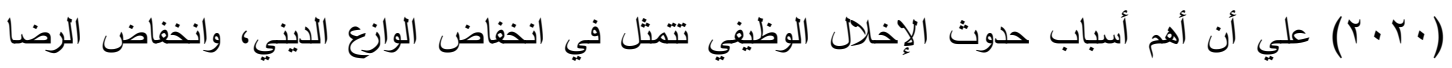
الوظيفي، وضعف الثقافة التظيمية، وعدم عدالة الإجراءات التحفيزية والعقابية. كما توصلت دراسة خضر (1) (1) إلي وجود تأثير سلبي للعدالة التظيمية علي الإخلال الوظيفي، أي أن تطبيق العدالة التظيمية

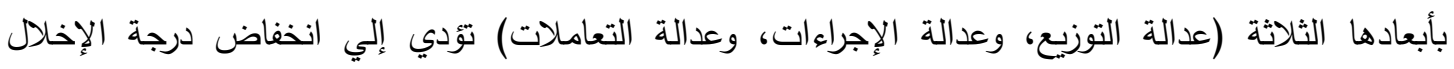

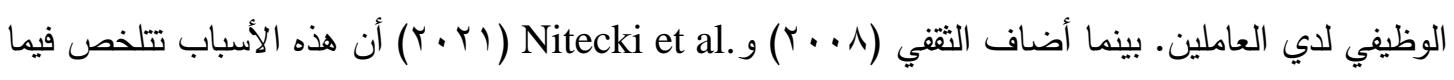

أ- ضغوط العمل؛

ب- ضعف سياسة الحوافز والمكافآت؛

ج- نمط القيادة المطبق؛

د- سوء بيئة العمل؛

هـ - نقص الفرص التدريبية؛

و - عدم وضوح وعدالة سياسات وقوانين العمل.

وهناك عدة مظاهر يمكن من خلالها الحكم علي إخلال العاملين بوظائفهم داخل الشركات، وتتمثل أهم هذه

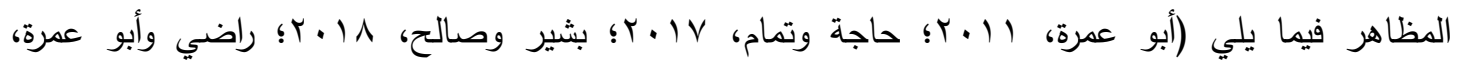
$:(r \cdot r$.

أ- - البطء في تتفيذ المهام؛

ب- عدم الإلتزام بتتفيذ تعليمات المديرين؛

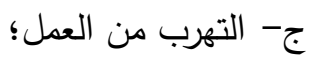

د- تعدد إضاعة الوقت في أمور شخصية لا تخص العمل؛ العصل

هـ - إفشاء أسرار العمل؛

و - سوء استخدام السلطة؛

ز - استخدام الوظيفة في تحقيق مكاسب شخصية؛

ح- الرشوة والواسطة؛ 
ط- عدم الإلتزام والولاء الوظيفي؛ ي- عدم الإلتزام بأوقات العمل الرسمية سواء بالحضور أو الإنصراف في غير أوقات العمل الرسمية أو التغيب بشكل متكرر .

وفي ضوء ما سبق؛ وما تؤكده الدراسات السابقة من تأثير للإستقرار الوظيفي علي كل من الإحباط الوظيفي، والسعادة الوظيفية، والإخلال الوظيفي. بجانب تأثير الإحباط الوظيفي علي كل من السعادة الوظيفية والإخلال

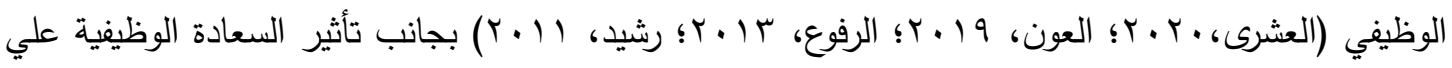
الإخلال الوظيفي؛ يوضح شكل رقم (1) نموذج الدراسة المقترح.

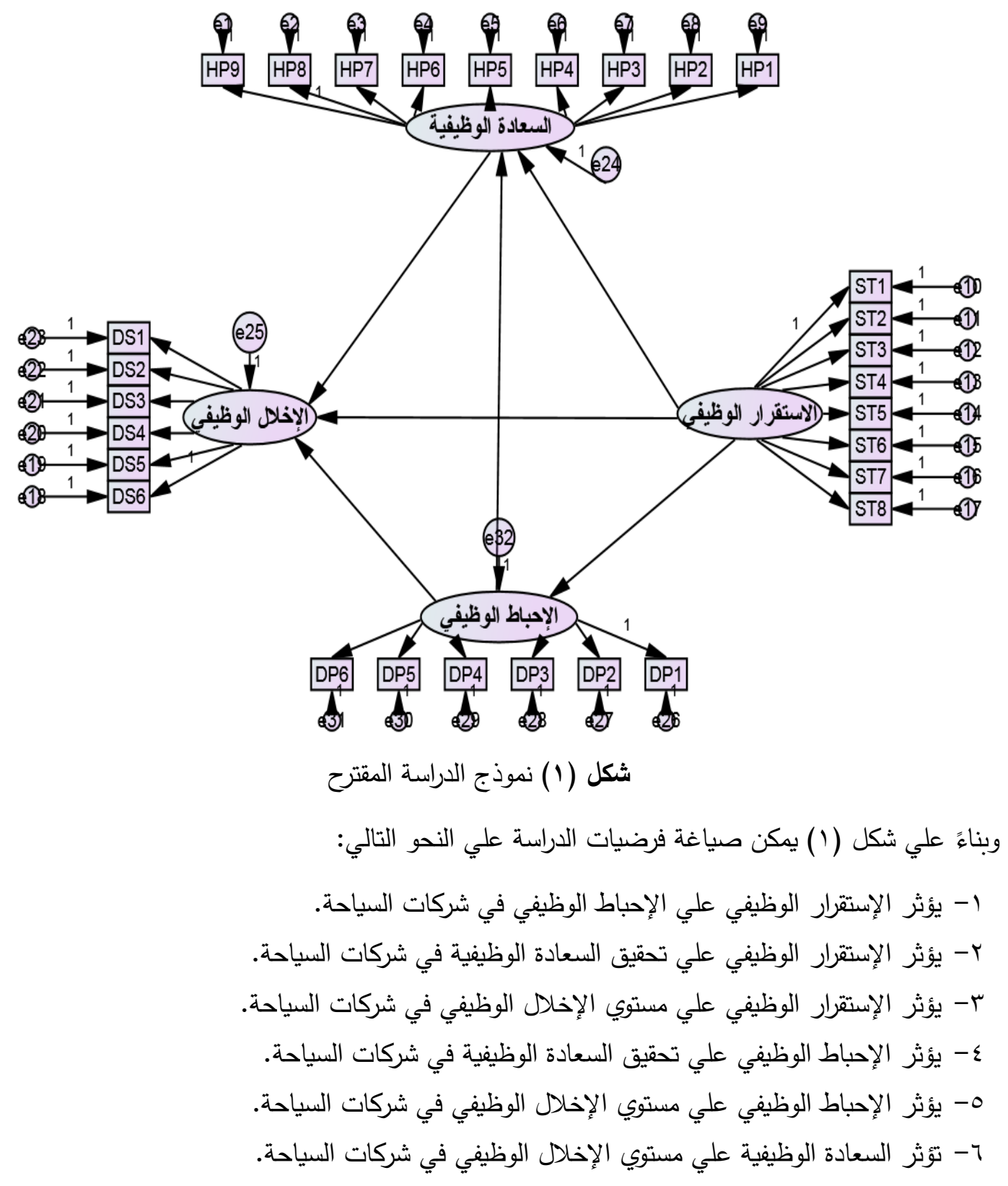


V- تلعب السعادة الوظيفية دوراً وسيطاً في العلاقة بين الإستقرار الوظيفي والإخلال الوظيفي في شركات

$$
\text { السياحة. }
$$

^- يختلف تأثير الإستقرار الوظيفي علي كل من الإحباط الوظيفي، والسعادة الوظيفية والإخلال الوظيفي وفقاً

$$
\text { لـ للمتغيرات الديموغرافية. }
$$

9- يختلف تأثير الإحباط الوظيفي علي السعادة الوظيفية والإخلال الوظيفي وفقاً للمتغيرات الديموغرافية. • 1- يختلف تأثير السعادة الوظيفية علي الإخلال الوظيفي وفقاً للمتغيرات الديموغرافية.

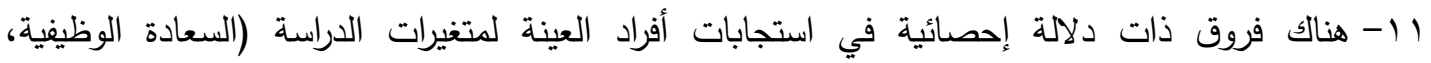
والإستقرار الوظيفي، والإحباط الوظيفي، والإخلال الوظيفي) تعزي للمتغيرات الديموغرافية.

منهج الدراسة طريقة البحث والتصميم

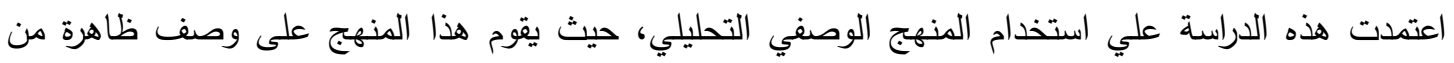

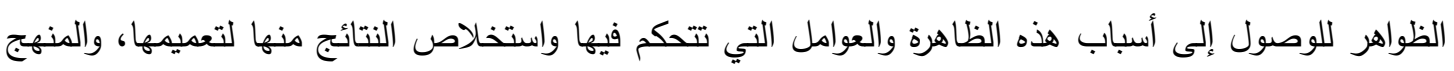

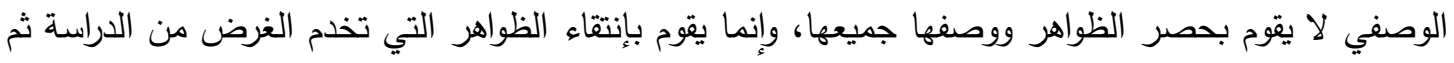

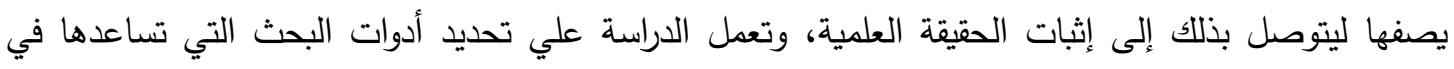

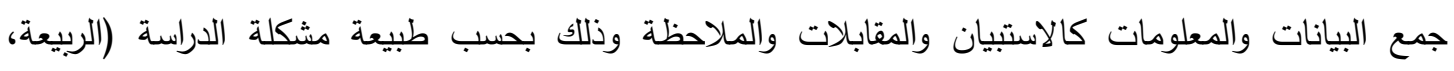

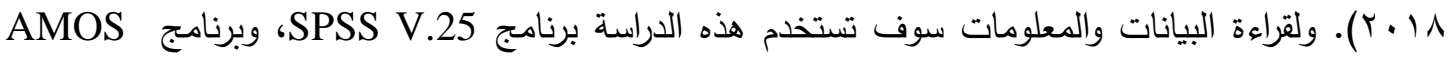

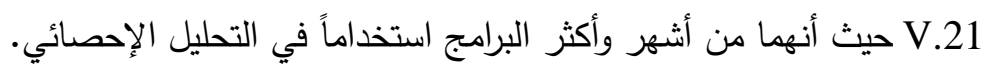

$$
\text { أدوات الدراسة ومصادر الحصول على المعلومات }
$$

لغرض الحصول على البيانات والمعلومات لتتفيذ أهداف الدراسة، استخدم الباحثان مصدرين أساسيين اللمعلومات، هما:

1- المصادر الثانوية: لغايات معالجة الإطار النظري للدراسة، فقد اعتمد الباحثان على بعض المصادر الثانوية

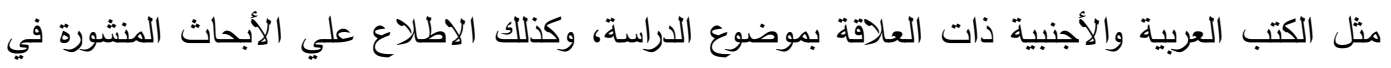

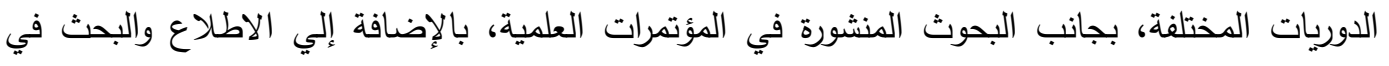

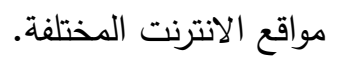

r- المصادر الأولية: لمعالجة الجوانب التحليلية لموضوع الدراسة لجأ الباحثان إلى جمع البيانات الأولية من

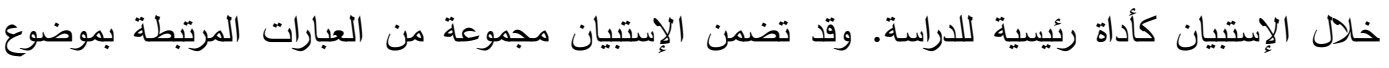
الدراسة، وتكونت الاستمارة من صفحة الغلاف التي تضمنت نبذة عن الدراسة وعنوانها والهدف منها،

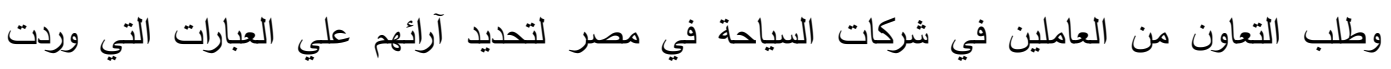
بالاستمارة، وقد تضمنت الاستمارة عدد 9 ب عبارة. وقد تكونت الاستمارة من خمسة محاور رئيسية يمكن

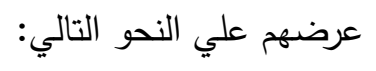


المحور الأول: البيانات الايموغرافية والوظيفية:

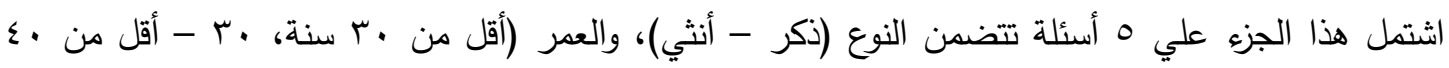

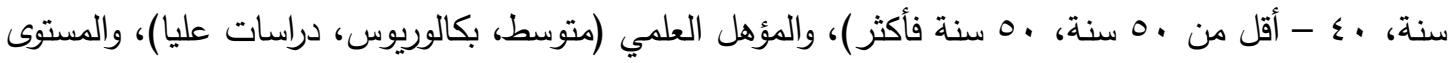

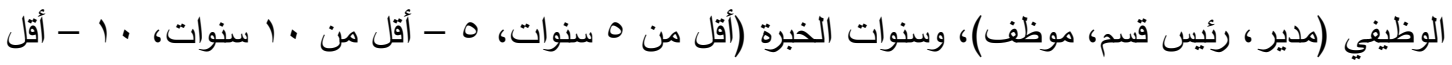

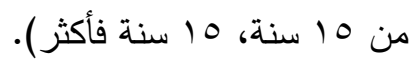

المحور الثاني: السعادة الوظيفية في شركات السياحة

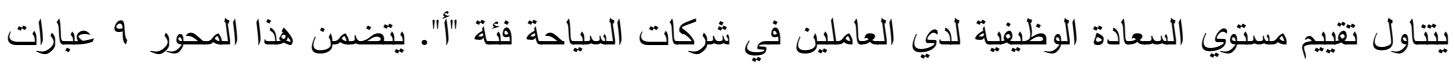

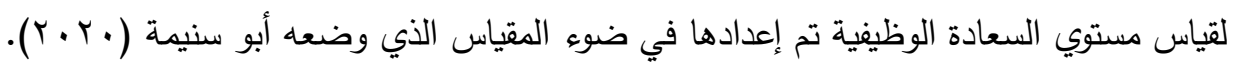
المحور الثالث: الإستقرار الوظيفي في شركات السياحة

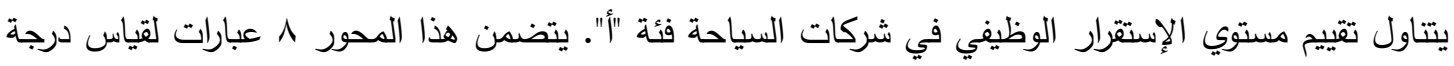

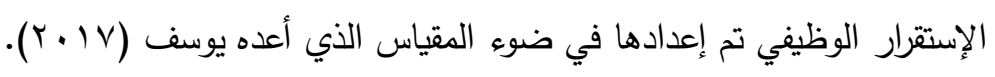

\section{المحور الرابع: الإحباط الوظيفي في شركات السياحة}

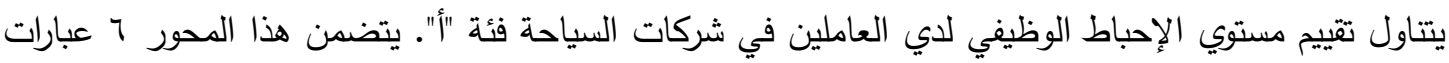

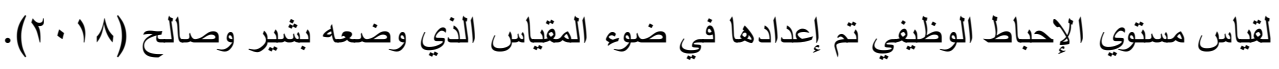

المحور الخامس: الإخلال الوظيفي في شركات السياحة

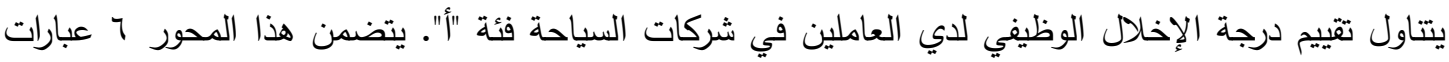

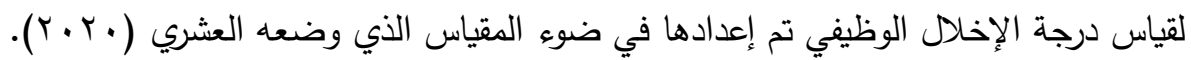

وقد اعتمد الباحثان في الإجابة علي عبارات الأبعاد من الثاني للخامس علي مقياس ليكرت الخماسي الذي يعتمد

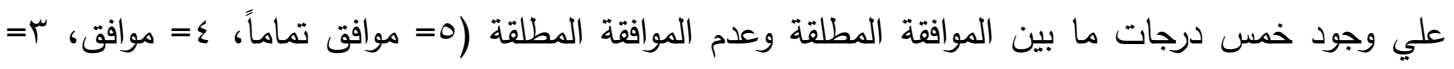
محايد، ب= غير موافق، (= غير موافق داف بن إطلاقاً).

صدق أداة الدراسة وثباتها

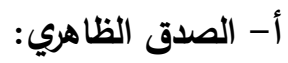

للتحقق من الصدق الظاهري لأداة الدراسة، تم عرض الأداة مع أهداف الدراسة وفروضها على عدد من أعضاء

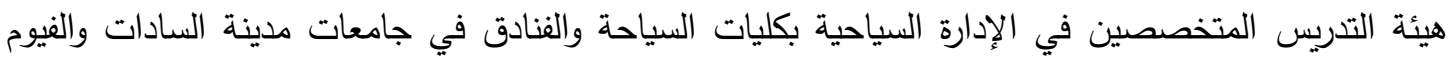

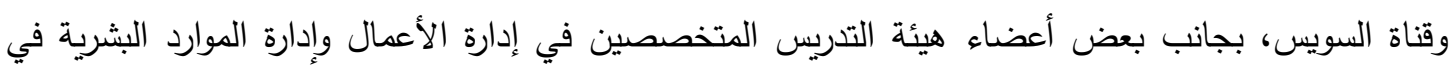

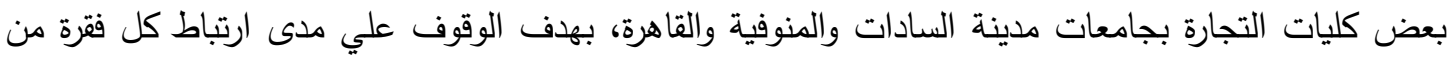

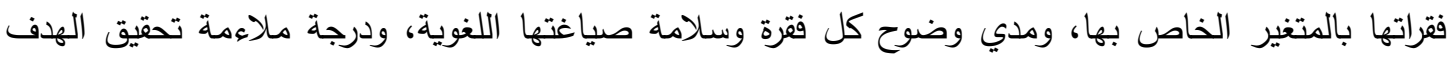
الذي وضعت من أجله. وقد تم مراعاة الأخذ بجميع ملاحظات المحكمين وتتفيذ وتعديل الاستمارة وفقًا لها. 


\section{ب- الثبات والصدق الذاتي والبنائي لأداة الدراسة} من أجل البرهنة على أن الاستبيان يقيس العوامل المراد قياسها والتحقق من صدقها قاما الباحثان بإجراء اختبارات الثبات والصدق لمعرفة ددى ثبات وصدق الاستبيان، وقد جاءت النتائج على النحو التالي:

أولًا: ثبات الإستبيان

قام الباحثان بإجراء اختبار (Cronbach Alpha) لغرض تقييم تماسك المقياس. وتبلغ القيمة المقبولة لـ Cronbach Alpha

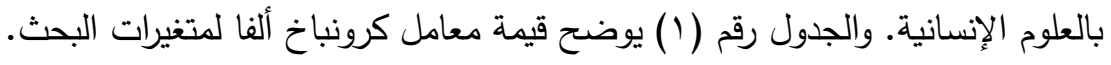

\begin{tabular}{|c|c|c|}
\hline \multicolumn{3}{|c|}{ الجدول (1) معاملات الثبات الداخلي للاستبيان الكلي } \\
\hline 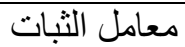 & عدد فقرات المتغير & المتغير \\
\hline$\cdot \wedge \leqslant V$ & 9 & 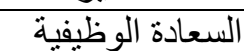 \\
\hline$\cdot .9 \cdot 1$ & $\Lambda$ & 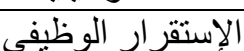 \\
\hline$\therefore \vee \neg 1 \wedge$ & 7 & 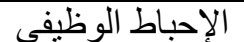 \\
\hline$\therefore \wedge \wedge \mathrm{V}$ & 7 & الإخلال الوظيفي \\
\hline$\cdot . \wedge 9 \leqslant$ & rq & الإستبيان الكلى \\
\hline
\end{tabular}

تدل مؤشرات كرونباخ ألفا في الجدول رقم (1) على تمتع أداة البحث بصورة عامة بمعامل ثبات مرتفع وبقدرتها

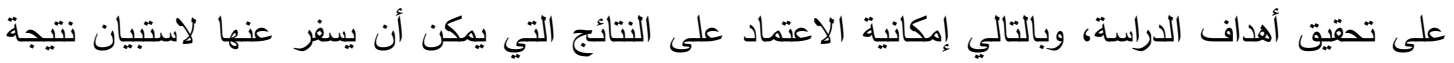

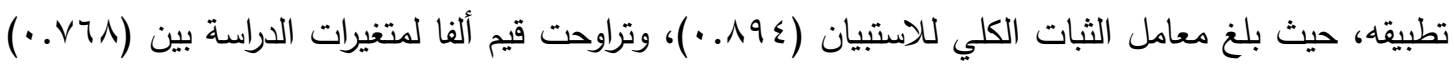
فيحدها الأدنى، و (19.9. ) فيحدها الأعلى، وهي قيم أعلى من المعدل القياسي للدراسات الإنسانية

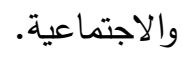

ثانيًا: الصدق الذاتي لمحاور الإستبيان وهو ما تمثله العلاقة بين الصدق والثبات، حيث تم حساب الصدق الذاتي من خلال حساب الجذر التربيعي

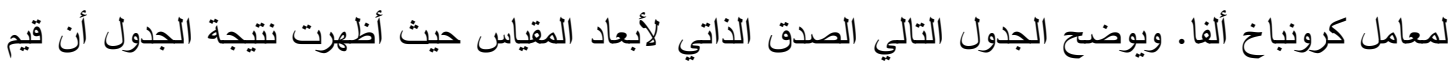
الصدق الذاتي قد كانت مرتفعة.

\begin{tabular}{|c|c|c|}
\hline \multicolumn{3}{|c|}{ الجدول (r) الصدق الذاتي للاستبيان الكلي } \\
\hline 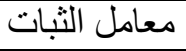 & عدل عقر ات المتغير & المتغير \\
\hline$\cdot .94$. & 9 & السعادة الوظيفية \\
\hline$\cdot .9 \leqslant 9$ & $\Lambda$ & الإستقرار الوظيفي \\
\hline$\cdot . \wedge \vee 7$ & 7 & الإحباط الوظيفي \\
\hline$\cdot .9 \leq Y$ & 7 & الإخلال الوظيفي \\
\hline$\cdot .9 \leqslant 7$ & rq & الإستبيان الكلي \\
\hline
\end{tabular}

ثالثًا: الصدق البنائي تم حساب معامل ارتباط بيرسون بين كل محور من محاور المقياس مع الدرجة الكلية للاستبان، ويوضح

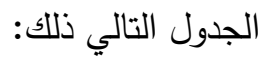


الجدول (r) معامل ارتباط كل محور من محاور المقياس مع الدرجة الكلية للاستبيان

\begin{tabular}{|c|c|c|c|}
\hline مستوى الدلالة & معامل الإرتباط & البعد & \\
\hline$\because \cdots$ & .91 . & السعادة الوظيفية & \\
\hline$\because \cdots$ & $\cdot . \Lambda V T$ & الإستقر ار الوظيفي & \\
\hline$\because \cdots$ & $.9 r \mu$ & الإحباط الوظيفي & $r$ \\
\hline$\because \cdots$ & $.91 \varepsilon$ & الإخلال الوظيفي & $\xi$ \\
\hline
\end{tabular}

تبين نتائج الجدول رقم (r) إلى أن معاملات الإرتباط بين محاور الإستبيان (السعادة الوظيفي، والإستقرار

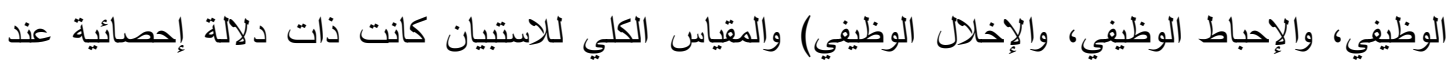

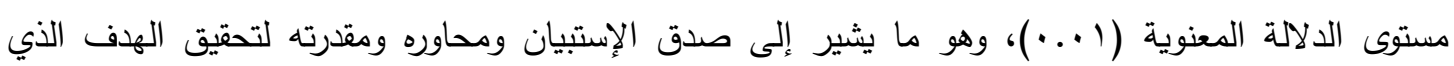
صممت من أجله.

\section{مجتمع وعينة الدراسة}

تمثل مجتمع الدراسة في العاملين (مديرين، ورؤساء أقسام، وموظفين) بشركات السياحة المصرية فئة "أ" في القاهرة، والتي يبلغ عددها گه ب ا شركة (Ministry of Tourism and Antiquities, 2021). وقد تم توزيع (1) استمارة علي عينة عشوائية من العاملين في تلك الثركات إلكترونياً عن طريق شبكات التواصل

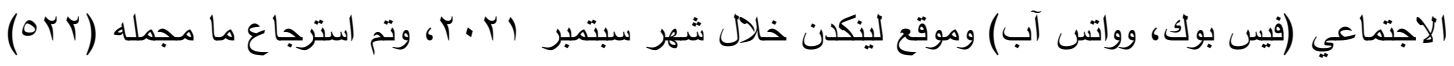
استبيان، ووجد أن هنالك (T؛ استمارة صالحة للتحليل الإحصائي، ووجد أن هناك هـ استمارة غير صالحة

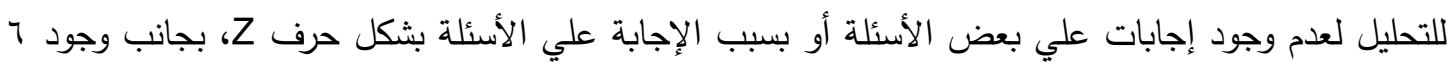

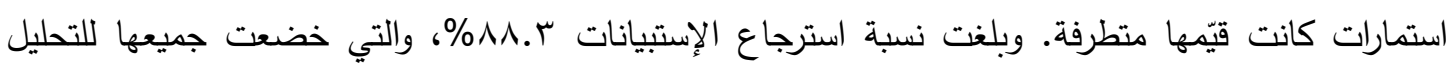
الإحصائي.

\section{المتغيرات الايموغرافية والوظيفية لأفراد عينة الدراسة}

توضح الجداول التالية المتغيرات الديموغرافية لأفراد عينة الدراسة (النوع، العمر، المؤهل العلمي، المستوى

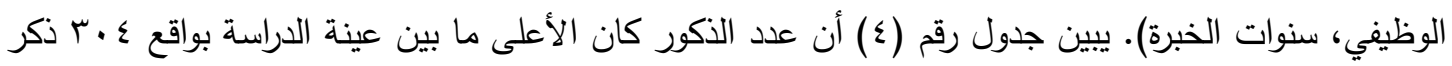

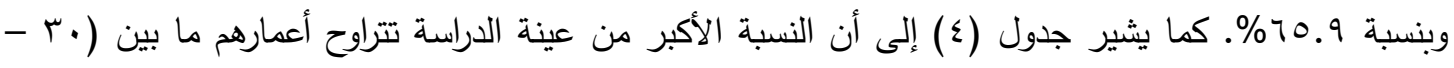

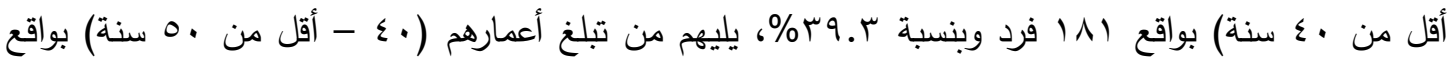

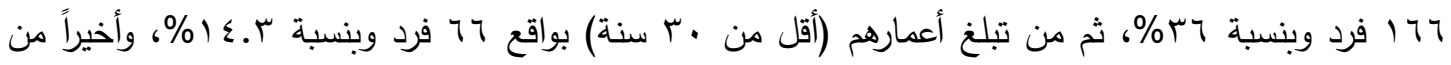

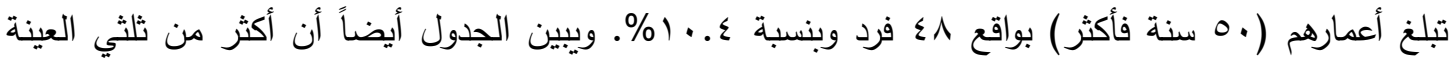

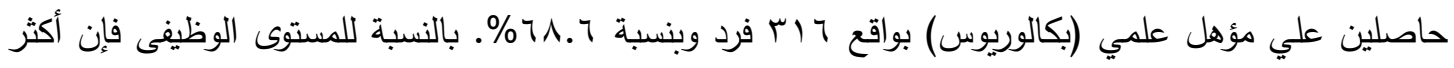

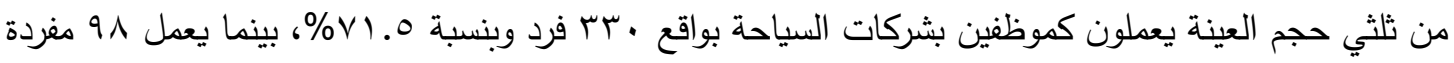

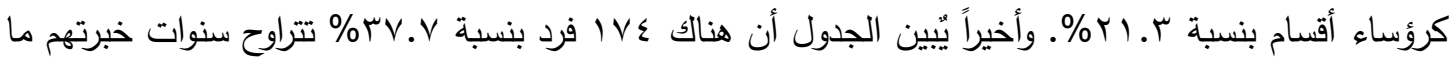

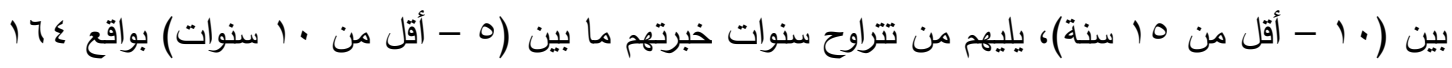

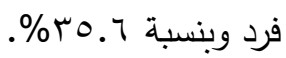


الجدول (ع ) توزيع أفراد العينة وفقاً للمتغيرات الديموغرافية والوظيفية

\begin{tabular}{|c|c|c|c|c|}
\hline المؤوية & التكر ار & الفئة & المتغير & 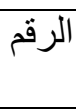 \\
\hline$\% 70.9$ & $\Gamma \cdot \varepsilon$ & ذكر & \multirow[t]{2}{*}{ الجنس } & \multirow[t]{2}{*}{1} \\
\hline$\% \Gamma \leqslant .1$ & $10 \mathrm{~V}$ & أنثي & & \\
\hline$\% 1 \leq . r$ & 77 & أقل من • "ا سنة & \multirow[t]{4}{*}{ العمر } & \multirow[t]{4}{*}{$r$} \\
\hline$\%$ \%ั. & 111 & •r - أقل من •ـ سنة & & \\
\hline$\%$ \% & 177 & •ـ ـ أقل من •0 سنة & & \\
\hline$\% 1 \cdot . \varepsilon$ & $\varepsilon \wedge$ & •0 سنة فأكثر & & \\
\hline$\% Y \leqslant . Y$ & $11 \varepsilon$ & متوسط & \multirow[t]{3}{*}{ المؤهل العلمي } & \multirow[t]{3}{*}{ r } \\
\hline$\% \Upsilon 1.7$ & MIT & بكالوريوس & & \\
\hline$\%\urcorner . V$ & TI & در اسات عليا & & \\
\hline$\% \vee . Y$ & Tr & مدير & \multirow{3}{*}{ المستوى الوظيفي } & \multirow[t]{3}{*}{$\varepsilon$} \\
\hline$\%$ \%I.r & 91 & رئيس قسم & & \\
\hline$\% \vee 1.0$ & ru. & موظف & & \\
\hline$\% \backslash \vee .7$ & $\Lambda 1$ & أقل من 0 سنوات & \multirow[t]{4}{*}{ سنوات الخبرة } & \multirow[t]{4}{*}{0} \\
\hline$\%$ \%०.7 & $17 \varepsilon$ & ○ـ أقل من · ( سنو ات & & \\
\hline$\%$ \%V.V & $I V \varepsilon$ & • 1 - أقل من 10 سنة & & \\
\hline$\% 9.1$ & $\sum Y$ & 10 سنة فأكثر & & \\
\hline$\% 1 \ldots$ & $\sum 71$ & \multicolumn{3}{|c|}{ المجموع } \\
\hline
\end{tabular}

المعالجة الإحصائية المستخدمة

بهدف الوصول إلى المؤشرات التي تختبر فروض الدراسة، قام الباحثان باستخدام برنامجين إحصائيين، وهما SPSS V.26، و AMOS V.21. وقد تم استخدام الأساليب الإحصائية التالية: ا - اختبار معامل الثبات والاعتمادية: وتم استخدامه لقياس مدي ثبات أداة الدراسة. r - التكرارات والنسب المئوية والمتوسطات الحسابية والانحراف المعياري: وذلك لوصف خصائص العينة، وتحديد استجابات أفراد العينة تجاه جميع محاور أداة الدراسة. ب- التحليل العاملي الاستكشافي والتوكيدي: لدراسة العلاقات بين العوامل الكامنة والمؤشرات التي تمثله والعوامل فيما بينها. وكذلك لتقديم أدلة الصدق البنائي للمقياس. ع - تحليل الانحدار البسيط: لتحديد أثر المتغير المستقل علي المتغير التابع، وبيان قيمة هذا التأثير. ه- مؤشرات المطابقة: لتحديد مدي تطابق نموذج الدراسة المقترح مع بيانات العينة، وتثمل هذه المؤشرات مربع كاي المعياري، ومؤشر المطابقة المقارن (CFI)، ومؤشر جودة المطابقة (GFI)، ومؤشر المطابقة المعياري (NFI)، ومؤشر المطابقة المتزايد (IFI)، ومؤشر توكر لويس (TLI)، وأخيراًمؤشر جذر متوسط

$$
\text { مربع الخطأ التقريبي (RMSEA). }
$$

ج- أسلوب تحليل المسار : لتحديد أثر المتغير المستقل علي المتغيرات التابعة بشكل مباشر ، وكذلك تحديد أثر المتغير المستقل علي المتغير التابع في وجود متغير وسيط. 
V- ط طريقةBOTSTRAP: لتحديد إذا ما كان للمتغير الوسيط دور في العلاقة بين المتغير المستقل

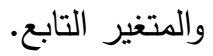

^- اختبار "ت": لتحديد الفروق في استجابات أفراد العينة للمتغيرات الدراسة، ويتم استخدامه في حالة تحديد الفروق بين عينتين مستقلتين. 9- اختبار ONE WAY ANOVA: لتحديد الفروق في استجابات أفراد العينة للمتغيرات الدراسة، ويتم استخدامه في حالة تحديد الفروق بين أكثر من عينتين مستقلتين.

نتائج التحليل واختبار الفرضيات تحليل نتائج الدراسة لوصف مستوي السعادة الوظيفية، والإستقرار الوظيفي، والإحباط الوظيفي، والإخلال الوظيفي لاي العاملين في

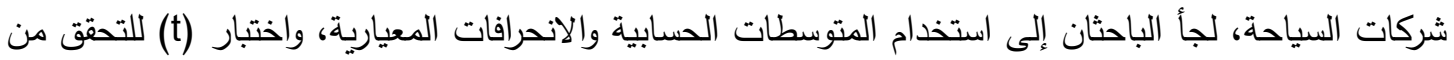

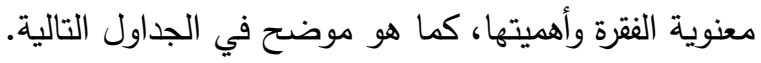
أولاً: مستوي السعادة الوظيفية في شركات السياحة

الجدول (ه) المتوسطات الحسابية والانحرافات المعيارية وقيم (t) لمستوى السعادة الوظيفية

\begin{tabular}{|c|c|c|c|c|c|c|c|}
\hline الأهية & ألرتيبة & 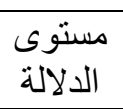 & المحسوبة t & الانحريافي & الحستوسطي & مستوي السعادة الوظيفية & r \\
\hline مرتفعة & 9 & $\because \cdots$ & Y7.OYI & $1 . r$ & r.0 & |أشعر بالرضا عن وظبفتي & 1 \\
\hline مرتفعة & 0 & $\because \cdots$ & M. YOO & $\cdot \wedge 1$ & $\varepsilon . r$ & كبير أهتم بزملائي في العمل بشكل & r \\
\hline مرتفعة & $\mathrm{V}$ & $\because \cdots$ & $\Gamma \cdot . \wedge \xi 1$ & $.9 V$ & $r .9 V$ & متفائل بشأن مستقبلي الوظيفي & $r$ \\
\hline مرتفعة & 7 & $\because \cdots$ & $\varepsilon Y . O T V$ &.$V r$ & $\varepsilon .$. & 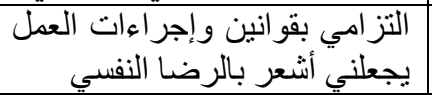 & $\xi$ \\
\hline مرتفعة & $r$ & $\because \cdots$ & $\varepsilon 1.90 \%$ &. .77 & 5.11 & |أري أَن وظيفتي ممتعة & 0 \\
\hline مرتفعة & $r$ & $\because \cdots$ & ר. & .09 & $\sum . Y_{1}$ & أشلفعر أنني قادر علي القيام بما & 7 \\
\hline مرتفعة & $\varepsilon$ & $\because \cdots$ & $r \cdot . \wedge V \varepsilon$ &.$\wedge \wedge$ & $\varepsilon .9$ & |أمتلك طاقة إيجابية كافية لأداء & $\mathrm{V}$ \\
\hline مرتفعة & $\Lambda$ & $\because \cdots$ & YI.OY. & $\therefore \vee 9$ & $r . \wedge q$ & أستطيع التأثير الإيجابي في & $\Lambda$ \\
\hline مرتفعة & 1 & $\because \cdots$ & VI.YYT & .01 & $\varepsilon .{ }_{\Lambda}$ & 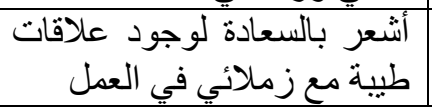 & 9 \\
\hline مرتفعة & & $\because \cdots$ & $09.0 \leqslant V$ &. .74 & $\varepsilon .1$ & 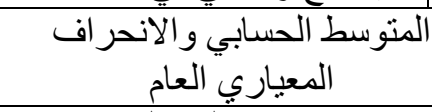 & \\
\hline \multicolumn{8}{|c|}{ تم حساب قيمة (t) الجدولية بالاستتاد إلى الوسط الافتر اضي للفقرة و البالغ ( } \\
\hline
\end{tabular}

تثير نتائج الجدول رقم (0) إلى استجابات عينة الدراسة على عبارات متغير السعادة الوظيفية، وبشكل عام

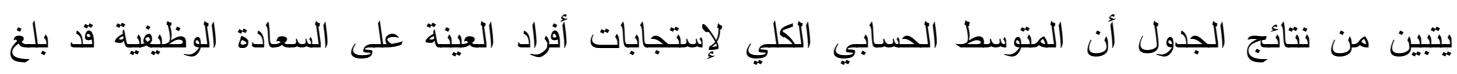

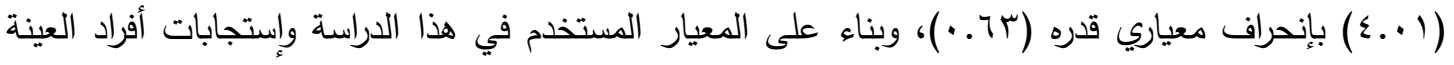


فإن هذا المتوسط الحسابي يشير إلى أن مستوي السعادة الوظيفية في شركات السياحة مرتفعاً. وقد تراوحت

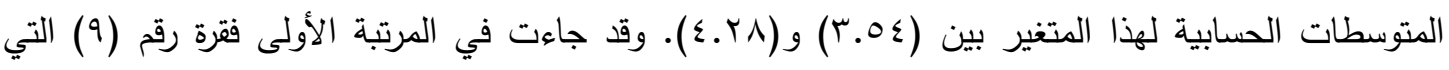

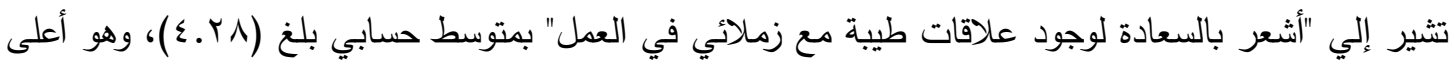

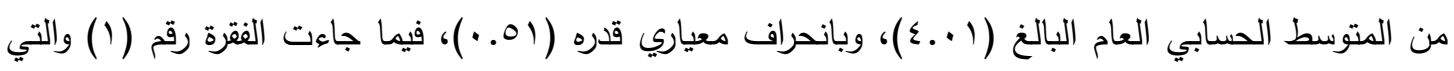

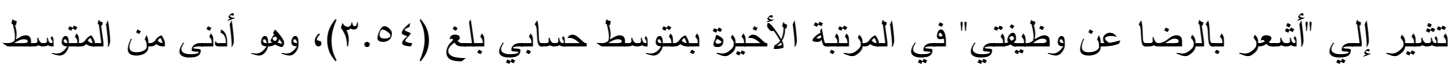

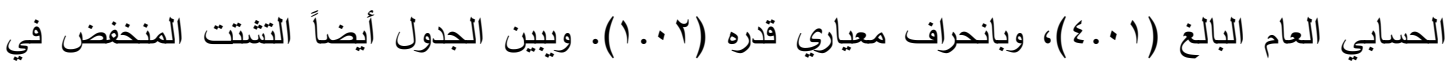

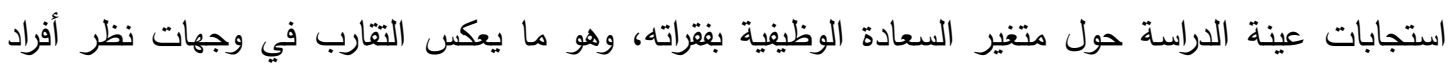

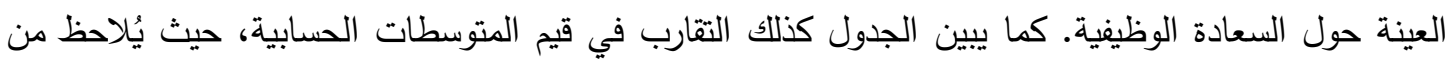

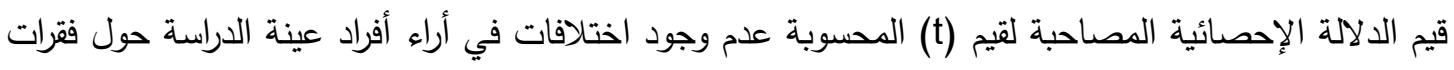
هذا المتغير ، حيث كانت الدلالة الإحصائية لكافة المستويات أدنى من مستوى الدالالة المعنوية (0. ...).

ثانياً: مستوي الإستقرار الوظيفي في شركات السياحة

الجدول (آ) المتوسطات الحسابية والانحرافات المعيارية المعيارية وقيم (t) لمستوى الإستقرار الوظيفي الإبي

\begin{tabular}{|c|c|c|c|c|c|c|c|}
\hline الأهمية & الأهمية & ال الدلالة & المحسوبة t & الانحر اف المعياري & الحسابي & مستوي الإستقرار الوظيفي & s \\
\hline مرتفعة & 0 & $\because \cdots$ & $\varepsilon V .10 r$ & .99 & r.AI & أفكر في عملي بأنه وظيفة دائمة & 1 \\
\hline متوسطة & $\Lambda$ & $\because \cdots$ & $r q . \wedge \cdot v$ & 1.11 & r.Y人 & يتناسب مع حجم العمل أحصل عليه & r \\
\hline مرتفعة & $\varepsilon$ & $\because \cdots$ & or.ru & 1.4 & $r .90$ & أشُعر بأن ساعات العمل ملائمة & $r$ \\
\hline مرتفعة & 7 & $\because \cdots$ & $\varepsilon 9 . \vee \leqslant$. & $.9 \mathrm{~V}$ & $r . V V$ & الاستر احات أثتاء العمل كافية & $\varepsilon$ \\
\hline مرتفعة جداً & 1 & $\because \cdots$ & AT.OTE & $.0 \mathrm{~V}$ & $\varepsilon . Y Y$ & جيدة علاقي مع زملائي في العمل & 0 \\
\hline مرتفعة & $r$ & $\because \cdots$ & $\varepsilon \wedge .90 \mathrm{~V}$ & .94 & r.91 & و والعاملين تفالكم بين الإدارة & 7 \\
\hline مرتفعة & V & $\because \cdots$ & 77.41. & $1 . \cdots$ & $T .77$ & باستي الإدارة احتياجات العاملين & V \\
\hline مرتفعة & $r$ & $\because \cdots$ & 09. Yos &.$V T$ & $\varepsilon .9$ & |أشعر بالعدالة في التعاملات & $\Lambda$ \\
\hline مرتفعة & & $\because \cdots$ & $97 . \vee 05$ &.$\wedge 1$ & r.Ao & 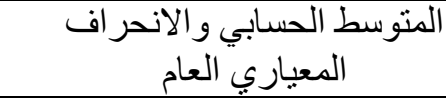 & \\
\hline \multicolumn{8}{|c|}{ تم حساب قيمة (t) الجدولية بالاستناد إلى الوسط الافتر اضي للفقرة و البالغ (3) } \\
\hline
\end{tabular}

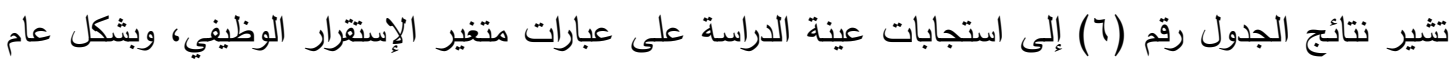

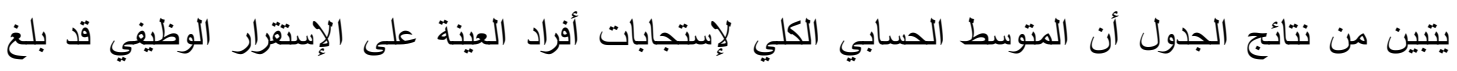

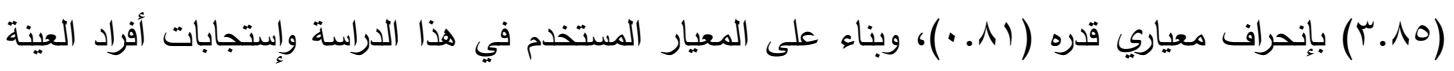

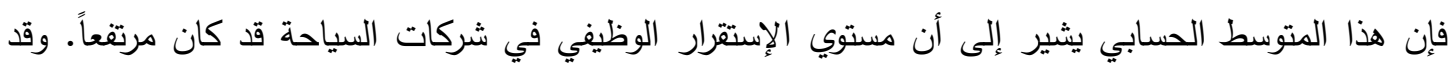

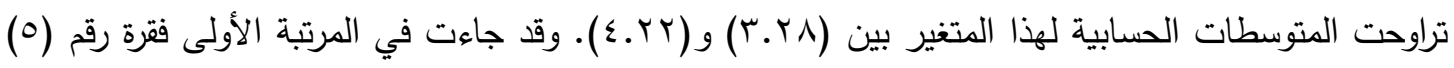




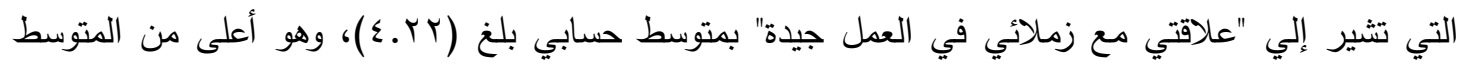

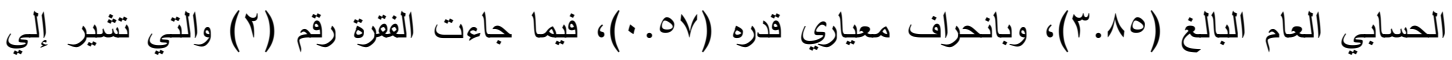

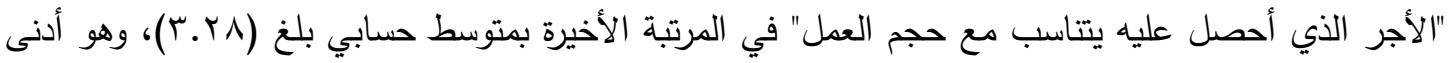

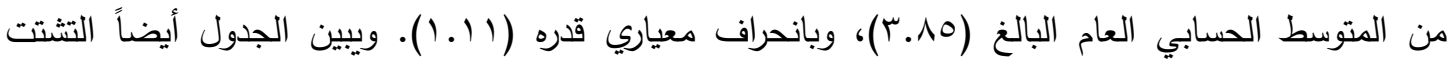
الدنخف في استجابات عينة الدراسة حول متغير الإستقرار الوظيفي بفقراته، وهو ما يعكس التقارب في وجهات

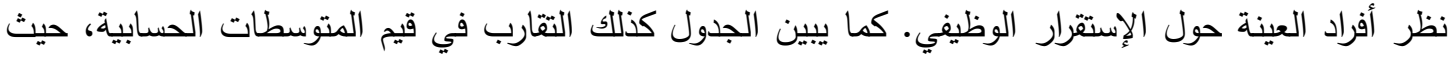

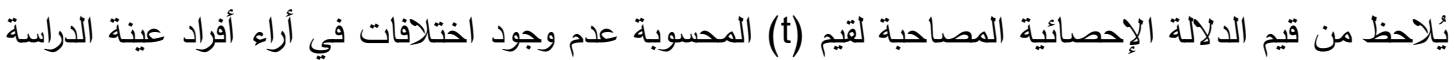

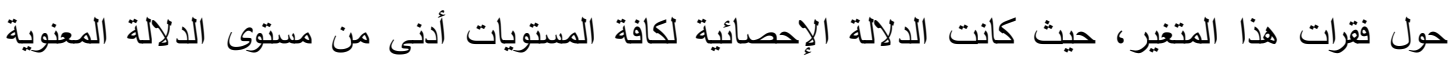

ثالثاً: مستوي الإحباط الوظيفي في شركات السياحة

الجدول (V) المتوسطات الحسابية والانحرافات المعيارية وقيم (t) لستوى الإحباط الوظيفي

\begin{tabular}{|c|c|c|c|c|c|c|c|}
\hline الأهمية & الأرتيبة & مستوى & المحسوبة t & الالحياري اف & الحسابي & مستوي الإحباط الوظيفي & b \\
\hline منخفضة جداً & $\varepsilon$ & $\because \cdots$ & r9.0rद & $1 . \cdot 1$ & $1 . v 1$ & أنشعر بعدم الحماس في عمل & 1 \\
\hline 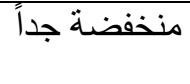 & 0 & $\because \cdots$ & TO.YIद & .90 & 1.74 & |أشئسر بأني دوري في العمل & T \\
\hline منخفضة & 1 & $\because \cdots$ & $01 . \vee 09$ &. $\mathrm{~V} \varepsilon$ & T.M & ألتقاقص حماسي تدريجياً في & r \\
\hline منخفضة & r & $\because \cdots$ & $\varepsilon \varepsilon . V T V$ & $\cdot \triangle \wedge$ & $r_{.} \cdot \varepsilon$ & أشعر بالإحباط في العمل & $\varepsilon$ \\
\hline منخفضة جداً & 7 & $\because \cdots$ & Tr. ¿OV & 1.0 & 1.09 & أشعر بالتعب في العمل سريعاً & 0 \\
\hline منخفضة & r & $\because \cdots$ & $\varepsilon 1.4 \cdot 9$ & .94 & 1.94 & غامضر بأني مستقبلي الوظيفي & 1 \\
\hline منخفضة & & $\because \cdots$ & $\sum 1.41$ & $\cdot v 1$ & I.AV & المنو سط الحسابي و الانحر اف اف & \\
\hline \multicolumn{8}{|c|}{ تم حساب قيمة (t) الجدولية بالاستناد إلى الوسط الافتر اضي للققرة و البالغ (3) } \\
\hline
\end{tabular}

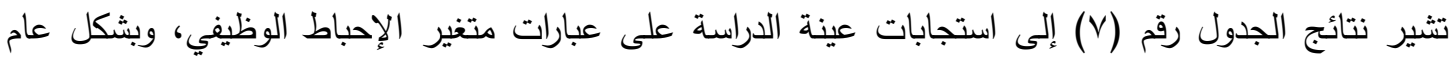

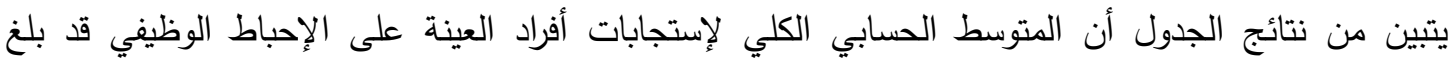

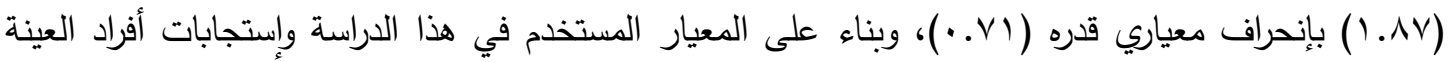

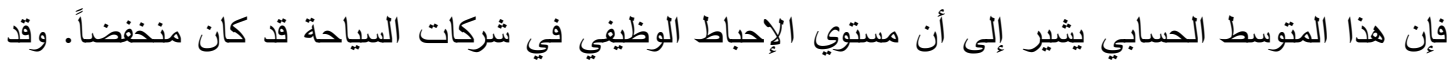

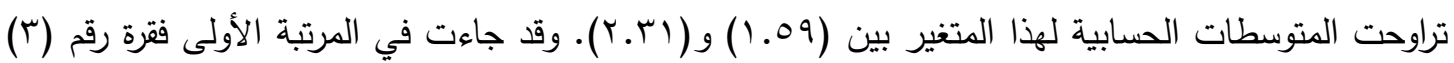

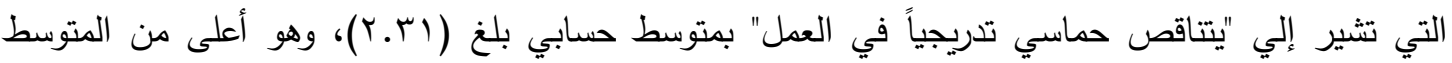

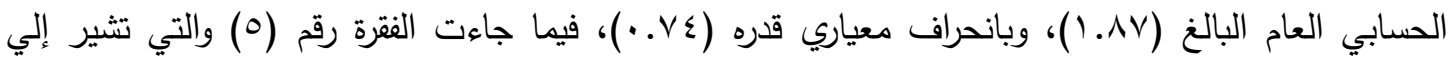

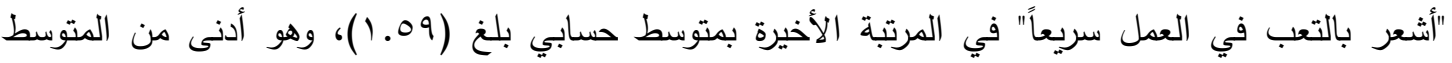

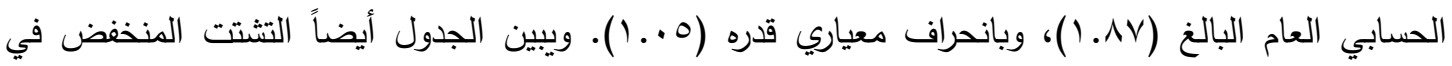

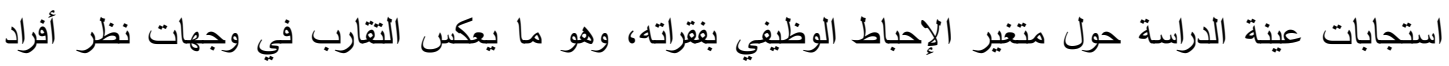




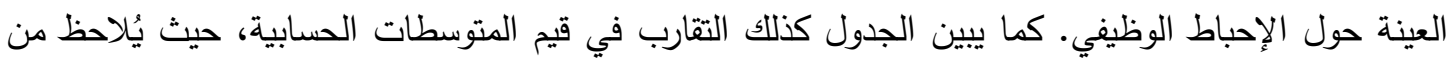

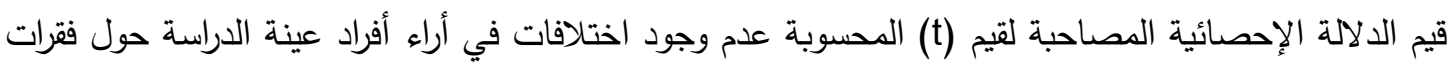
هذا المتغير ، حيث كانت الدلالة الإحصائية لكافة المستويات أدنى من مستوى الداللة المعنوية (0. ...).

رابعاً: مستوي الإخلال الوظيفي في شركات السياحة

الجدول (^) المتوسطات الحسابية والانحرافات المعيارية المعيارية وقيم (t) لمستوى الإخلال الوظيفي

\begin{tabular}{|c|c|c|c|c|c|c|c|}
\hline الأهمية & الأرتيبة & مالدالة & المحسوبة t & المعياري ال المع & ال المتوسطي & مستوي الإخلال الوظيفي & r \\
\hline منخفاً & 0 & $\because \cdots$ & ro.vol & $.9 \mathrm{~V}$ & $1.7 \varepsilon$ & القضاء أضطر للخروج من الأمور & 1 \\
\hline منخفضة & $\varepsilon$ & $\because \cdots$ & $\varepsilon \varepsilon . Y T \leqslant$ & $\because \wedge \Lambda$ & $1 . \mathrm{Vr}$ & | أتأخر عن العمل بشكل متكرر & r \\
\hline منخفاً & 7 & $\because \cdots$ & $r \cdot Y T \leqslant$ & $\cdot .94$ & 1.09 & أنصرف من عملي قبل انتهاء العضاء & $r$ \\
\hline منخفضة & $\tilde{r}$ & $\because \cdots$ & $\leqslant 9.10 \leqslant$ & $\therefore .19$ & $1 . V V$ & | أغيب عن عملي بشكل متكرر & $\varepsilon$ \\
\hline منخفضة & r & $\because \cdots$ & $0 V . \leqslant 19$ & 9.9. & $r_{.} .$. & | دأهتم بوقت الاهتمام بإنجازي العملي & 0 \\
\hline منخفضة & 1 & $\because \cdots$ & $7 \cdot . r \leqslant q$ & $\cdot . \vee \varepsilon$ & $r . \cdot r$ & |أتغيب عن عملي بدون إبلاغ & 7 \\
\hline منخفضة & & $\because \cdots$ & $01 . \wedge \leqslant 7$ &. .01 & 1.199 & المتوسط الحسابي و الانحر اف افعيام & \\
\hline
\end{tabular}

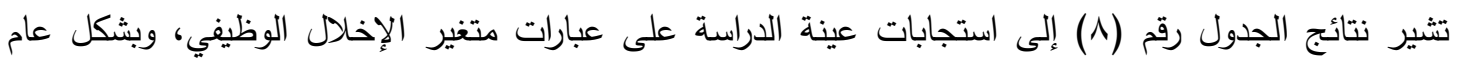

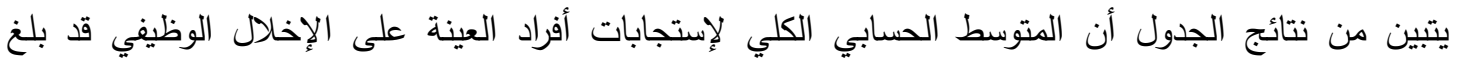

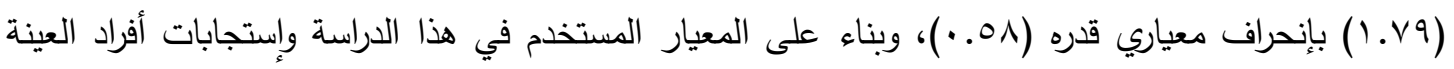

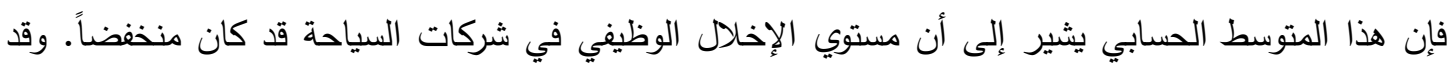

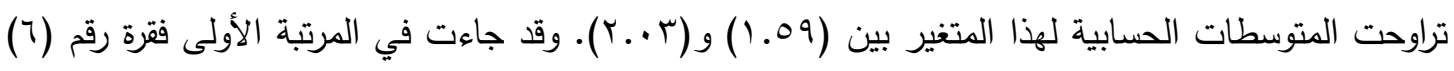

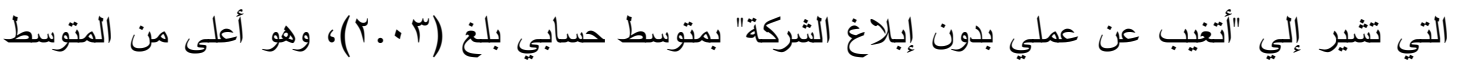

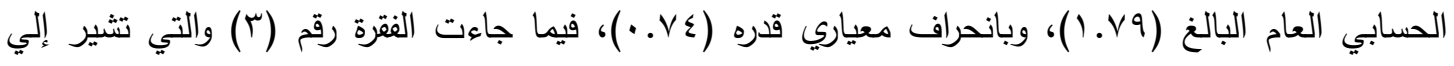

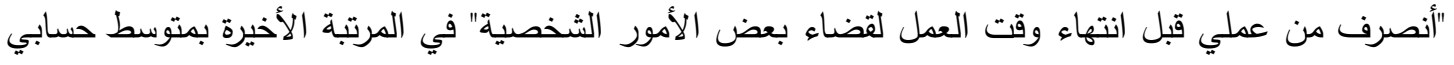

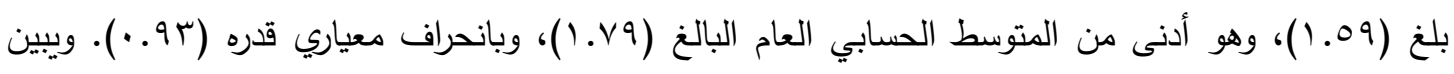

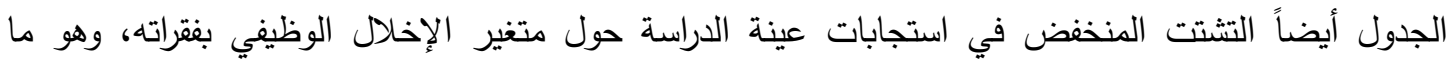

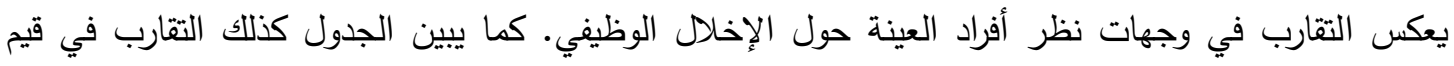

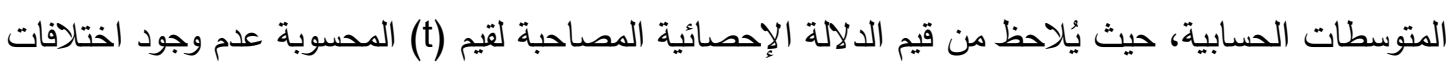


في أراء أفراد عينة الدراسة حول فقرات هذا المتغير ، حيث كانت الدلالة الإحصائية لكافة المستويات أدنى من مستوى الدلالة المعنوية (0. . (.). التحليل العاملي الاستكثافي والتوكيدي

القيم المتطرفة

تم استخدام Mahalabonis Distance لتحديد القيم المتطرفة. ويوضح جدول رقم (9) القيم المتطرفة. وقد تم كثف ومعالجة القيم المتطرقة والتخلص منها، حيث تم التخلص من 1 استمارات تجاوز بعدها عن مركز الكتلة Mahalabonis Distance

\begin{tabular}{|c|c|}
\hline \multicolumn{2}{|c|}{ الجدول (9) القيم المتطرفة } \\
\hline Mahalabonis Distance & رقم الاستمارة \\
\hline $79.10 \leqslant$ & Tr \\
\hline$M \Lambda .0 Y I$ & 91 \\
\hline$T V . I Y \varepsilon$ & $1 \leqslant \varepsilon$ \\
\hline$q \cdot . \leqslant 1 r$ & 184 \\
\hline V0.007 & rq4 \\
\hline N. rol & rAY \\
\hline
\end{tabular}

التحليل العاملي الاستكثافي

تم إجراء التحليل العاملي الاستكثافي بطريقة تحليل المكونات الرئيسية ( Principal Components (Analysis - PCA

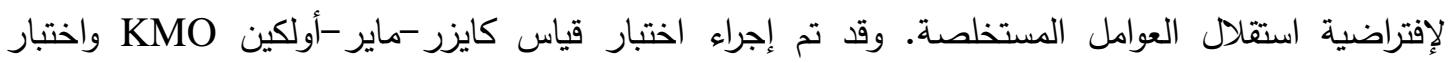

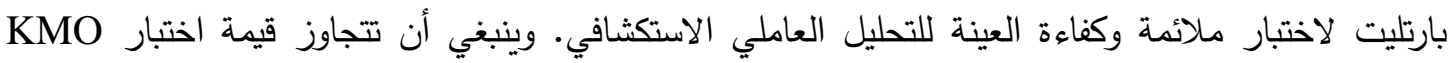

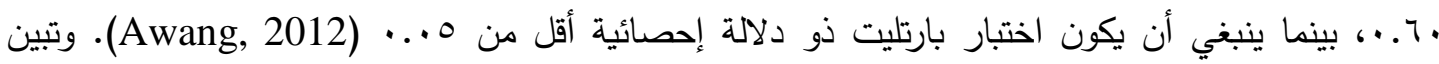

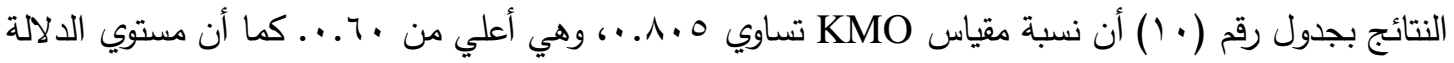
في اختبار بارتليت يساوي ...... وهي أقل من ه .... .. وهذا يدل علي أن العينة مناسبة للتحليل العاملي. الجدول (· ا (1) اختبار كايزر -ماير -أولكين وبارتليت

\begin{tabular}{|c|c|c|}
\hline$\cdot .1 \cdot 0$ & KMO & \\
\hline TYAE.TYQ & APPROX. Chi Square مربع كاي التقريبي & \multirow{3}{*}{ اختبار بارتليت } \\
\hline roq & $\mathrm{df}$ & \\
\hline$\because \cdots$ & Sig. & \\
\hline
\end{tabular}

يوضح الجدول رقم (1) العوامل المستخرجة وتثبعاتها بعد التدوير المتعامد لمصفوفة مفردات متغيرات السعادة الوظيفية، والإستقرار الوظيفي، والإحباط الوظيفي، والإخلال الوظيفي. وتبلغ القيمة الدنيا الدقبولة لتحميل العوامل

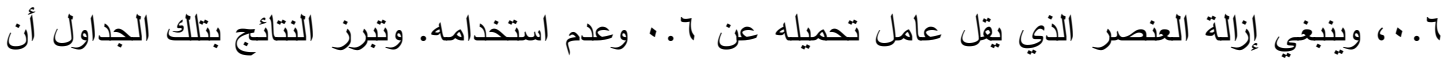

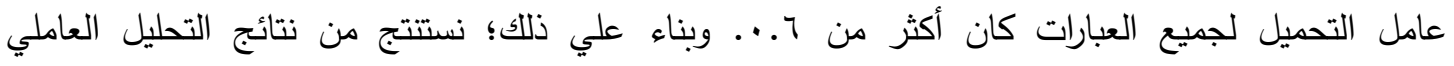

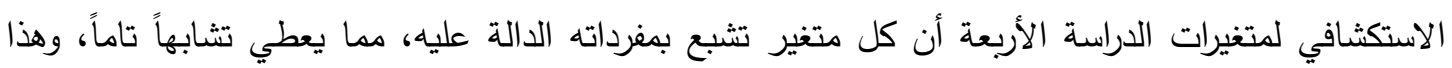


يؤكد صدق القائمة عند إجراء التحليل العاملي الاستشكافي، مما يفي بمتطلبات الدراسة ويسمح بتطبيق القائمة علي عينة الدراسة

الجدول (1 (1) العوامل المستخرجة وتشبعاتها بعد التدوير المتعامد لمصفوفة مفردات متغيرات السعادة الوظيفية والإستقرار الوظيفي والإحباط الوظيفي والإخلال الوظيفي بعدئي

\begin{tabular}{|c|c|c|c|c|}
\hline \multicolumn{4}{|c|}{ المتغير ات } & \multirow{2}{*}{ المفردة } \\
\hline الإخلال الوظيفي & الإحباط الوظيفي & الإستقر ار الوظيفي & السعادة الوظيفية & \\
\hline & & & $\because V O \leqslant$ & 1 \\
\hline & & & $\because \Lambda \cdot r$ & $r$ \\
\hline & & & $\because .7 \wedge V$ & $r$ \\
\hline & & & .794 & $\varepsilon$ \\
\hline & & & .1001 & 0 \\
\hline & & & $\because V \mu \Lambda$ & 7 \\
\hline & & & $.77 \varepsilon$ & V \\
\hline & & &.$V \cdot 9$ & $\Lambda$ \\
\hline & & & .701 & 9 \\
\hline & & .791 & & 1. \\
\hline & &.$V V T$ & & 11 \\
\hline & & $\because 199$ & & IT \\
\hline & &.$\wedge \cdot 9$ & & $1 T$ \\
\hline & & $\because \vee \vee \wedge$ & & $1 \leq$ \\
\hline & &.$V 9 Y$ & & 10 \\
\hline & & $\because$. ATo & & 17 \\
\hline & & $\because V 9 V$ & & IV \\
\hline &.$\wedge T Y$ & & & 11 \\
\hline & $.79 \varepsilon$ & & & 19 \\
\hline & .700 & & & $r \cdot$ \\
\hline & .101 & & & 41 \\
\hline & $\because \vee \wedge I$ & & & TY \\
\hline & .791 & & & Tr \\
\hline$\because V V T$ & & & & YE \\
\hline .790 & & & & ro \\
\hline$\because V T_{0}$ & & & & r7 \\
\hline.$\vee 79$ & & & & TV \\
\hline..$\vee 91$ & & & & rᄉ \\
\hline. $\mathrm{VOV}$ & & & & rq \\
\hline
\end{tabular}

التحليل العاملي التوكيدي

تم استخدام التحليل العاملي التوكيدي لمفردات المتغيرات الأربعة باستخدام طريقة أقصي احتمال ) Maximum (Likelihood - ML قيمة مؤشرات المطابقة للمتغيرات الأربعة. 
الجدول (Y I I ) قيمة مؤشرات المطابقة

\begin{tabular}{|c|c|c|c|c|c|c|c|c|}
\hline RMSEA & AGFI & GFI & AGFI & CFI & NNFI & NFI & IFI & المتغير ات \\
\hline$\because M r$ & .971 & .97. & $\because .9 \vee \varepsilon$ & .901 & .977 & $.9 V T$ & .901 & السعادة الوظيفية \\
\hline$\because \leqslant 1$ & $\cdot .909$ & $.97 \leq$ & $\cdot .9 \vee V$ & $.9 V$. & $\cdot .979$ & .901 & $.9 V V$ & الإستقر ار الوظيفي \\
\hline 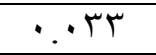 & .97. & .907 & $.9 V T$ & $.90 \mathrm{~V}$ & $\cdot .9 \vee \wedge$ & $.9 V T$ & $\cdot .9 \wedge$. & الإحباط الوظيفي \\
\hline$\because 19$ & $\cdot .9 \wedge \mu$ & .97. & $\because .971$ & .901 & $\because .977$ & $\because 9 \vee 7$ & $\because .901$ & الإخلال الوظيفي \\
\hline
\end{tabular}

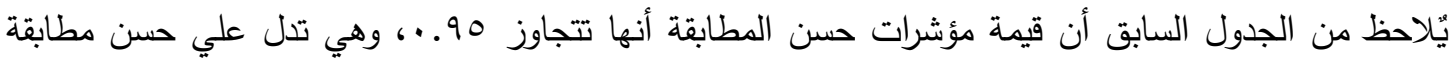
مقبولة. ويوضح جدول رقم (T I) تشبعات المفردات على العوامل، وقيمة اختبار "ت" المناظرة، والخطأ المعياري لكل مفردة. كما يبين جدول رقم (ب ا) قيمة "ت" لمفردات المتغيرات الأربعة، وارتفاعها عن 9 و. ال، وهذا ما يؤكد صدق التحليل العاملي التوكيدي لمتغيرات الدراسة، مما يسمح بتطبيقها علي عينة الدراسة. الجدول (r I ا تشبعات المفردات على العوامل، وقيمة اختبار "ت" المناظرة، والخطأ المعياري لكل مغردة

\begin{tabular}{|c|c|c|c|c|c|}
\hline الدلالة & ت & الخطأ المعياري & التشبع & م & المتغير \\
\hline$\because \cdots$ & 17.91 & $\because 0 Y$ &.$\wedge \Lambda \mu$ & 1 & \multirow[t]{9}{*}{ السعادة الوظبفية } \\
\hline$\because \cdots$ & IT. $\leqslant \varepsilon$ & $\because 71$ & .1809 & T & \\
\hline$\because \cdots$ & $r T^{\prime} \cdot r$ & $\because \leqslant Y$ & $.97 \mathrm{~V}$ & $r$ & \\
\hline$\because \cdots$ & $17 . \varepsilon$ & $\because 0$ & $\because \wedge r$. & $\varepsilon$ & \\
\hline$\because \cdots$ & $r \cdot r \varepsilon$ & $\because$ 苗人 &.$V V T$ & 0 & \\
\hline$\because \cdots$ & מוIT & $\because r q$ & $.9 \cdot r$ & 7 & \\
\hline$\because \cdots$ & 18.71 & $\because \leqslant V$ & .AM & V & \\
\hline$\because \cdots$ & Yr.YI & $\because T \varepsilon$ & $\because \vee \wedge 9$ & $\Lambda$ & \\
\hline$\because \cdots$ & 10.10 & $\because .04$ & . ATO & 9 & \\
\hline$\because \cdots$ & $1 \wedge . \wedge 1$ & $\because \varepsilon V$ &.$\wedge \wedge \varepsilon$ & 1 & \multirow[t]{8}{*}{ الإستقرار الوظيفي } \\
\hline$\because \cdots$ & IT... & $\because 77$ &.$V 9 r$ & $r$ & \\
\hline$\ldots$ & $1 . V T$ &.$\wedge r$ &.$\wedge \wedge$. & $r$ & \\
\hline$\because \cdots$ & $1 \wedge . \leqslant T$ & $\because \leqslant 9$ & .9 .1 & $\varepsilon$ & \\
\hline$\because \cdots$ & $14.9 \mathrm{~V}$ & $\because 71$ &.$\wedge \Lambda \mathrm{Y}$ & 0 & \\
\hline$\because \cdots$ & $17 . \leqslant T$ & $\because .01$ &.$\wedge \vee 1$ & 7 & \\
\hline$\because \cdots$ & ITI & $\because 0 \leqslant$ & .819 & $\mathrm{~V}$ & \\
\hline$\because \cdots$ & 11.11 & $\because .7 \mu$ &.$\wedge r 7$ & $\Lambda$ & \\
\hline$\because \cdots$ & IT.Y & $\because .01$ &.$V 7 V$ & 1 & \multirow[t]{6}{*}{ الإحباط الوظيفي } \\
\hline$\because \cdots$ & 17.1 & .01 &.$\wedge r$ & $r$ & \\
\hline$\because \cdots$ & $r \cdot \Delta V$ & $\because 19$ &.$\wedge 1 \varepsilon$ & $r$ & \\
\hline$\because \cdots$ & $|V . r|$ & $\because .0 Y$ & $.9 \cdot$ & $\varepsilon$ & \\
\hline$\because \cdots$ & 17.71 & $\because \varepsilon V$ & $\because \vee \wedge \varepsilon$ & 0 & \\
\hline$\because \cdots$ & $1 \leq .9 \leq$ & $\because .0 Y$ & $\because V V V$ & 7 & \\
\hline$\because \cdots$ & $r \cdot r \Lambda$ & $\because+9$ & $\because 199$ & 1 & \multirow[t]{6}{*}{ الإخلال الوظيفي } \\
\hline$\because \cdots$ & IT.OV & $\because V Y$ & .9 .0 & $r$ & \\
\hline$\ldots$ & $17 .$. & .00 &.$\wedge \wedge$. & $r$ & \\
\hline$\because \cdots$ & A. Vo & $\because 199$ & $\because \vee \vee q$ & $\varepsilon$ & \\
\hline$\because \cdots$ & $1 Y . \varepsilon$ & $\because V Y$ &.$\wedge T V$ & 0 & \\
\hline$\because \cdots$ & $1 \leq . V$ & .04 & $\because \vee \vee q$ & 7 & \\
\hline
\end{tabular}


الصدق التقاربي والصدق التمييزي تم قياس متوسط التباين المستخرج (AVE)، ومربع التباين الأقصي المشترك بين المتغيرات (MSV)، ومتوسط

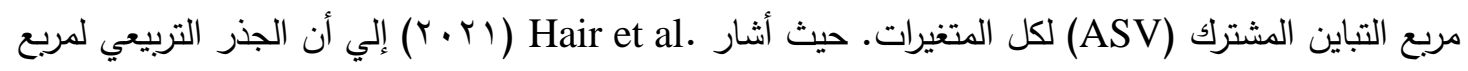
متوسط التباين المستخرج يجب أن يزيد عن أعلي ارتباط تربيعي مع أي متغير آخر • وبناء علي النتائج بجدول رقم (ع ا) يمكن ملاحظة أن الجذر التربيعي لمربع متوسط التباين المستخرج لمتغير معين أكبر من قيمة

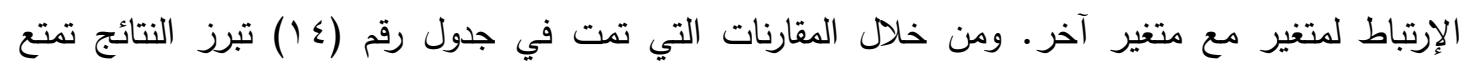

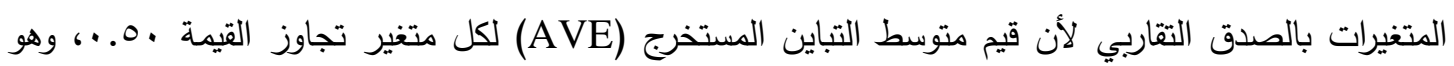

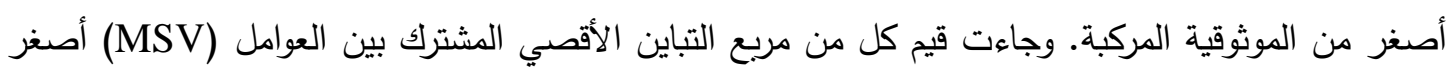
من قيم متوسط التباين المستخرج (AVE)، كما أن قيم متوسط مربع التباين المشترك (ASV) أصغر من من قيح مربع التباين الأقصي المشترك (MSV) لكل المتغيرات، وهو ما يدل علي تمتع النموذج بالصدق التمييزي. كما

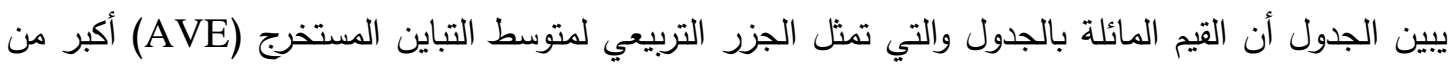
باقي القيم في المصفوفة، وهذا مؤشر آخر يؤكد الصدق التمييزي.

\begin{tabular}{|c|c|c|c|c|c|c|c|}
\hline الإخلالي & الإِطباط & الإستقرار & الوظعادة & ASV & MSV & AVE & المتغير ات \\
\hline & & & $.11 \mathrm{r}$ & $.1 \cdot 1$ & . YOV & $.70 \mathrm{r}$ & السعادة الوظيفية \\
\hline & & .011 & .099 &. .111 & •TrE & . & الإستقرار الوظيفي \\
\hline & $\because V q r$ & $\because 7 \ldots$ & .7 .1 & $.10 \leqslant$ & .199 & $.7 \cdot 1$ & الإحباط الوظيفي \\
\hline .110 & . TYY & $\because .09 \mathrm{~V}$ & $.7 \leqslant V$ &.$I Y Y$ & $\cdot r \cdot \Lambda$ & $\because .0 \wedge Y$ & الإخلال الوظيفي \\
\hline
\end{tabular}

اختبار فرضيات الدراسة ومناقشة النتائج

تحليل الانحدار البسيط

الجدول (0)

\begin{tabular}{|c|c|c|c|c|c|c|c|c|}
\hline المسنوية & ف ف & $\mathrm{R}^{2}$ & $\mathrm{r}$ & المعنوية & 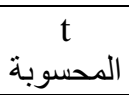 & $\begin{array}{c}\text { Coefficients } \\
\text { معاملات }\end{array}$ & المتغير & التابع \\
\hline \multirow{2}{*}{$\because \cdots$} & \multirow{2}{*}{ r. } & \multirow[t]{2}{*}{.099} & \multirow[t]{2}{*}{$\because \vee \vee \varepsilon_{-}$} & $\because \cdots$ & $V .09 V$ & $\because V \leqslant 1$ & ثالابحدار & الوظبفي الإحباط \\
\hline & & & & $\because \cdots$ & $1 T$. ros & $.0 \% 4$ & الإستقيفي & \\
\hline \multirow{2}{*}{$\because \cdots$} & \multirow{2}{*}{$r \varepsilon \varepsilon .07 V$} & \multirow[t]{2}{*}{$\cdot .74 \Lambda$} & \multirow[t]{2}{*}{$\cdot . \wedge \cdot 1$} & $\because \cdots$ & $9.0 \leq 1$ & $\because 100$ & ثابت & \multirow[t]{2}{*}{ الوظيفية } \\
\hline & & & & $\because \cdots$ & M.YYE & $.77 \varepsilon$ & الإظتقفي ار & \\
\hline \multirow{2}{*}{$\because \cdots$} & \multirow{2}{*}{ Yl. .v०q } & \multirow[t]{2}{*}{$\because \varepsilon 9 V$} & \multirow[t]{2}{*}{$\cdot .7 \wedge V_{-}$} & $\because \cdots$ & $0.79 \mathrm{~V}$ & $\cdot .00 r$ & ثابت & \multirow[t]{2}{*}{ الإخظيفي } \\
\hline & & & & $\because \cdots$ & $1 \leqslant . Y \cdot 1-$ & $\cdot \Sigma 1 \cdot-$ & الإستقفر ار & \\
\hline
\end{tabular}




\begin{tabular}{|c|c|c|c|c|c|c|c|c|}
\hline \multirow{2}{*}{$\because \cdots$} & \multirow{2}{*}{ YVT. $\{01$} & \multirow[t]{2}{*}{$.0 T r$} & \multirow[t]{2}{*}{$\because V Y Y_{-}$} & $\because \cdots$ & $1.04 \leqslant$ & $.9 r \leq$ & ثابتحدار & \multirow[t]{2}{*}{ الوظعادة } \\
\hline & & & & $\because \cdots$ & $r_{1}, r T V_{-}$ & $\because v \cdot r_{-}$ & الإظبيفي & \\
\hline \multirow{2}{*}{$\because \cdots$} & \multirow{2}{*}{$\mid V \Lambda . \varepsilon \varepsilon Y$} & \multirow[t]{2}{*}{$\because r \wedge q$} & \multirow[t]{2}{*}{$.71 \leq$} & $\because \cdots$ & 1.000 & $\because \wedge 0 \mathrm{~V}$ & ثابت & \multirow[t]{2}{*}{ الإخظلافي } \\
\hline & & & & $\because \cdots$ & $1 V . \leqslant 9 V$ & .040 & الوظيفي & \\
\hline \multirow{2}{*}{$\because \cdots$} & \multirow{2}{*}{$r . . r \leqslant v$} & \multirow[t]{2}{*}{$\because 570$} & \multirow[t]{2}{*}{$.7 V 1-$} & $\because \cdots$ & V.rus & .VM & ثابت & \multirow[t]{2}{*}{ الوظيفي } \\
\hline & & & & $\because \cdots$ & $10.10 \mathrm{~V}$ & $\theta \leqslant \varepsilon r_{-}$ & الوظعادية & \\
\hline
\end{tabular}

يوضح جدول رقم (10) النتائج التالية:

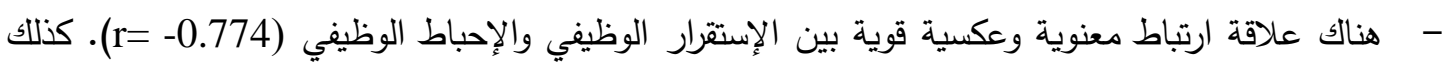

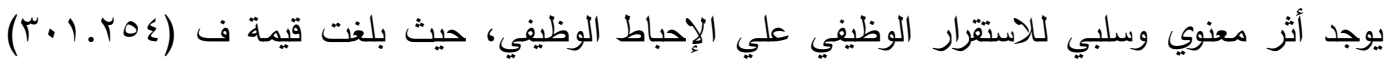

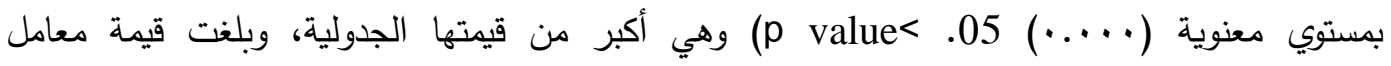

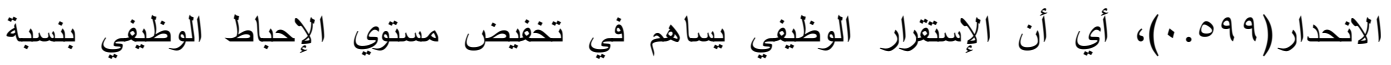

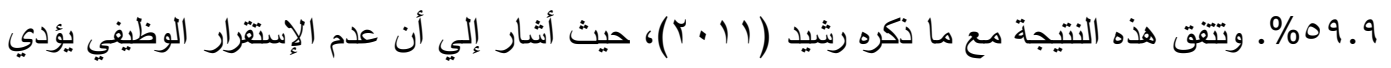

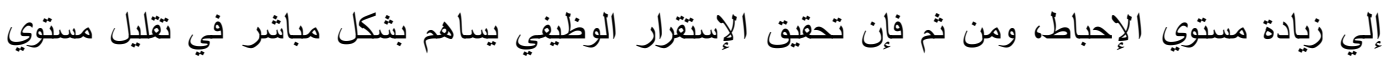

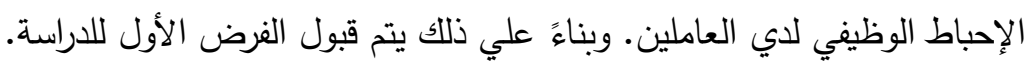

- - هناك علاقة ارتباط معنوية وطردية قوية بين الإستقرار الوظيفي والسعادة الوظيفية (r=0.801). كما أن

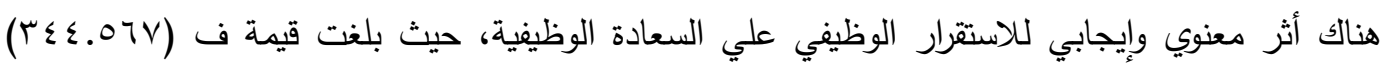

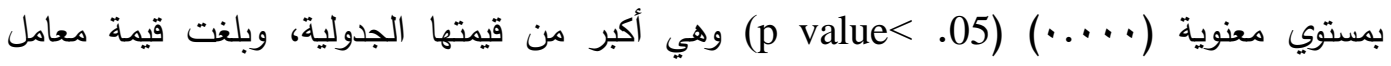

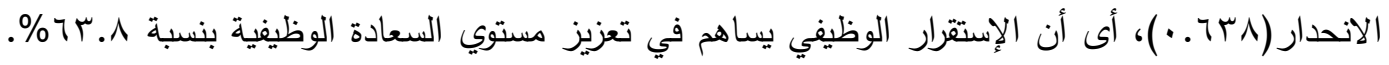

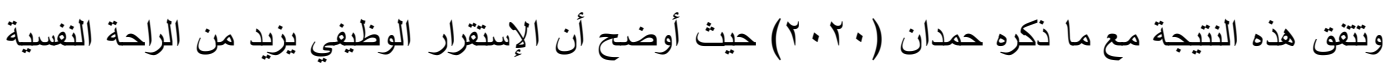

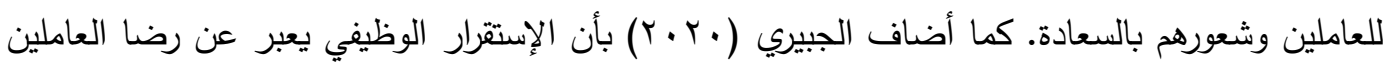

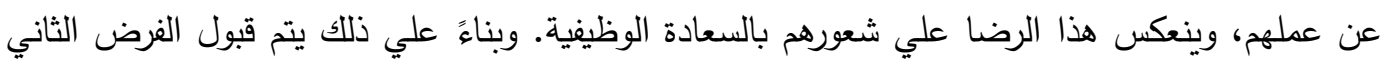
اللاراسة.

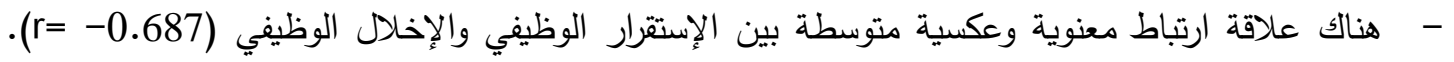

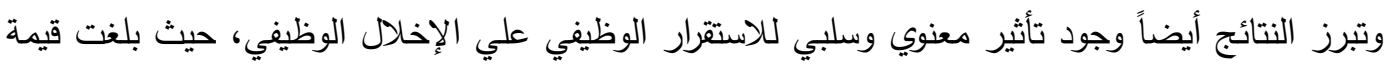

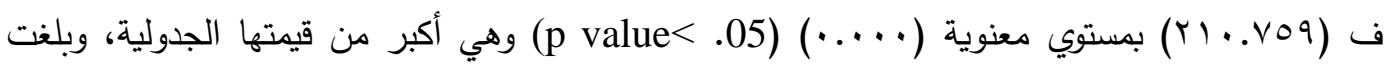

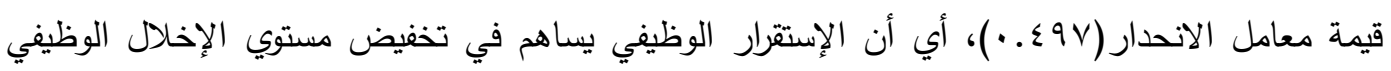

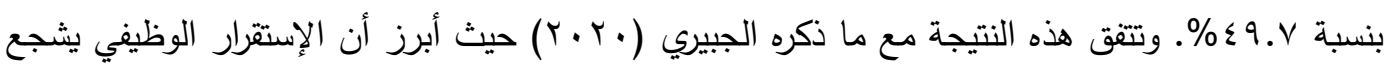


العاملين علي بذل المزيد من الجهود لتحقيق أهداف الثركة. وبناءً علي ذلك يتم قبول الفرض الثالث للدراسة.

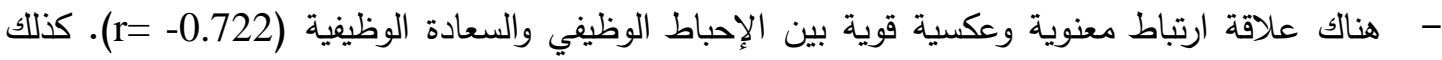

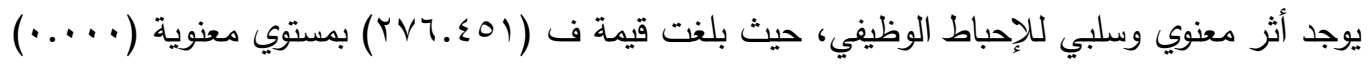

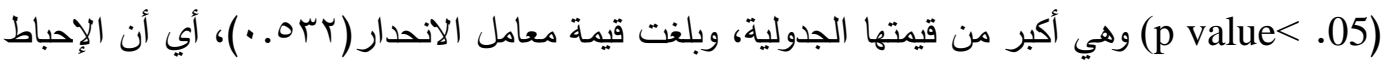

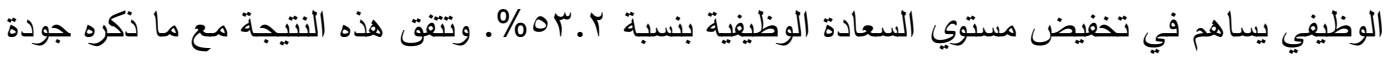

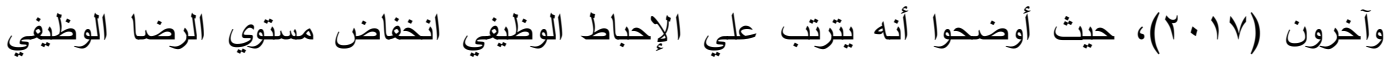

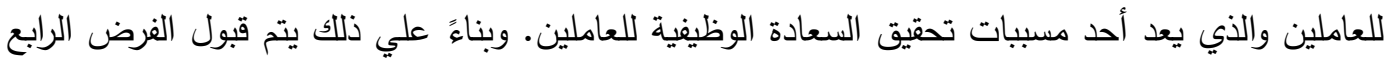
للدراسة. - - هناك علاقة ارتباط معنوية وطردية متوسطة بين الإحباط الوظيفي والإخلال الوظيفي (r= 0.614). كذللك

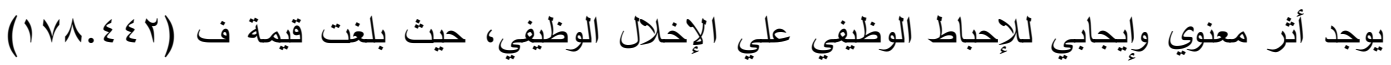

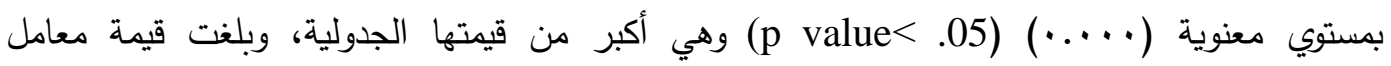

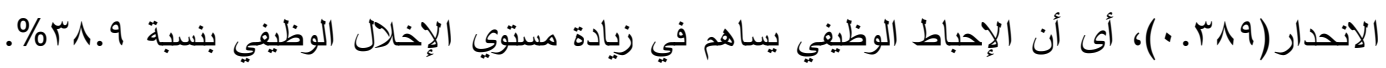

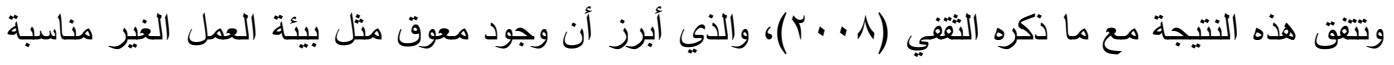
والمليئة بالصراعات، وكذللك سياسات وقوانين العمل الغير مناسبة تؤدي إلي عدم رغبة العاملين في القيام

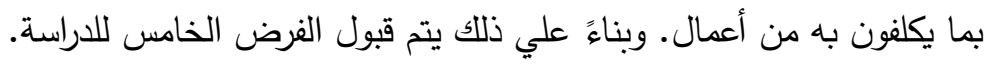
- - مناك علاقة ارتباط معنوية وعكسية متوسطة بين السعادة الوظيفية والإخلال الوظيفي (r= -0.671). كما

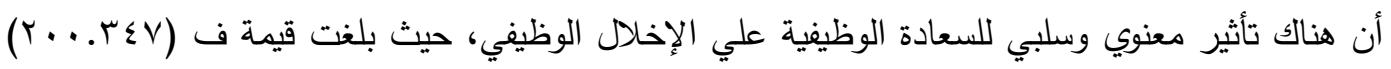

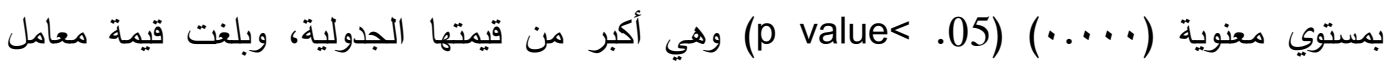

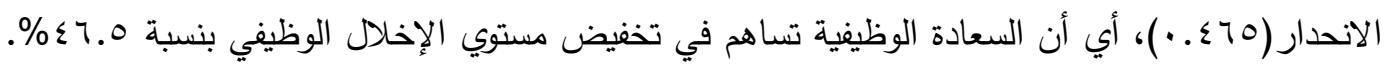

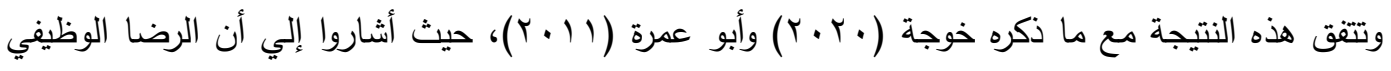

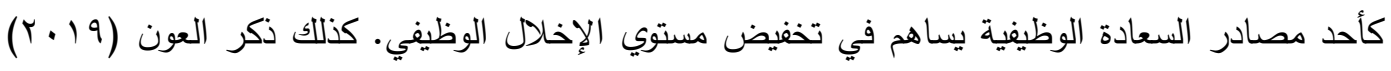

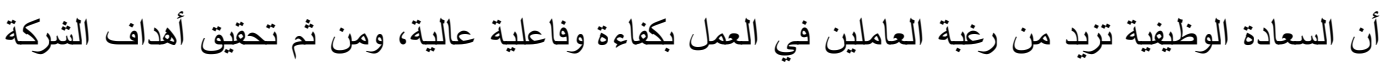

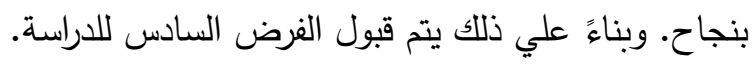

نتائج تحليل المسار يوضح جدول رقم (7 (1) قيم مؤشرات جودة مطابقة نموذج تحليل المسار لأثر الإستقرار الوظيفي علي الإخلال

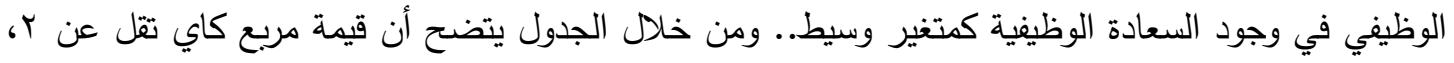

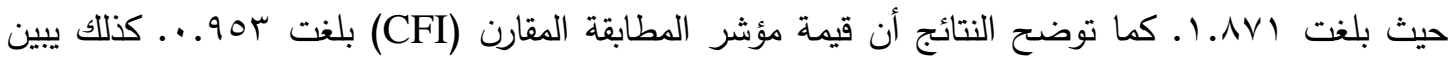

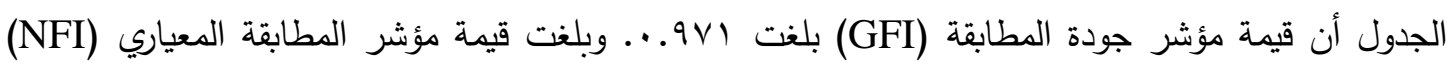

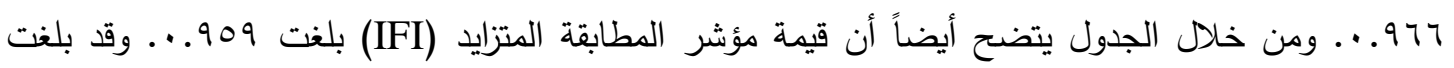


قيمة مؤشر توكر لويس (TLI) .91.... وأخيراً بلغت قيمة متوسط جذر متوسط مربع الخطأ التقربي

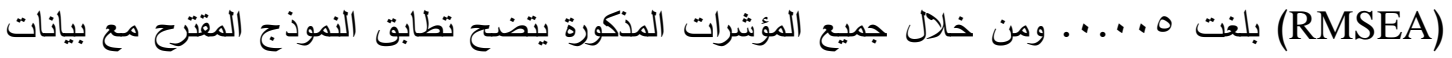

العينة.

الجدول رقم (1 ا ) مؤشرات حسن المطابقة

\begin{tabular}{|c|c|}
\hline قيمة المؤشر & مؤشر ات حسن المطابقة \\
\hline $1 . \wedge \mathrm{VI}$ & 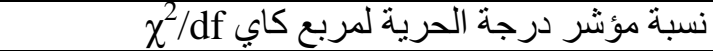 \\
\hline $.90 \mathrm{r}$ & مؤشر المطابقة المقارنCFI \\
\hline $.9 \times 1$ & مؤشر حسن المطابقة GFI \\
\hline$\cdot .977$ & مؤشر المطابقة المعياريNI موي \\
\hline$\cdot .909$ & IFI مؤشر المطابقة التز ايدية \\
\hline$\cdot .91$. & مؤشر تاكر_لويسTLI \\
\hline$\because \cdots 0$ & منوسط جذر متوسط مربع الخطأ الثقريبي RMSEA \\
\hline
\end{tabular}

يبين جدول رقم (IV) نتائج تحليل أثر الإستقرار الوظيفي علي الإخلال الوظيفي في وجود السعادة الوظيفية

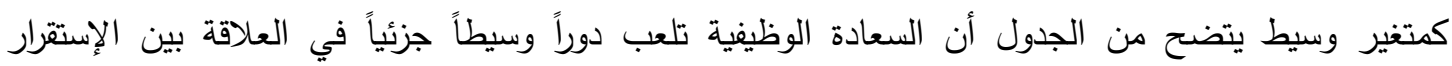

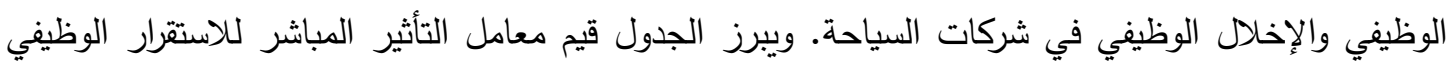

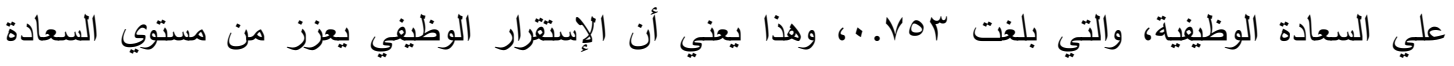

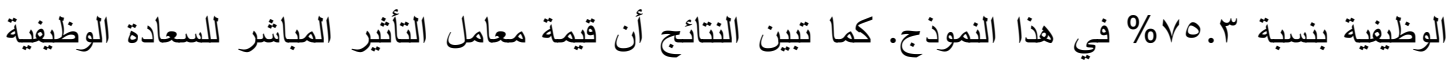

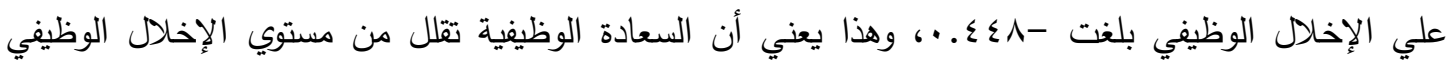

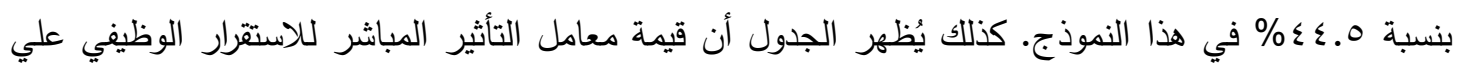

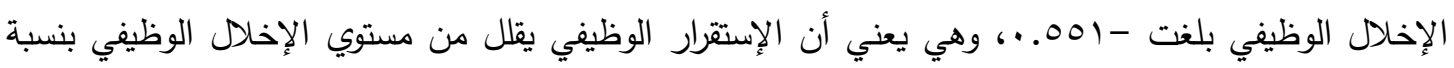

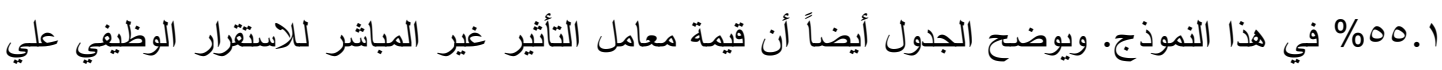

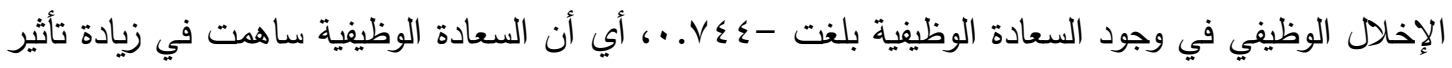

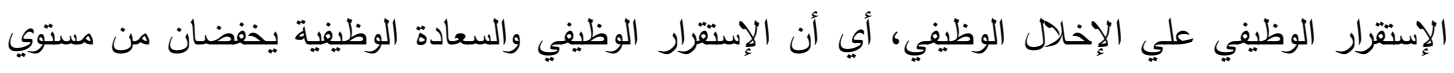

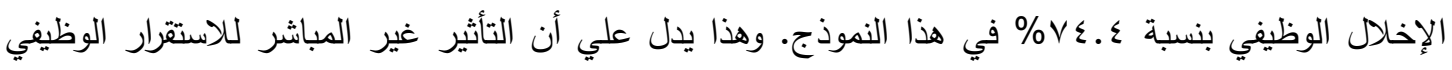

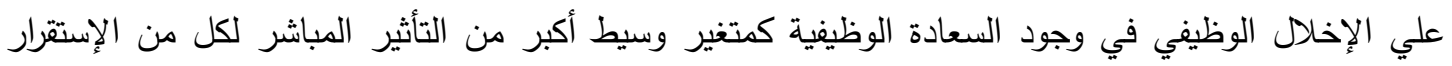

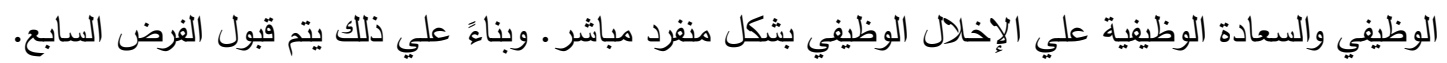

الجدول (IV) نتائج تحليل أثر الاستقرار الوظيفي علي الإخلال الوظيفي في وجود السعادة الوظيفية كمتغير وسيط

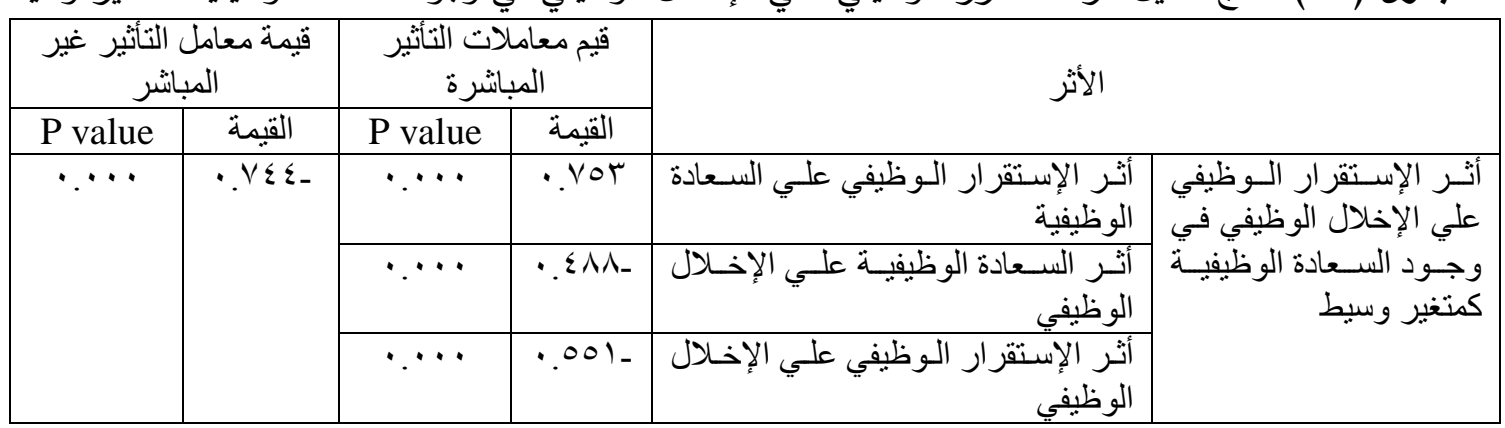


ويوضح شكل رقم (r) نتائج تحليل المسار لأثر الإستقرار الوظيفي علي الإخلال الوظيفي في وجود السعادة الوظيفية كمتغير وسيط.

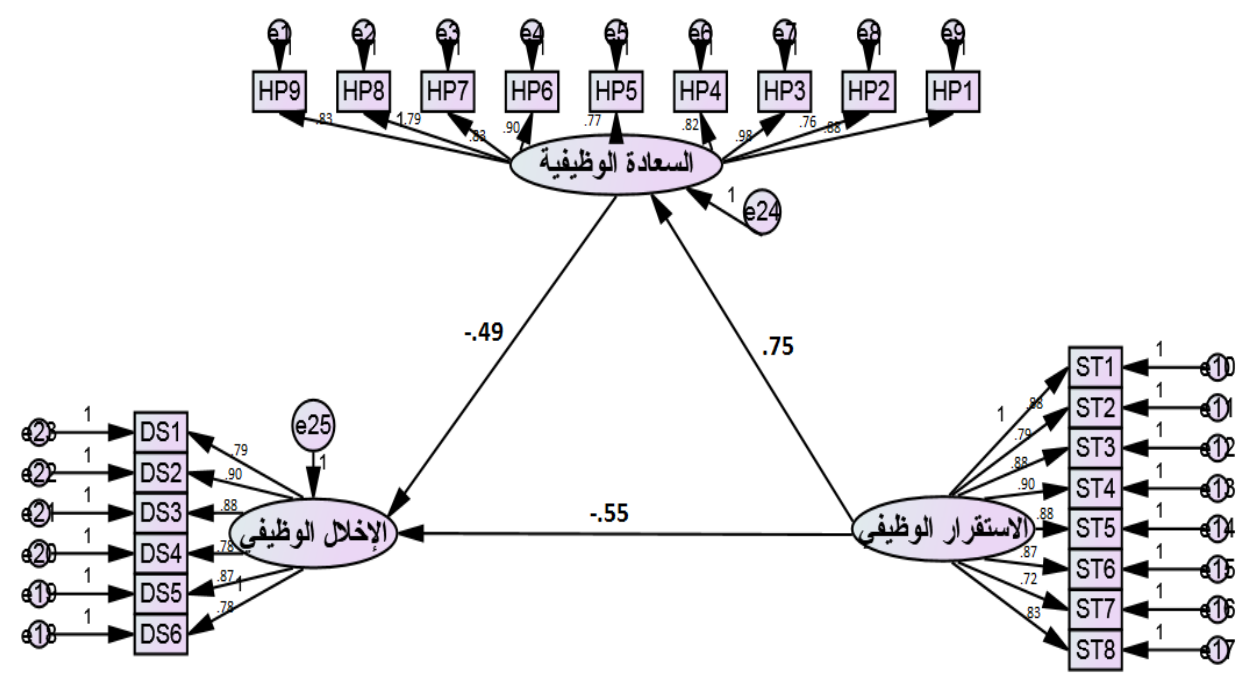

شكل (ץ) نتائج تحليل المسار لأثر الإستقرار الوظيفي علي الإخلال الوظيفي في وجود السعادة الوظيفية كمتغير وسيط

نتائج اختبار أثر الإستقرار الوظيفي علي كل من الإحباط الوظيفي، والسعادة التنظيمية والإخلال الوظيفي وفقاً للمتغيرات الايموغرافية أولاً: أثر الإستقرار الوظيفي علي الإحباط الوظيفي الجدول (11) أثر الإستقرار الوظيفي علي الإحباط الوظيفي وفقاً للمتغيرات الديموغرافية

\begin{tabular}{|c|c|c|c|}
\hline المعنوية & قيمة التأثثير & \multicolumn{2}{|l|}{ المتغير } \\
\hline$\because \cdots$ & $. .7 Y 1-$ & ذكر & النوع \\
\hline$\because \cdots$ & TYO_ & أنثي & \\
\hline$\because \cdots$ & $.0 .1-$ & أقل من • ب سنة & العمر \\
\hline$\because \cdots$ &.$r 0 q_{-}$ & 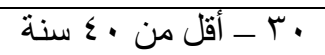 & \\
\hline$\because \cdots$ &.$\triangleq Y \Gamma_{-}$ & •. - أقل من • • سنة & \\
\hline$\because \cdots$ &.$r 99_{-}$ & •0 سنة فأكثر & \\
\hline$\because \cdots$ & $\cdot . \leqslant \leqslant Y_{-}$ & متوسط & المؤهل العلمي \\
\hline$\because \cdots$ & $\cdot .(9)-$ & بكالوريوس & \\
\hline$\because \cdots$ &.$\leqslant 00_{-}$ & در اسات عليا & \\
\hline$\because \cdots$ & $.1 \wedge \Lambda_{-}$ & مدير & الوظيفة \\
\hline$\because \cdots$ &.$r 0 q_{-}$ & رئيس قسم & \\
\hline$\because \cdots$ & $.0 .9-$ & موظف & \\
\hline$\because \cdots$ & $\cdot .71 \varepsilon_{-}$ & أقل من ه سنوات & سنو ات الخبرة \\
\hline$\because \cdots$ & $.0 . \Gamma_{-}$ & 0 - أقل من · ا سنوات & \\
\hline$\because \cdots$ & . ¿l1- & •1 - أقل من 10 سنة & \\
\hline$\because \cdots$ & $\cdot r \wedge q_{-}$ & 10 سنة فأكثر & \\
\hline
\end{tabular}


يبرز جدول رقم (1) النتائج التالية:

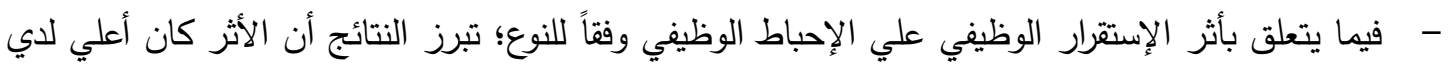

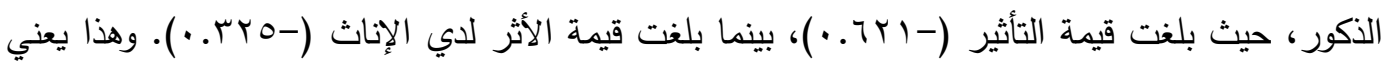

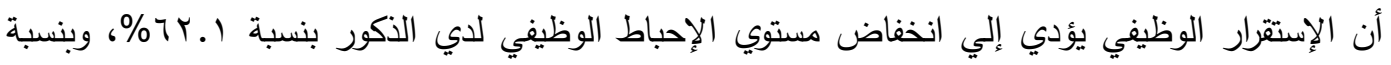

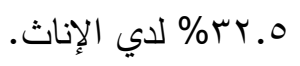
- - فيما يتعلق بأثر الإستقرار الوظيفي علي الإحباط الوظيفي وفقاً للعمر ؛ تبرز النتائج أن الأثر كان أعلي لاي

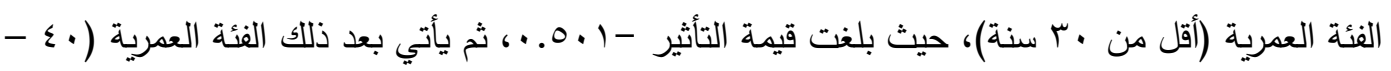

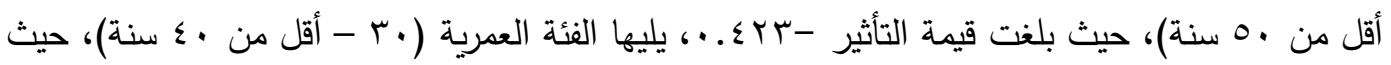

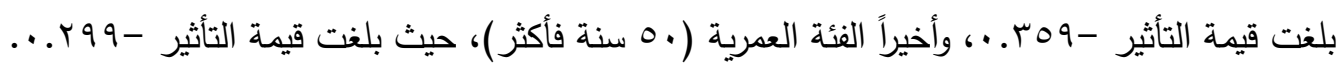
- - فيما يتعلق بأثر الإستقرار الوظيفي علي الإحباط الوظيفي وفقاً للمؤهل العلمي؛ تبرز النتائج أن الأثر كان

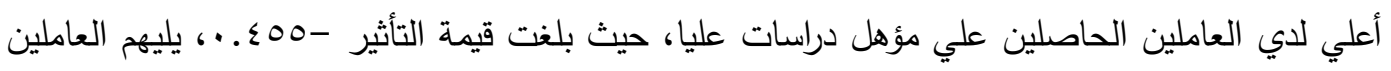

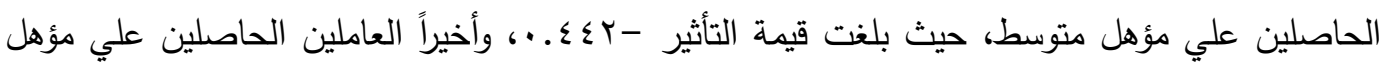

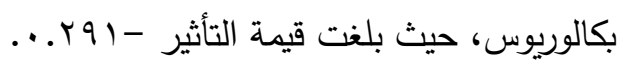
- - فيما يتعلق بأثر الإستقرار الوظيفي علي الإحباط الوظيفي وفقاً للوظيفة؛ تبرز النتائج أن الأثر كان أعلي

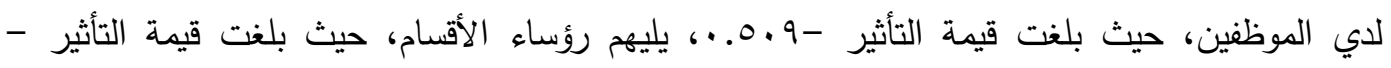

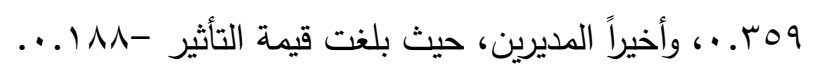
- - فيما يتعلق بأثر الإستقرار الوظيفي علي الإحباط الوظيفي وفقاً لسنوات الخبرة؛ تبرز النتائج أن الأثر كان

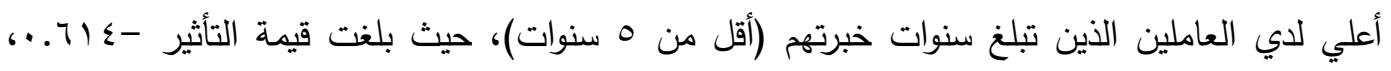

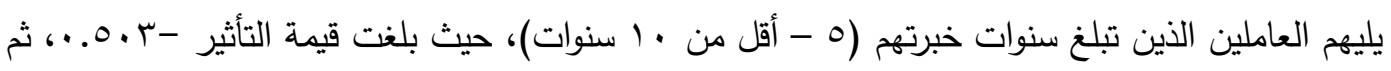

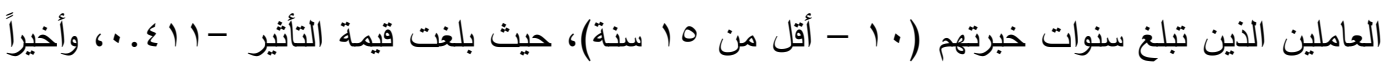

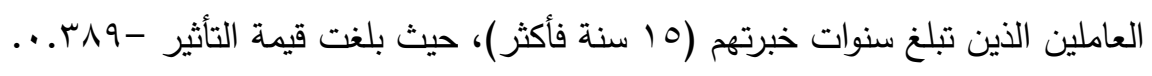

ثانياً: أثر الإستقرار الوظيفي علي السعادة الوظيفية الجدول (9 1) أثر الإستترار الوظيفي علي السعادة الوظيفية وفقاً للمتغيرات الديموغرافية

\begin{tabular}{|c|c|c|c|}
\hline المعنوية & قيمة التأثثر & \multicolumn{2}{|c|}{ المتغير } \\
\hline$\because \cdots$ & $\cdot . \leqslant \leqslant Y$ & ذكر & النوع \\
\hline$\because \cdots$ & .099 & أنثي & \\
\hline$\because \cdots$ &.$\leqslant 91$ & أقل من • ب سنة & العمر \\
\hline$\because \cdots$ &.$r 7 \varepsilon$ & •r - أقل من • ع سنة & \\
\hline$\because \cdots$ & 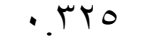 & • ـ - أقل من • • سنة & \\
\hline$\because \cdots$ &.$Y 11$ & •0 سنة فأكثر & \\
\hline$\because \cdots$ & .0 .1 & متوسط & المؤهل العلمي \\
\hline$\because \cdots$ & .71 & بكالوريوس & \\
\hline
\end{tabular}




\begin{tabular}{|c|c|c|c|}
\hline$\because \cdots$ & $\because$ rYA & در اسات عليا & \\
\hline$\because \cdots$ & $\because r \cdot r$ & مدير & \multirow[t]{3}{*}{ الوظيفة } \\
\hline$\because \cdots$ & $\because \leqslant 10$ & رئيس قسم & \\
\hline$\because \cdots$ & .071 & موظف & \\
\hline$\because \cdots$ &.$r 99$ & أقل من ه سنوات & \multirow[t]{4}{*}{ سنوات الخبرة } \\
\hline$\because \cdots$ & $\because \leqslant \wedge \mathrm{V}$ & 0 - أقل من • ا سنو ات & \\
\hline$\because \cdots$ & •r. & • 1 - أقل من 10 سنة & \\
\hline$\because \cdots$ &. .191 & 10 سنة فأكثر & \\
\hline
\end{tabular}

يبين جدول رقم (9 1 ) النتائج التالية: - فيما يتعلق بأثر الإستقرار الوظيفي علي السعادة الوظيفية وفقاً للنوع؛ تبرز النتائج أن الأثر كان أعلي لدي

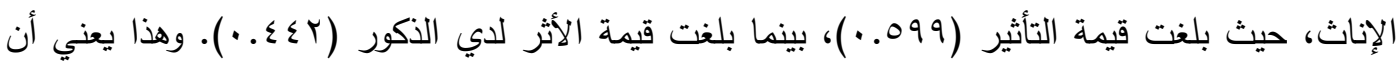

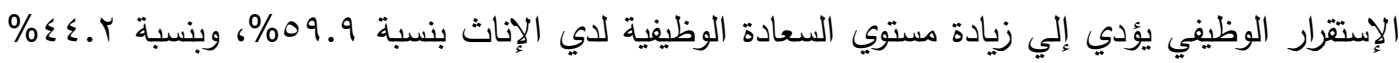
لدي الذكور • - فيما يتعلق بأثر الإستقرار الوظيفي علي السعادة الوظيفية وفقاً للعمر؛ تبرز النتائج أن الأثر كان أعلي لدي

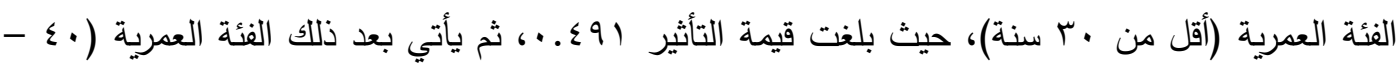

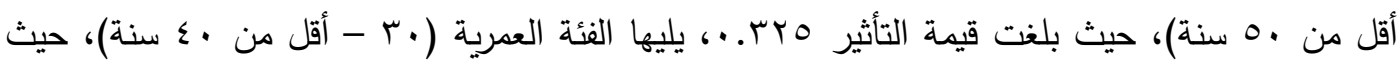

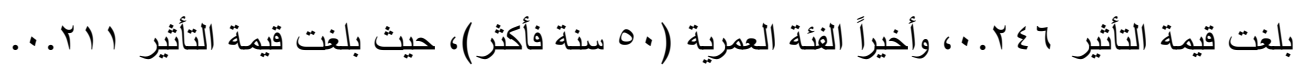
- فيما يتعلق بأثر الإستقرار الوظيفي علي السعادة الوظيفية وفقاً للمؤهل العلمي؛ تبرز النتائج أن الأثر كان

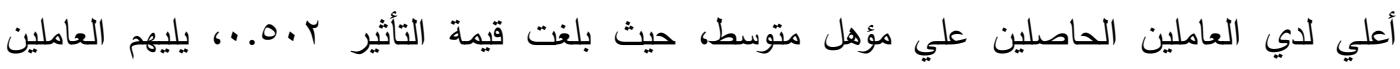
الحاصلين علي مؤهل بكالوريوس، حيث بلغت قيمة التأثير اباج ...، وأخيراً العاملين الحاصلين علي مؤهل

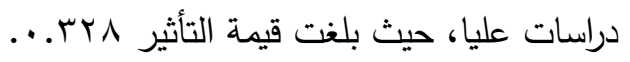
- فيما يتعلق بأثر الإستقرار الوظيفي علي السعادة الوظيفية وفقاً للوظيفة؛ تبرز النتائج أن الأثر كان أعلي لدي

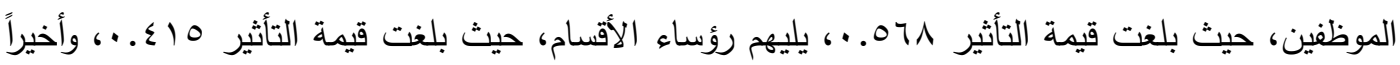

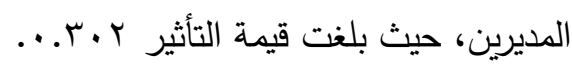

- فيما يتعلق بأثر الإستقرار الوظيفي علي السعادة الوظيفية وفقاً لسنوات الخبرة؛ تبرز النتائج أن الأثر كان

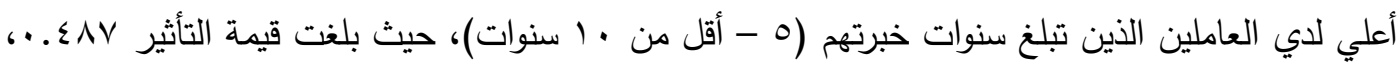

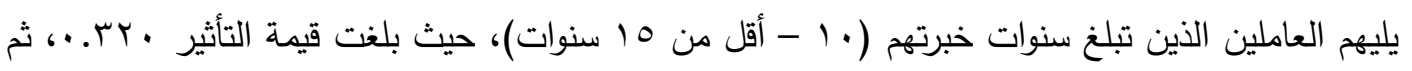

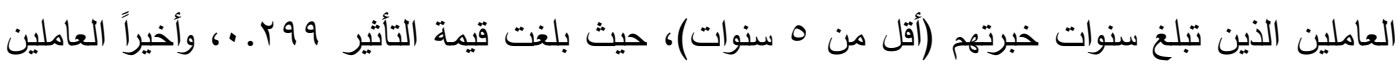
الذين تبلغ سنوات خبرتهم (10 سنة فأكثر)، حيث بلغت قيمة التأثير 91 ا ... 
ثالثاً: أثر الإستقرار الوظيفي علي الإخلال الوظيفي الجدول (·r) أثر الاستقرار الوظيفي علي الإخلال الوظيفي وفقاً للمتغيرات الديموغرافية

\begin{tabular}{|c|c|c|c|}
\hline المعنوية & قيمة التأثير & \multicolumn{2}{|l|}{ المتغير } \\
\hline$\ldots$ & $.00 \cdot-$ & ذكر & النو ع \\
\hline$\because \cdots$ & $\cdot r \leqslant 1-$ & أنثي & \\
\hline$\because \cdots$ & $\because Y \leq 1-$ & أقل من ، ب سنة & العمر \\
\hline$\because \cdots$ &.$\varepsilon r V_{-}$ & • r _ أقل من • ؛ سنة & \\
\hline$\because \cdots$ & $.00 T_{-}$ & • ـ - أقل من • 0 سنة & \\
\hline$\because \cdots$ & $.49 q_{-}$ & • م سنة فأكثر & \\
\hline$\because \cdots$ & . MYY & متوسط & المؤهل العلمي \\
\hline$\because \cdots$ & $\because \leqslant \wedge 1-$ & بكالوريوس & \\
\hline$\because \cdots$ & $. r \cdot 1-$ & در اسـات عليا & \\
\hline$\because \cdots$ & $. Y 11-$ & مدير & الوظيفة \\
\hline$\because \cdots$ & - & رئيس قسم & \\
\hline$\because \cdots$ & •. & موظف & \\
\hline$\because \cdots$ &.$\leqslant 1 \Lambda_{-}$ & أقل من ه سنوات & سنو ات الخبرة \\
\hline$\because \cdots$ &.$\leqslant 7 r_{-}$ & 0 - أقل من • ا سنو ات & \\
\hline$\because \cdots$ & $. M V I-$ & • 1 - أقل من 10 سنة & \\
\hline$\because \cdots$ & •r. & 10 سنة فأكثر & \\
\hline
\end{tabular}

يوضح جدول رقم (·r) النتائج التالية:

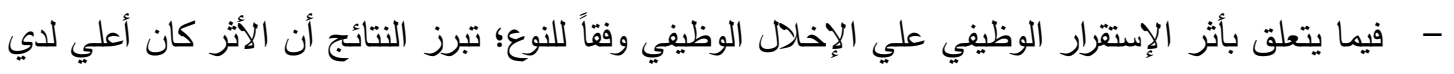

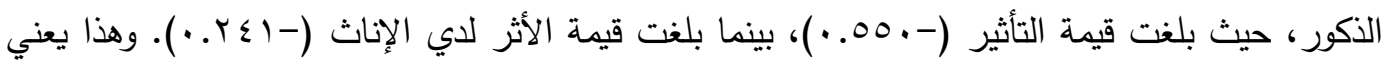

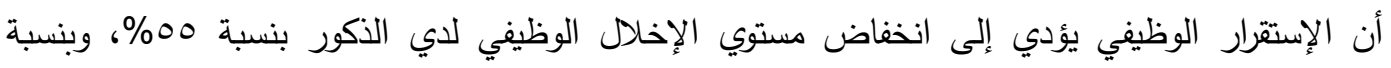

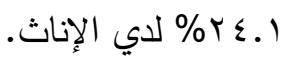

- - فيما يتعلق بأثر الإستقرار الوظيفي علي الإخلال الوظيفي وفقاً للعمر ؛ تبرز النتائج أن الأثر كان أعلي لاي

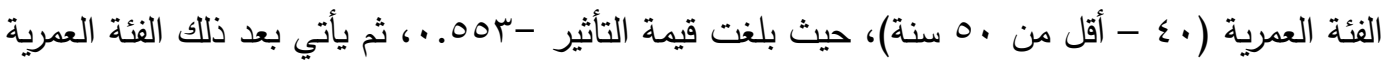

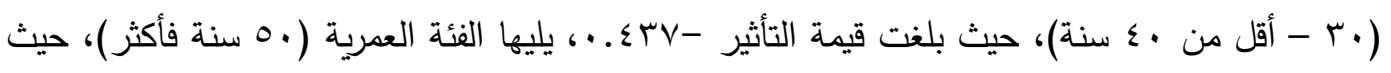

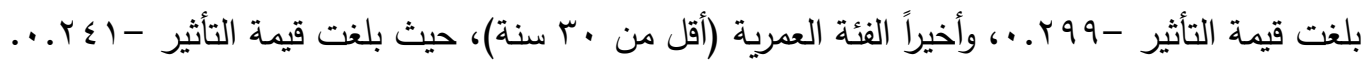
- - فيما يتعلق بأثر الإستقرار الوظيفي علي الإخلال الوظيفي وفقاً للمؤهل العلمي؛ تبرز النتائج أن الأثر كان

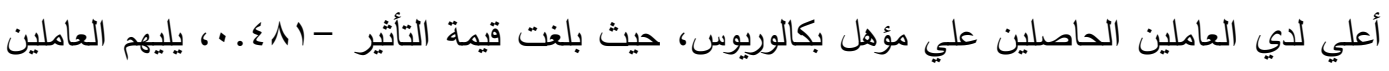

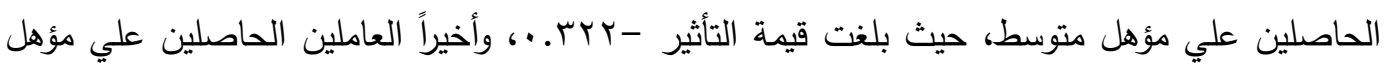

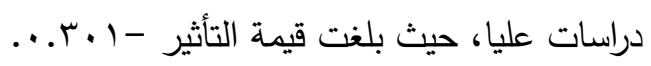


- - فيما يتعلق بأثر الاستقرار الوظيفي على الإخلال الوظيفي وفقاً للوظيفة؛ تبرز النتائج أن الأثر كان أعلي

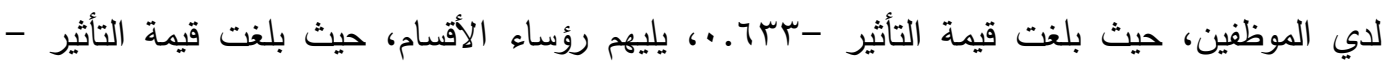

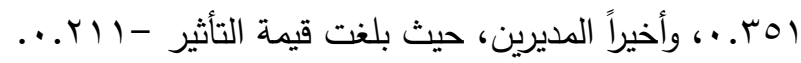

- - فيما يتعلق بأثر الاستقرار الوظيفي على الإخلال الوظيفي وفقاً لسنوات الخبرة؛ تبرز النتائج أن الأثر كان

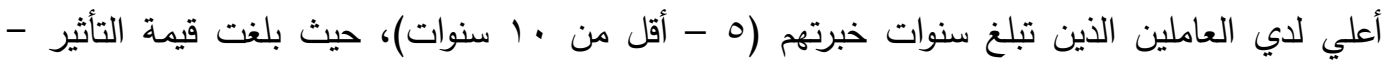

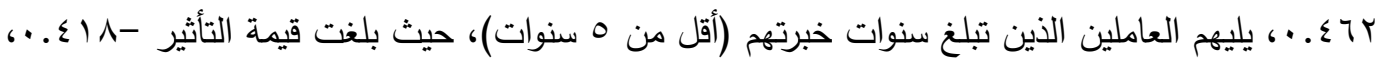

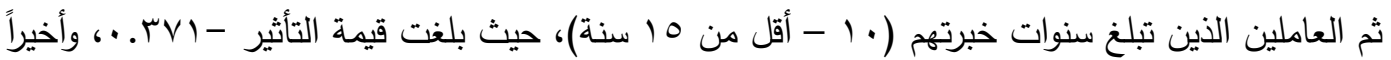

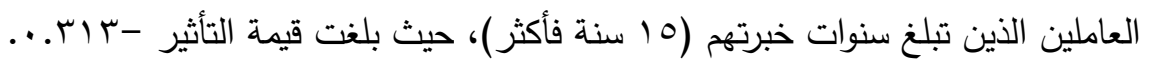
وبناءً على النتائج السابقة بجدول رقم 1 1 و 19 و ـ r يتم قبول الفرض الثامن. نتائج اختبار أثر الإحباط الوظيفي على السعادة الوظيفية والإخلال الوظيفي وفقاً للمتغيرات الديموغرافية أولاً: أثر الإحباط الوظيفي على السعادة الوظيفية الجدول (YT) أثر الإحباط الوظيفي على السعادة الوظيفية وفقاً للمتغيرات الديموغرافية

\begin{tabular}{|c|c|c|c|}
\hline المعنوية & قيمة التأثير & \multicolumn{2}{|l|}{ المتغير } \\
\hline$\because \cdots$ &.$r 09$ & ذكر & \multirow{2}{*}{ النوع } \\
\hline$\because \cdots$ & $.0 Y 1-$ & أنتي & \\
\hline$\because \cdots$ &.$\leqslant 91-$ & أقل من • r سنة & \multirow[t]{4}{*}{ العمر } \\
\hline$\because \cdots$ & $\cdot \varepsilon \cdot Y_{-}$ & •r - أقل من • ع سنة & \\
\hline$\because \cdots$ & $. r \leq \varepsilon-$ & • ؛ - أقل من •0 سنة & \\
\hline$\because \cdots$ &. $.19 \Lambda_{-}$ & •0 سنة فأكثر & \\
\hline$\because \cdots$ & $\cdot r \cdot \Lambda_{-}$ & متوسط & \multirow{3}{*}{ المؤهل العلمي } \\
\hline$\because \cdots$ & $\cdot . \varepsilon \leqslant \mu-$ & بكالوريوس & \\
\hline$\because \cdots$ &..$M T Y_{-}$ & در اسات عليا & \\
\hline$\because \cdots$ & $\cdot r \cdot q_{-}$ & مدير & \multirow[t]{3}{*}{ الوظيفة } \\
\hline$\because \cdots$ & $\cdot . \leqslant \leqslant V_{-}$ & رئيس قسم & \\
\hline$\because \cdots$ & $\cdot . T \cdot Y_{-}$ & موظف & \\
\hline$\because \cdots$ &.$\leqslant V \varepsilon_{-}$ & أقل من 0 سنوات & \multirow[t]{4}{*}{ سنوات الخبرة } \\
\hline$\because \cdots$ &.$\leqslant 10_{-}$ & ○ـ أقل من · ( سنو ات & \\
\hline$\because \cdots$ & . rrq_ & • 1 - أقل من 10 سنة & \\
\hline$\because \cdots$ & $\cdot Y V T_{-}$ & 10 سنة فأكثر & \\
\hline
\end{tabular}

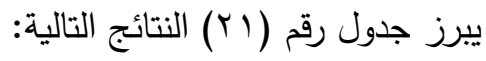
- فيما يتعلق بأثر الإحباط الوظيفي على السعادة الوظيفية وفقاً للنوع؛ تبرز النتائج أن الأثر كان أعلي لاي

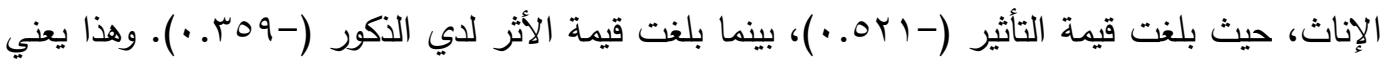

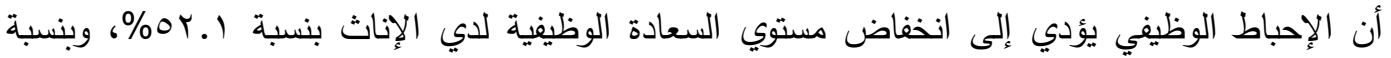

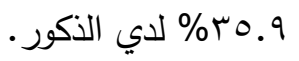


- - فيما يتعلق بأثر الإحباط الوظيفي على السعادة الوظيفية وفقاً للعمر ؛ تبرز النتائج أن الأثر كان أعلي لدي

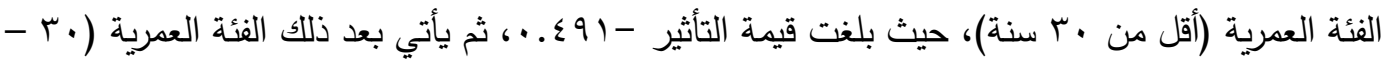

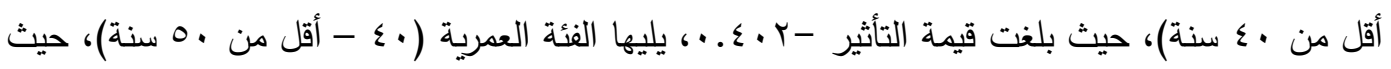

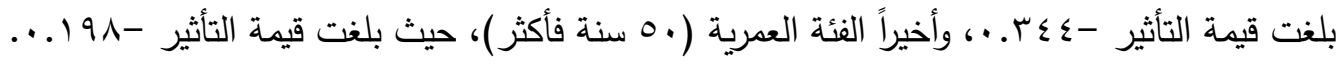
- - فيما يتعلق بأثر الإحباط الوظيفي علي السعادة الوظيفية وفقاً للمؤهل العلمي؛ تبرز النتائج أن الأثر كان

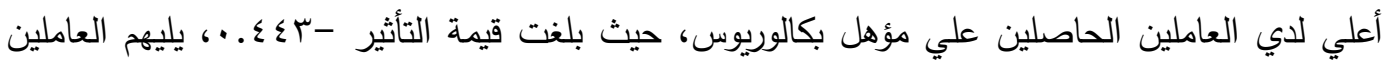

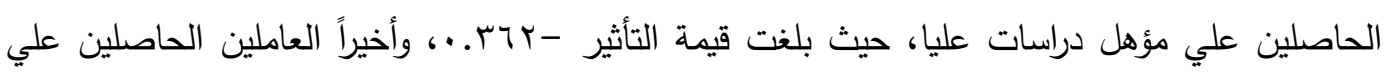
مؤهل متوسط، حيث بلغت قيمة التأثير -1 . م. ... - - فيما يتعلق بأثز الإحباط الوظيفي علي السعادة الوظيفية وفقاً للوظيفة؛ تبرز النتائج أن الأثر كان أعلي لدي

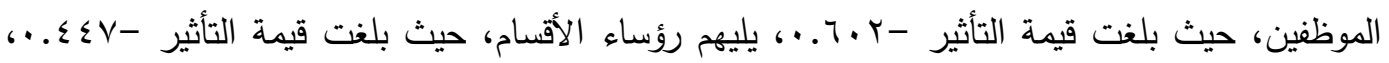

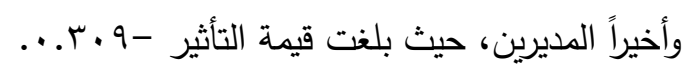
- - فيما يتعلق بأثر الإحباط الوظيفي علي السعادة الوظيفية وفقاً لسنوات الخبرة؛ تبرز النتائج أن الأثر كان

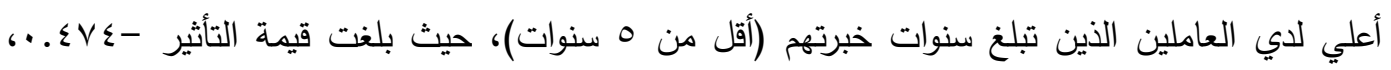

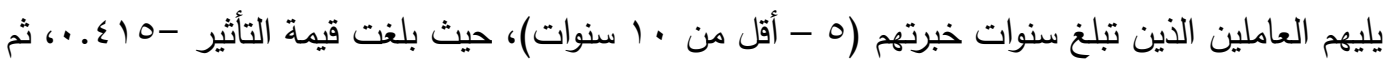

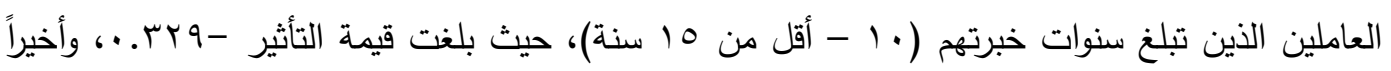

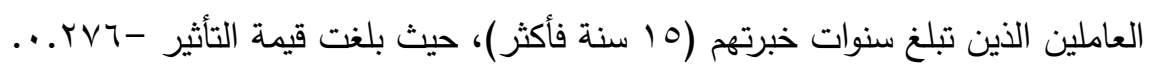

ثانياً: أثر الإحباط الوظيفي على الإخلال الوظيفي الجدول (Yr) أثر الإحباط الوظيفي علي الإخلال الوظيفي وفقاً للمتغيرات الديموغرافية

\begin{tabular}{|c|c|c|c|}
\hline المعنوية & قيمة التأثنير & \multicolumn{2}{|l|}{ المتغير } \\
\hline$\because \cdots$ & $.0 \wedge r$ & ذكر & \multirow[t]{2}{*}{ النوع } \\
\hline$\because \cdots$ &.$\leqslant Y$. & أنتي & \\
\hline$\because \cdots$ & $.07 \pi$ & أقل من • س سنة & \multirow{4}{*}{ العمر } \\
\hline$\because \cdots$ &.$\varepsilon \cdot 1$ & • ب - أقل من • ع سنة & \\
\hline$\because \cdots$ &.$\varepsilon Y V$ & • ـ - أقل من • 0 سنة & \\
\hline$\because \cdots$ & . & • 0 سنة فأكثر & \\
\hline$\because \cdots$ & . TON & متوسط & \multirow{3}{*}{ المؤ هل العلمي } \\
\hline$\because \cdots$ & rוT & بكالوريوس & \\
\hline$\because \cdots$ & .014 & در اسـات عليا & \\
\hline$\because \cdots$ & $. r \leqslant 0$ & مدير & \multirow[t]{3}{*}{ الوظيفة } \\
\hline$\because \cdots$ & . M人I & رئيس قسم & \\
\hline$\because \cdots$ & $\because \varepsilon \vee 7$ & موظف & \\
\hline$\because \cdots$ &.$O Y \Lambda$ & أقل من 0 سنوات & \multirow[t]{4}{*}{ سنو ات الخبرة } \\
\hline$\because \cdots$ &..$\leqslant \varepsilon r$ & o - أقل من • ا سنو ات & \\
\hline$\because \cdots$ & . rVA & • 1 - أقل من 10 سنة & \\
\hline$\because \cdots$ & •II & 1 سنة فأكثر & \\
\hline
\end{tabular}


يبين جدول رقم (rr) النتائج التالية:

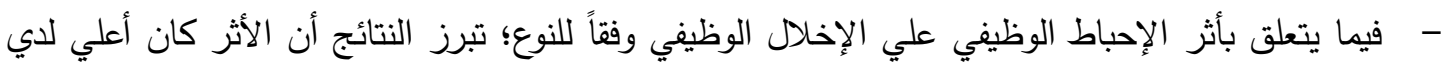

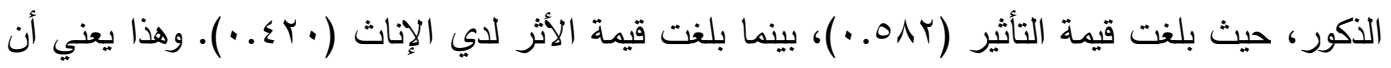

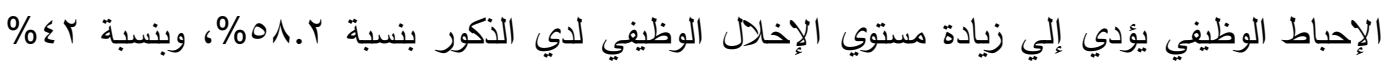
لإي الإناث. - - فيما يتعلق بأثر الإحباط الوظيفي علي الإخلال الوظيفي وفقاً للعمر ؛تبرز النتائج أن الأثر كان أعلي لاي

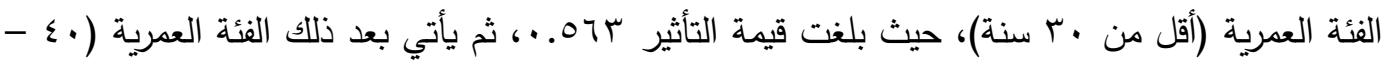

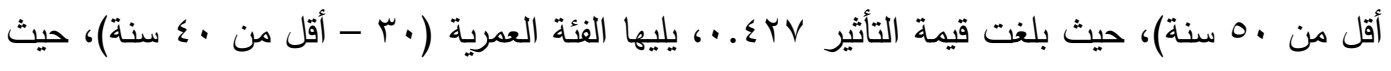

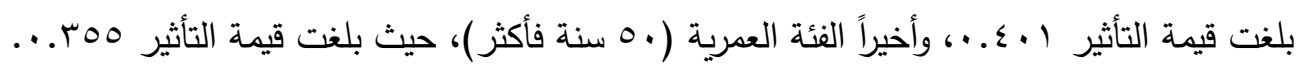
- - فيما يتعلق بأثر الإحباط الوظيفي علي الإخلال الوظيفي وفقاً للمؤهل العلمي؛ تبرز النتائج أن الأثر كان

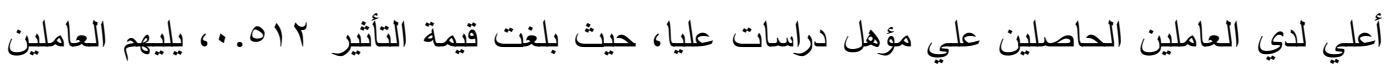

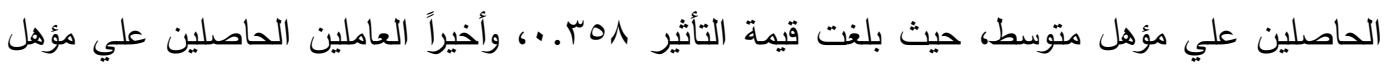

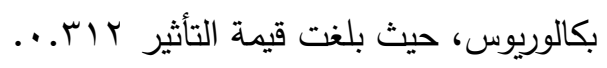

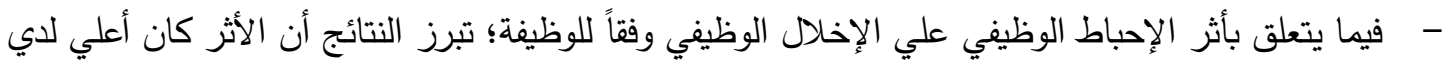

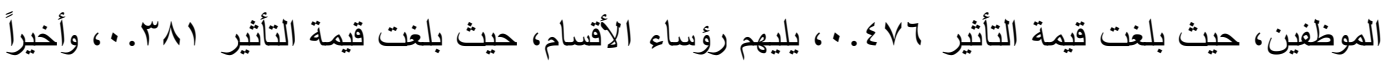

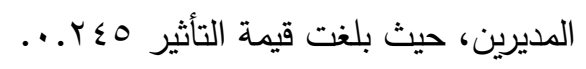
- - فيما يتعلق بأثر الإحباط الوظيفي علي الإخلال الوظيفي وفقاً لسنوات الخبرة؛ تبرز النتائج أن الأثر كان

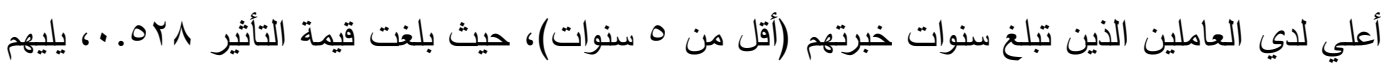

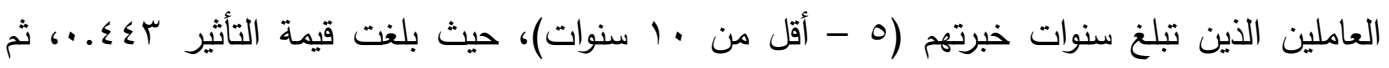

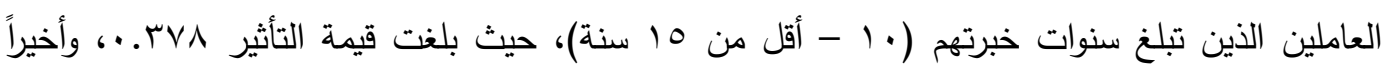

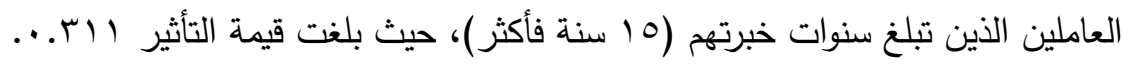
وبناءً علي النتائج السابقة بجدول رقم 1 و و r r يتم قبول الفرض التاسع. نتائج اختبار أثر السعادة الوظيفية علي الإخلال الوظيفي وفقاً للمتغيرات الايموغرافية الجدول (r ا r) أثر السعادة الوظيفية علي الإخلال الوظيفي وفقاً للمتغيرات الديموغرافية

\begin{tabular}{|c|c|c|c|}
\hline المعنوية & قايمة التأثيّر & لمتغير & \\
\hline$\because \cdots$ & $\cdot r \wedge q_{-}$ & ذكر & \multirow[t]{2}{*}{ النوع } \\
\hline$\because \cdots$ & $\cdot \varepsilon r)$ & أنثي & \\
\hline$\because \cdots$ & $\cdot r \xi 1-$ & أقل من •"r سنة & \multirow[t]{4}{*}{ العمر } \\
\hline$\because \cdots$ & .479 & •r - أقل من •؛ سنة & \\
\hline$\because \cdots$ & $\cdot r \Lambda \Lambda_{-}$ & •ـ - أقل من •0 سنة & \\
\hline$\because \cdots$ & . MI & •0 سنة فأكثر & \\
\hline
\end{tabular}




\begin{tabular}{|c|c|c|c|}
\hline$\because \cdots$ & $\cdot r \wedge V_{-}$ & متوسط & \multirow{3}{*}{ المؤهل العلمي } \\
\hline$\because \cdots$ & $.0 .1-$ & بكالوريوس & \\
\hline$\because \cdots$ & . rY & در اسات عليا & \\
\hline$\because \cdots$ & - & مدير & \multirow[t]{3}{*}{ الوظيفة } \\
\hline$\because \cdots$ & $\cdot \varepsilon \varepsilon \cdot-$ & رئيس قسم & \\
\hline$\because \cdots$ &.$\leqslant 9 Y_{-}$ & موظف & \\
\hline$\because \cdots$ & . rYq_ & أقل من ه سنوات & \multirow[t]{4}{*}{ سنو ات الخبرة } \\
\hline$\because \cdots$ &.$\Sigma r_{-}$ & ○ - أقل من · ا سنو ات & \\
\hline$\because \cdots$ &.$Y 10_{-}$ & • 1 - أقل من 0 سنة & \\
\hline$\because \cdots$ & $\cdot r \cdot V_{-}$ & 10 سنة فأكثر & \\
\hline
\end{tabular}

يوضح جدول رقم (rr) النتائج التالية:

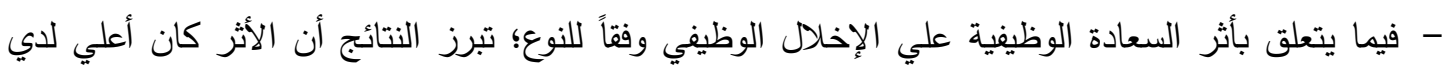

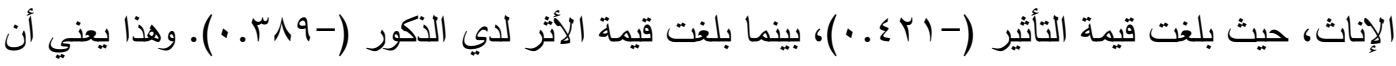

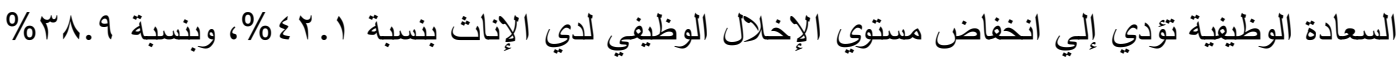

$$
\text { لاي الذكور · مان. }
$$

- فيما يتعلق بأثر السعادة الوظيفية علي الإخلال الوظيفي وفقاً للعمر ؛ تبرز النتائج أن الأثر كان أعلي لدي

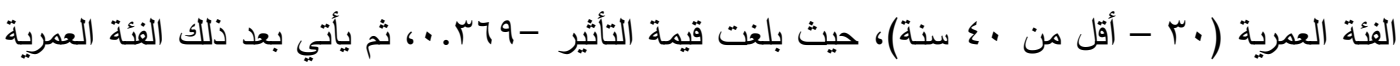

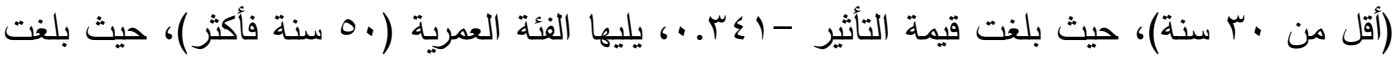

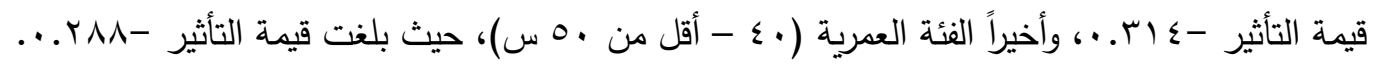

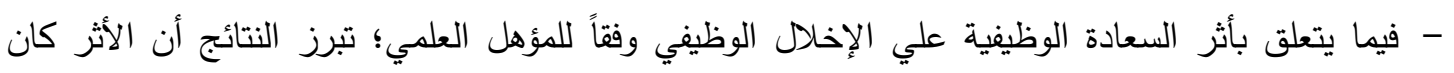

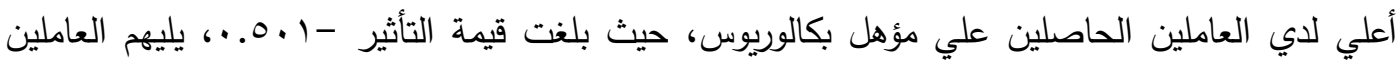

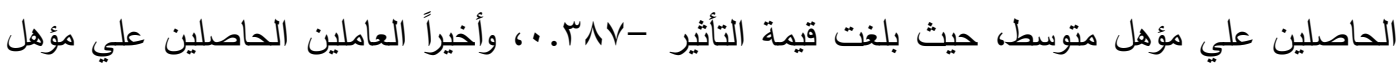

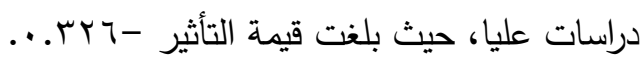

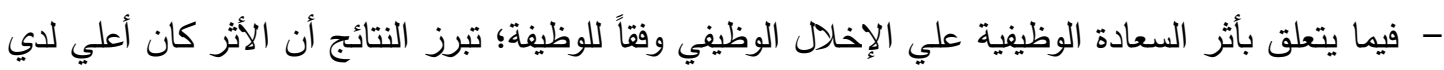

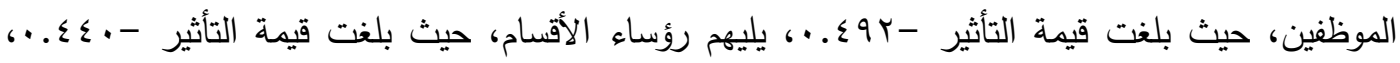

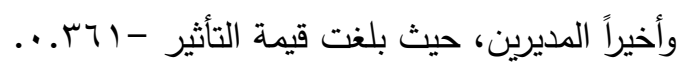

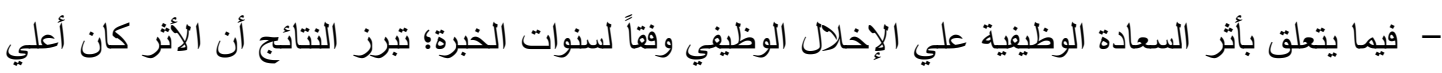

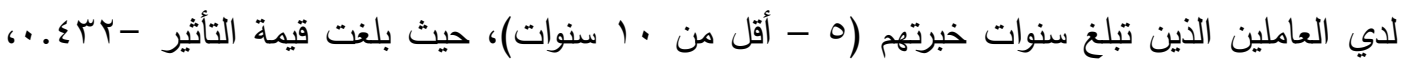

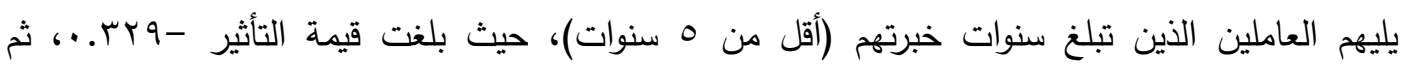

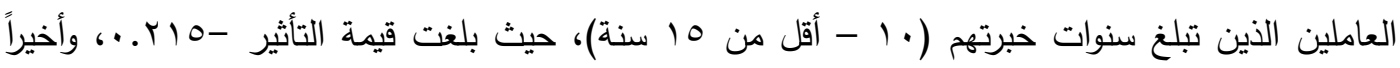

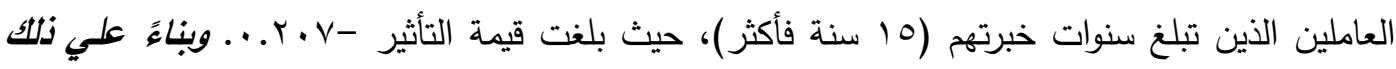
يتم قبول الفرض العاشر. 
نتائج اختبار الفروق الإحصائية في استجابات أفراد العينة لمتغيرات الدراسة وفقاً للمتغيرات الديموغرافية

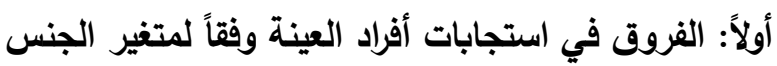
تم إجراء اختبار "ت" للتعرف علي الفروق والاختلافات الإحصائية في السعادة الوظيفية، والإستقرار الوظيفي،

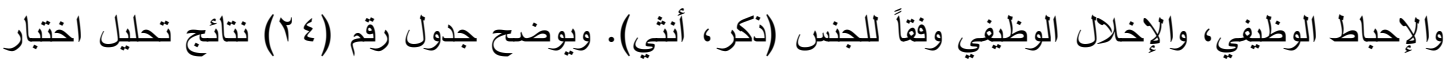

الجدول (؟ ب) نتائج تحليل اختبار "ت"

\begin{tabular}{|c|c|c|c|c|}
\hline \multirow{2}{*}{$\begin{array}{c}\text { الاحتمال } \\
\text { Sig. (p value) }\end{array}$} & \multicolumn{2}{|c|}{ متوسط العينة } & \multirow{2}{*}{ قالمحسوبة "تا } & \multirow[t]{2}{*}{ المتغير ات } \\
\hline & أنثي & ذكر & & \\
\hline . & $\varepsilon .10$ & $\Gamma . \wedge \wedge$ & $r .09 \varepsilon$ & السعادة الوظيفية \\
\hline .1 .9 & $r . V I$ & $r .91$ & E.OYT & الإستقر ار الوظيفي \\
\hline .0 .9 & 1.00 & $r .+1$ & $r .991$ & الإحباط الوظيفي \\
\hline $.0 \leq 1$ & 1.71 & $1 . \wedge$. & $r . Y \leq 1$ & الإخلال الوظيفي \\
\hline
\end{tabular}

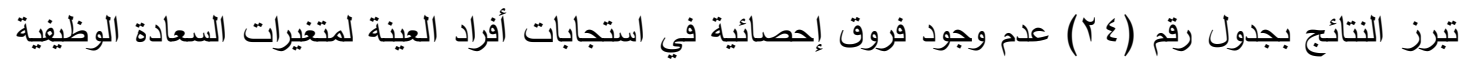

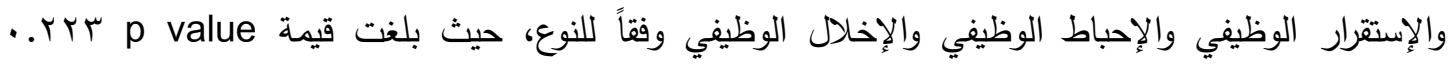

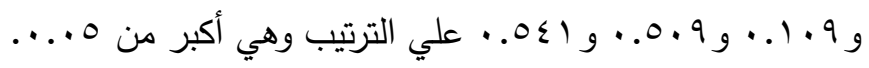

ثانياً: الفروق في استجابات أفراد العينة وفقاً لمتغير العمر تم إجراء اختبار "ONE WAY ANOVA" للتعرف علي الفروق والاختلافات الإحصائية في السعادة الوظيفية،

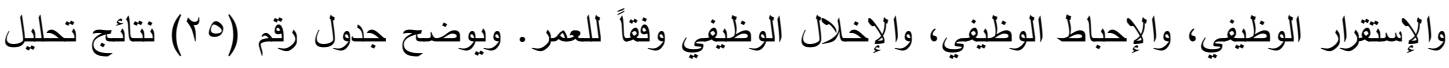

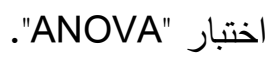

الجدول (ro) نتائج اختبار ANOVA وفقاً للعمر

\begin{tabular}{|c|c|c|c|c|c|}
\hline Sig. & قالمحسة (ف) & المربعات & المربعات & مصدر التباين & المتغير ات \\
\hline . YYI & r.qTr & 5.111 & ITMT & بين المجمو عات & \multirow[t]{3}{*}{ السعادة الوظيفية } \\
\hline & & $.1 \leqslant \varepsilon$ & 77.119 & داخل المجمو عات & \\
\hline & & & V^.โ7I & الإجمالي & \\
\hline $.1 \cdot 1$ & T.TOE & $r . I V V$ & 9.041 & بين المجمو عات & \multirow[t]{3}{*}{ الإستقرار الوظيفي } \\
\hline & & $.11 \varepsilon$ & $7 \cdot . V \cdot r$ & داخل المجمو عات & \\
\hline & & & $V \cdot . T M E$ & الإجمالي & \\
\hline . rqs & $\varepsilon . r+1$ & $r . V \leq r$ & II.YT. & بين المجمو عات & \multirow[t]{3}{*}{ الإحباط الوظيفي } \\
\hline & & $\because 7 \varepsilon$ & rq.ITr & داخل المجمو عات & \\
\hline & & & $\varepsilon \cdot . r T$ & الإجمالي & \\
\hline .1 .0 & r.YTE & Y. $\leqslant 1$. & V.YMI & بين المجموعات & \multirow[t]{3}{*}{ الإخلال الوظيفي } \\
\hline & & $\because 71$ & MIYYI & داخل المجمو عات & \\
\hline & & & rA.sor & الإجمالي & \\
\hline
\end{tabular}


يبين جدول رقم (Y0) عدم وجود فروق إحصائية في استجابات أفراد العينة لجميع متغيرات الدراسة السعادة

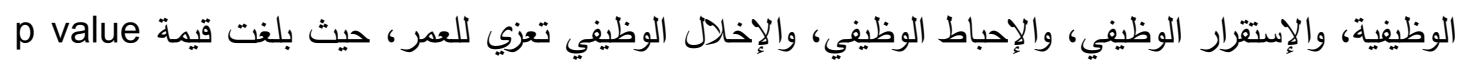

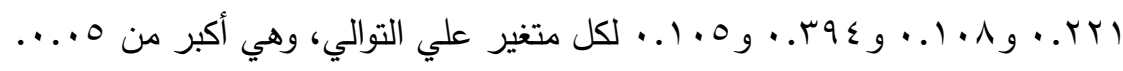

ثُالثاً: الفروق في استجابات أفراد العينة وفقاً لمتغير للمؤهل العلمي تم إجراء اختبار "ONE WAY ANOVA" للتعرف علي الفروق والاختلافات الإحصائية في السعادة الوظيفية، الإنيات

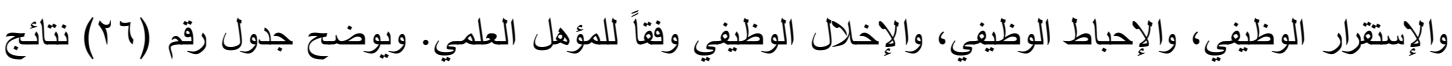

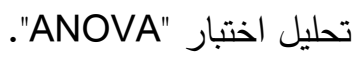

\begin{tabular}{|c|c|c|c|c|c|}
\hline Sig. & قايمة (ف) & المربعات & المربعات & مصدر التباين & المتغير ات \\
\hline .041 & ह.Yा। & r.741 & V.rut & بين المجمو عات & \multirow[t]{3}{*}{ السعادة الوظيفية } \\
\hline & &. .100 & VI.ITO & داخل المجمو عات & \\
\hline & & & $V \wedge . \leqslant 71$ & الإجمالي & \\
\hline \multirow[t]{3}{*}{$\cdot . V \leqslant r$} & $r .0 .1$ & $r .11 r$ & T.KYT & بين المجمو عات & \multirow[t]{3}{*}{ الإستقرار الوظيفي } \\
\hline & &. $.1 \Gamma 9$ & $7 \varepsilon . .11$ & داخل المجمو عات & \\
\hline & & & $V \cdot Y T \varepsilon$ & الإجمالي & \\
\hline \multirow[t]{3}{*}{$\cdot . r \cdot \mu$} & $r .9 \leq 1$ & $T .0 \leq 7$ & 0.91 & بين المجمو عات & \multirow[t]{3}{*}{ الإحباط الوظيفي } \\
\hline & & $\because V \mathrm{~V}$ & ro.rVI & داخل المجمو عات & \\
\hline & & & E. זัY & الإجمالي & \\
\hline \multirow[t]{3}{*}{. .194} & $0 . \cdots 1$ & $r .171$ & 7. TाO & بين المجمو عات & \multirow[t]{3}{*}{ الإخلال الوظيفي } \\
\hline & & $\because v$. & r. IIV & داخل المجمو عات & \\
\hline & & & $r \Lambda . \leqslant O r$ & الإجمالى & \\
\hline
\end{tabular}

يوضح جدول رقم (T) عدم وجود فروق إحصائية في استجابات أفراد العينة لجميع متغيرات الدراسة السعادة

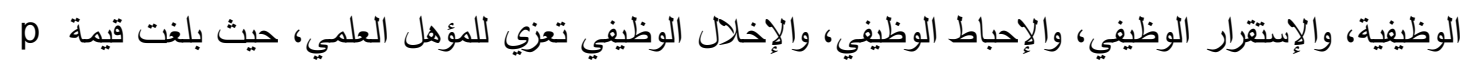
ا ا Value

رابعاً: الفروق في استجابات أفراد العينة وفقاً لمتفير الوظيفة

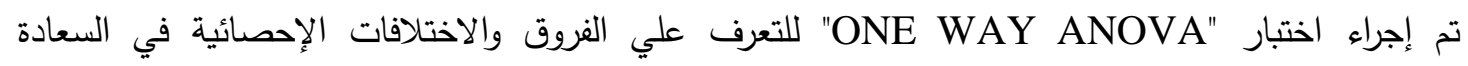

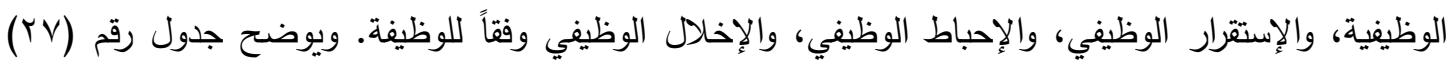
نتائج تحليل اختبار "ANOVA"

الجدول (rV) نتائج اختبار ANOVA وفقاً لللوظيفة

\begin{tabular}{|c|c|c|c|c|c|}
\hline Sig. & قالمحسة (ف) & المربعات & المربعوت & مصدر التباين & المتغير ات \\
\hline. $.11 Y$ & T...9 & $r .717$ & V.YMI & بين المجمو عات & \multirow{3}{*}{ السعادة الوظيفية } \\
\hline & & .100 & VI.YT. & داخل المجمو عات & \\
\hline & & & $V \wedge . \leqslant T)$ & الاحمال & \\
\hline
\end{tabular}




\begin{tabular}{|c|c|c|c|c|c|}
\hline.$r 94$ & T.1AV & T.977 & $0.9 \mu r$ & بين المجمو عات & \multirow[t]{3}{*}{ الإستقرار الوظيفي } \\
\hline & & $.1 \leq$ & $T E . T \cdot Y$ & داخل المجمو عات & \\
\hline & & & $V \cdot Y T S$ & الإجمالي & \\
\hline \multirow[t]{3}{*}{$\cdot .1 \cdot r$} & $r .7 \leq r$ & TIMT & $7.77 \%$ & بين المجمو عات & \multirow[t]{3}{*}{ الإحباط الوظيفي } \\
\hline & & $\because \cdot V r$ & r.V... & داخل المجمو عات & \\
\hline & & & $\varepsilon \cdot r q r$ & الإجمالي & \\
\hline \multirow[t]{3}{*}{$\because .91$} & r.9VI & 7.09. & V.1^. & بين المجموعات & \multirow[t]{3}{*}{ الإخلال الوظيفي } \\
\hline & & $\because \cdot 7 \wedge$ & TI.YVY & داخل المجمو عات & \\
\hline & & & rA.£Or & الإجمالي & \\
\hline
\end{tabular}

يبرز جدول رقم (YV) عدم وجود فروق إحصائية في استجابات أفراد العينة لجميع متغيرات الدراسة السعادة

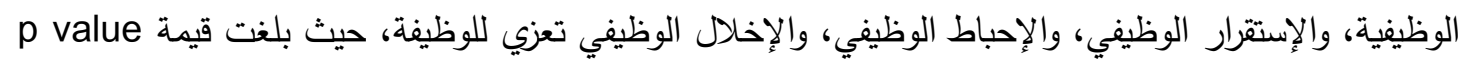

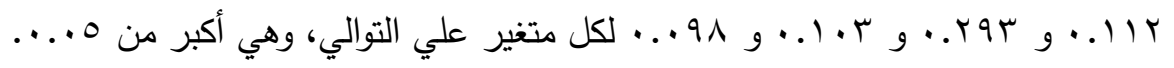

خامساً: الفروق في استجابات أفراد العينة وفقاً لمتغير لسنوات الخبرة تم إجراء اختبار "ONE WAY ANOVA" للتعرف علي الفروق والاختلافات الإحصائية في السعادة الوظيفية، والإستقرار الوظيفي، والإحباط الوظيفي، والإخلال الوظيفي وفقاً لسنوات الخبرة. ويوضح جدول رقم (^^) نتائج تحليل اختبار "ANOVA".

الجدول (YN) نتائج اختبار ANOVA وفقاً لسنوات الخبرة

\begin{tabular}{|c|c|c|c|c|c|}
\hline Sig. & قالمسمة (ف) & المربعات & المربعات & مصدر التباين & المتغير ات \\
\hline \multirow[t]{3}{*}{.$\wedge r M$} & T. $\leqslant 10$ & $r .11 V$ & $9 . r 0 \%$ & بين المجمو عات & \multirow[t]{3}{*}{ لسعادة الوظيفية } \\
\hline & & .101 & 79.1 .9 & داخل المجمو عات & \\
\hline & & & $\vee \wedge . \leq 71$ & الإجمالي & \\
\hline \multirow[t]{3}{*}{. TrY } & Y. $\leqslant 01$ & r.ङ11 & $1 \cdot Y T \leq$ & بين المجمو عات & \multirow[t]{3}{*}{ الإستقرار الوظيفي } \\
\hline & & $.1 M 1$ & $7 . \ldots$ & داخل المجمو عات & \\
\hline & & & $V \cdot Y T \varepsilon$ & الإجمالي & \\
\hline \multirow[t]{3}{*}{$.10 Y$} & r.941 & $r . \varepsilon \wedge \varepsilon$ & $1 \cdot . \leqslant 0 Y$ & بين المجمو عات & \multirow[t]{3}{*}{ الإحباط الوظيفي } \\
\hline & & $\because 70$ & 49.91 . & داخل المجمو عات & \\
\hline & & & $\varepsilon \cdot r$ r. & الإجمالي & \\
\hline \multirow[t]{3}{*}{$\because \cdot V V$} & T.YYT & Y.VAO & A. ros & بين المجمو عات & \multirow[t]{3}{*}{ لإخلال الوظيفي } \\
\hline & & $\because 77$ & $r \cdot .91$ & داخل المجمو عات & \\
\hline & & & rA.乏OT & الإجمالي & \\
\hline
\end{tabular}

يوضح جدول رقم (Y^) عدم وجود فروق إحصائية في استجابات أفراد العينة لجميع متغيرات الدراسة السعادة

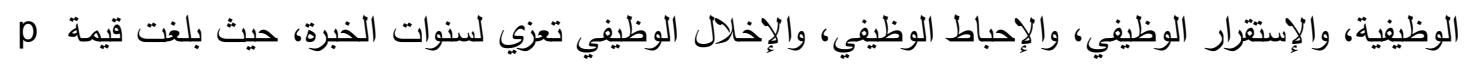
نقآح value

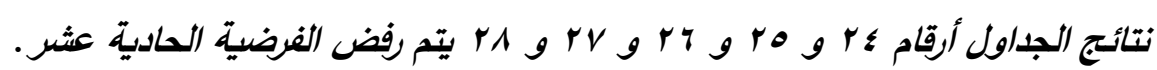


النتائج والتوصيات

توصلت الدراسة إلي وجود مستوي مرتفع من الإستقرار الوظيفي والسعادة الوظيفي لدي العاملين في شركات السياحة، بينما كان هناك مستوي منخفض من الإحباط الوظيفي والإخلال الوظيفي لدي هؤلاء العاملين. كما أبرزت نتائج الدراسة وجود علاقة وتأثير معنوي وعكسي للإستقرار الوظيفي علي كل من الإحباط الوظيفي

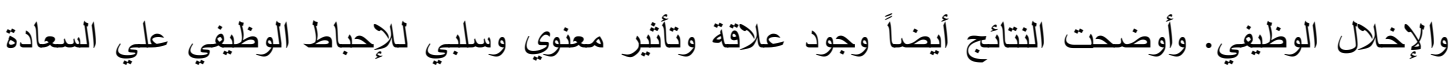
الوظيفية، في حين كان هناك تأثير معنوي وإيجابي للإحباط الوظيفي علي الإخلال الوظيفي. كذلك بينت النتائج وجود علاقة وتأثير معنوي وعكسي للسعادة الوظيفية علي الإخلال الوظيفي. علاوة علي ذلك؛ أكدت نتائج الدراسة علي أن السعادة الوظيفية تلعب دوراً وسيطاً جزئياً في العلاقة بين الإستقرار الوظيفي والإخلال الوظيفي في شركات السياحة المصرية. كما أظهرت نتائج الدراسة اختلاف تأثير

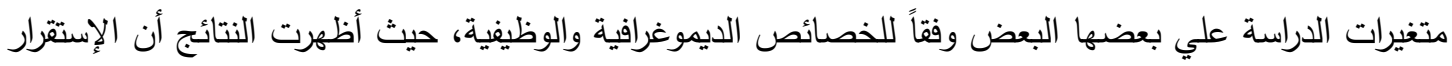
الوظيفي يؤثر علي الإحباط الوظيفي لاي الذكور بشكل أكبر من الإناث. كما كان تأثير الإستقرار الوظيفي علي

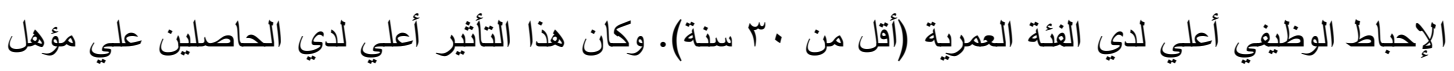

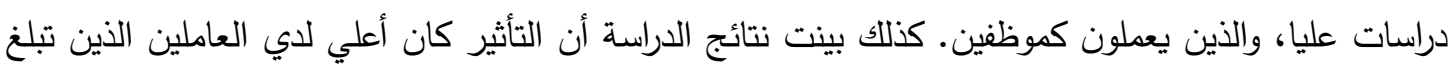
سنوات خبرتهم (أقل من 0 سنوات).

وأوضحت النتائج أن الإستقرار الوظيفي يؤثر علي السعادة الوظيفية لدي الإناث بشكل أكبر من الذكور. كما كان هذا التأثير أعلي لدي الفئة العمرية (أقل من ·r سنة). وكان هذا التأثير أعلي لدي الحاصلين الإني علي مؤهل متوسط، والذين يعملون كموظفين. كذللك أبرزت نتائج الدراسة أن التأثير كان أعلي لاي العاملين الذين تبلغ سنوات خبرتهم (من هالى أقل من · 1 سنوات). كذللك أظهرت النتائج أن الإستقرار الوظيفي يؤثر علي الإخلاد

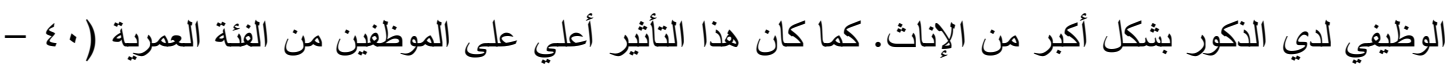
أقل من •• سنة). وكان هذا التأثير أعلي لاي الموظفين الحاصلين علي مؤهل بكالوريوس. كذلك أبرزت نتائج الدراسة أن التأثير كان أعلي لدي العاملين الذين تبلغ سنوات خبرتهم (0 - أقل من • ( سنوات). وأكدت النتائج أيضاً أن الإحباط الوظيفي يؤثر علي السعادة الوظيفية لاي الإناث بشكل أكبر من الذكور . كما كان هذا التأثير

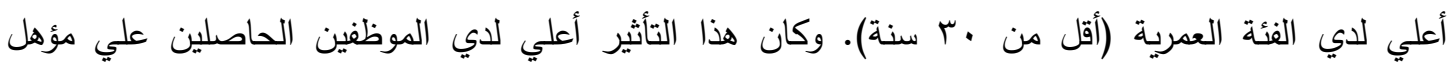

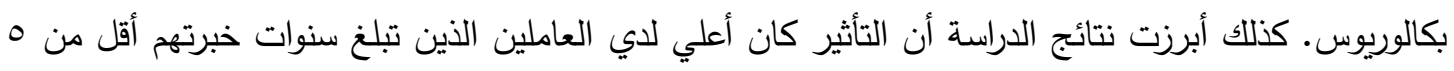
سنوات.

بالإضافة إلي ذلك؛ أوضحت النتائج أن الإحباط الوظيفي يؤثر علي الإخلال الوظيفي لدي الذكور بشكل أكبر

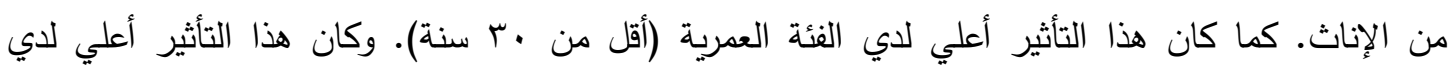
الحاصلين علي مؤهل دراسات عليا، والذين يعملون كموظفين. كذلك أبرزت نتائج الدراسة أن التأثير كان أعلي لدي العاملين الذين تبلغ سنوات خبرتهم (أقل من ه سنوات). وتوصلت النتائج إلي أن السعادة الوظيفية يؤثر

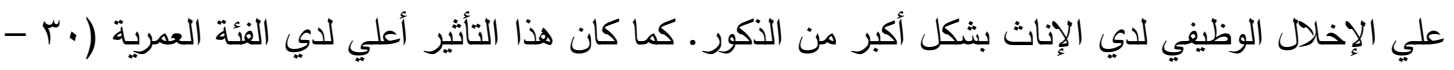


أقل من ·ـ سنة). وكان هذا التأثير أعلي لاي الحاصلين علي مؤهل بكالوريوس، والذين يعملون كموظفين.

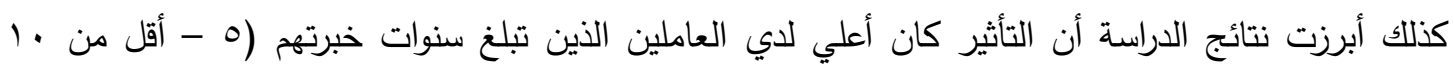

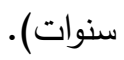

وأخيراً بينت نتائج الدراسة عدم وجود فروق ذات دلالة إحصائية في استجابات أفراد العينة لمتغيرات السعادة الوظيفية، والإستقرار الوظيفي، والإحباط الوظيفي والإخلال الوظيفي وفقاً للمتغيرات الديموغرافية والوظيفية. وفي ضوء ما توصلت إليه الدراسة من نتائج؛ ينغي علي شركات السياحة الاهتمام بتحقيق رضاء العاملين نظراً

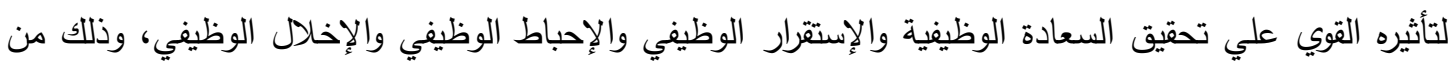

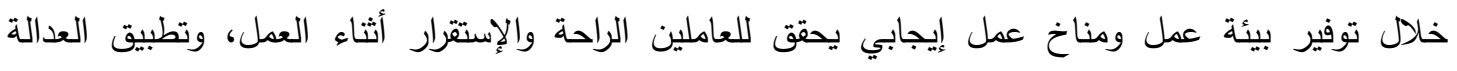

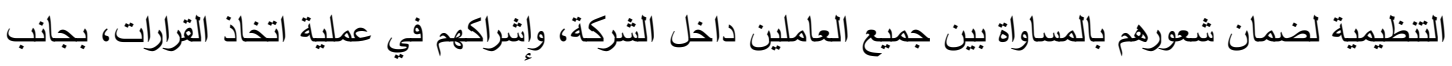

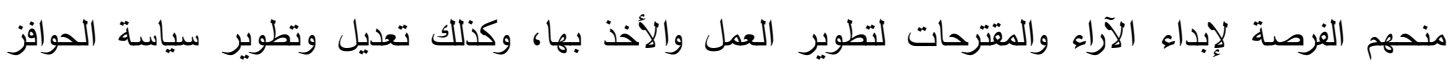

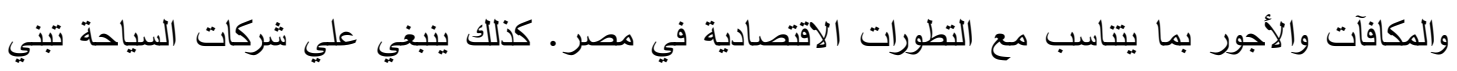

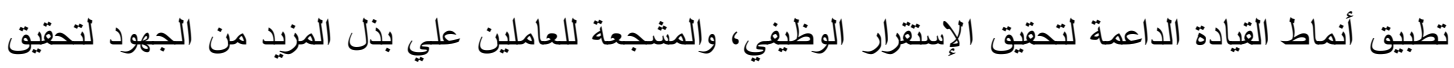
أهداف الثركة وأهدافهم الخاصة مثل نمط القيادة الخادمة والقيادة الملهمة.

علاوة علي ذللك؛ ينبغي علي المديرين في تلك الثركات الاهتمام بالاحتياجات الثخصية للعاملين، ومشاركتهم

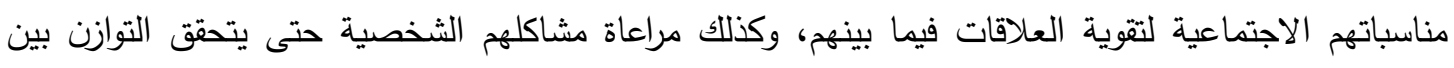

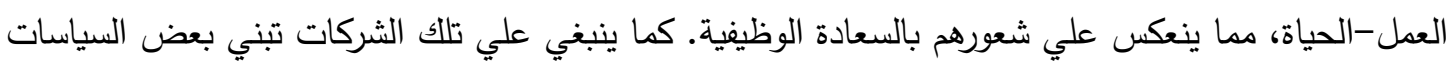

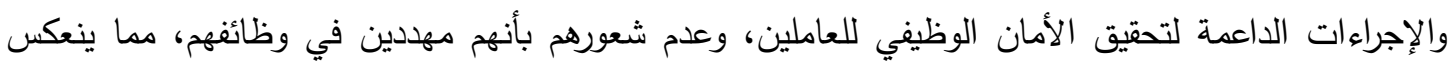

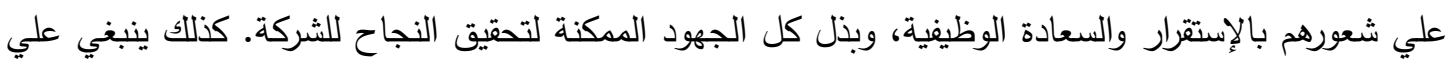

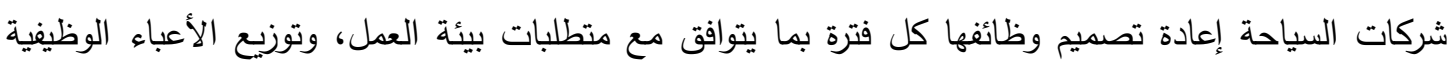

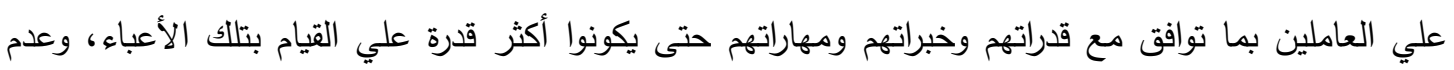
إحباطهم وظيفياً.

بالإضافة إلي ذلك؛ ينبغي علي تلك الثركات الاهتمام بتوفير الفرص التدريبية التي من شأنها تطوير مهارات

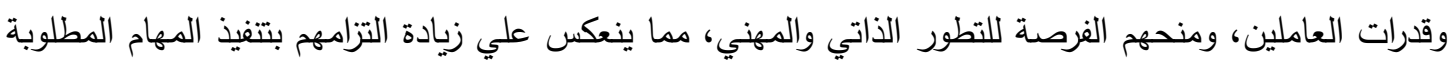

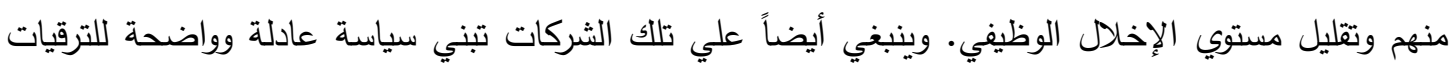

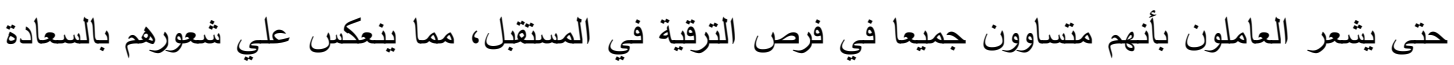
والتفاؤل بالمستقبل الوظيفي.

وأخيراً؛ إذا ما استمرت شركات السياحة في الاهتمام بتعزيز العوامل المسببة للسعادة الوظيفية والإستقرار الوظيفي

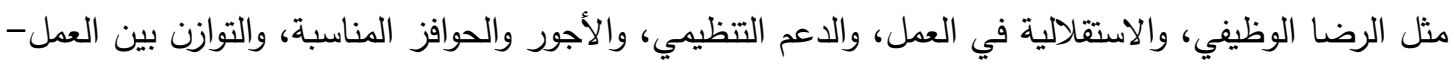

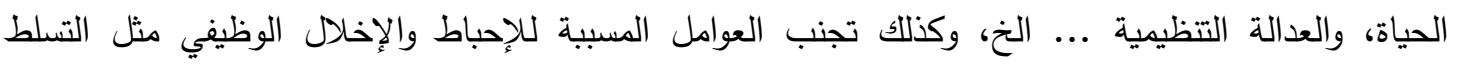

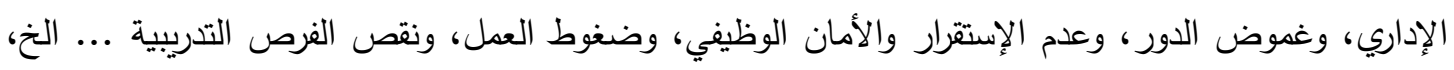


فإن ذللك قد يؤدى الى زيادة استقرار وسعادة العاملين في وظائفه، وزيادة مستوي تفاؤلهم بالنجاح الوظيفي، وهو ما سينعكس علي نمو واستمرار ونجاح وتتافسية تلك الشركات بشكل كبير في المستقبل.

الاراسات المستقبلية المقترحة

- - أثر سياسات إدارة الموارد البشرية علي الاستقرار الوظيفي في شركات السياحة.

- - تقييم دور سياسات إدارة الموارد البشرية في الحد من الإحباط والإخلال الوظيفي في شركات السياحة.

- العلاقة بين المرونة الإستراتيجية والإستقرار الوظيفي في شركات السياحة.

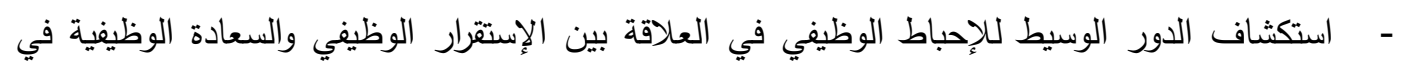

شركات الطيران.

المراجع

أولاً: المراجع العربية

- - أبو المعاطي، هنادي وفياض، سامح (9 (19) أثر الإحباط الوظيفي في الإلتزام العاطفي والتمثيل السطحي في بعض الفنادق المصرية: الخبرة الوظيفية وسيط محسن، مجلة اتحاد الجامعات العربية للسياحة والضيافة، $\left..1 Y V-I Y T_{6}(1)\right) V$

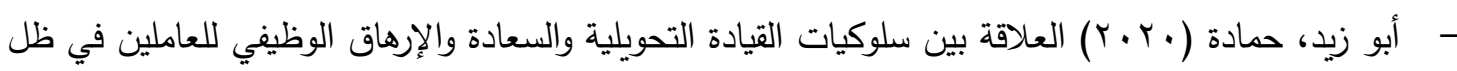

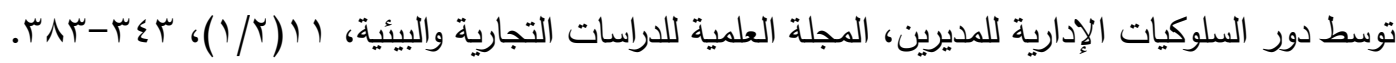
- أبو سنيمة، أسعد (·.Y.Y) الابتكار التظيمي لدي مديري المدارس الحكومية بمحافظات غزة وعلاقته بالسعادة الوظيفية لدي المعلمين من وجهة نظرهم، رسالة ماجستير غير منشورة، كلية التربية، جامعة الأقصى بغزة، فلسطين.

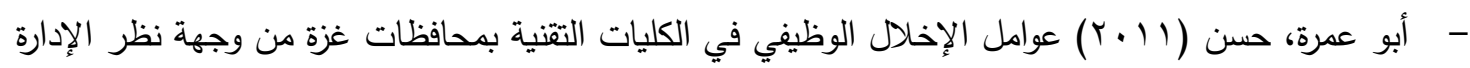
العليا، رسالة ماجستير غير منشورة، كلية التجارة، الجامعة الإسلامية - غزة، فلسطين.

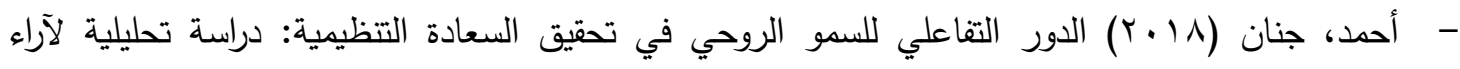

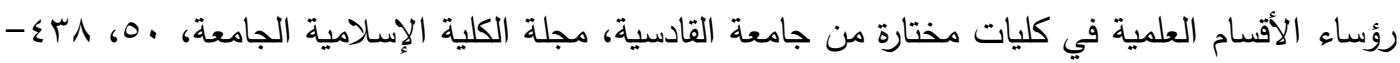

- - إسماعيل، عمار (Y.r.r) الدعم التنظيمي المدرك والآثار النفسية لفيروس كورونا كمتغيرين وسيطين في العلاقة بين برامج صيانة الموارد البشرية والسعادة الوظيفية، المجلة العلمية للدراسات والبحوث المالية

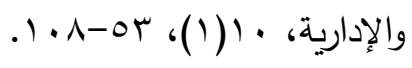

- آل إبراهيم، خالد (Y.Y.Y) دور الاتحاد العام لعمال سلطنة عمان في تحسين الإستقرار الوظيفي للعمال،

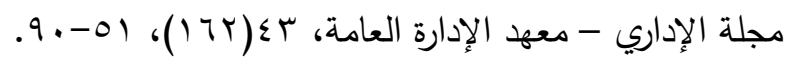

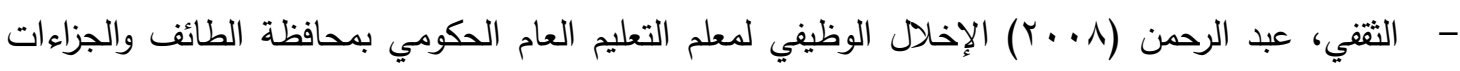
المناسبة لضبطها كما يراها المشرف التربوي والمدير والمعلم، رسالة ماجستير غير منشورة، كلية التربية،

$$
\text { جامعة أم القري، السعودية. }
$$


- الجبيري، فهز (·r.r. أثر طبيعة الوظيفة عليالإستقرار الوظيفي: دراسة تطبيقية علي العاملين بالمديرية

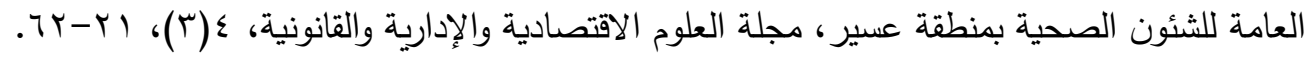

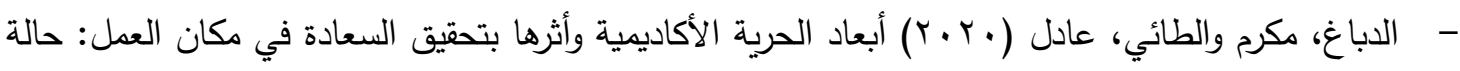

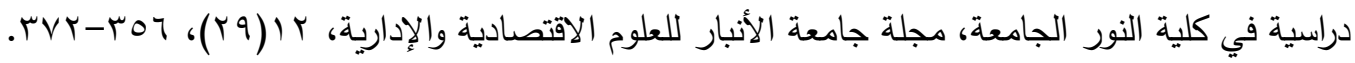
الربيعة، عبد العزيز (1) ( ب) البحث العلمي - حقيقته ومصادره ومادته ومناهجه وكتابته وطباعته ومناقشته، الجزء الأول، مكتبة الملك فهد الوطنية، الرياض.

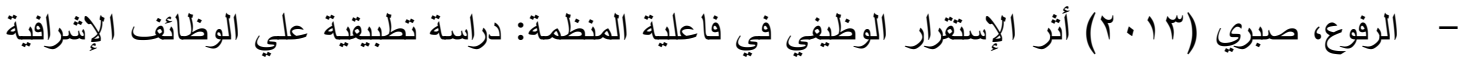
في سلطة منطقة العقبة الاقتصادية الخاصة، رسالة ماجستير غير منشورة، عمادة الدراسات العليا، جامعة مؤتة، الأردن.

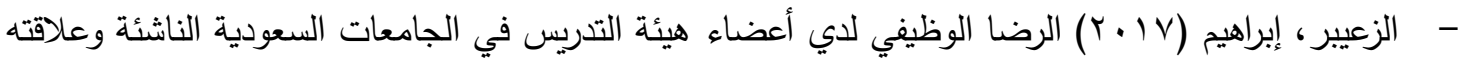

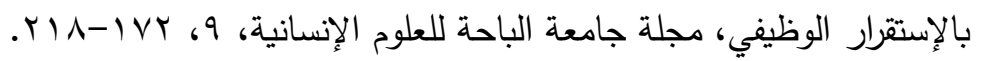

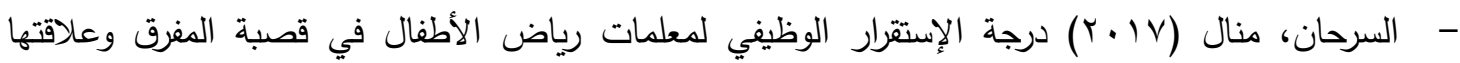
بمستوي الأداء الوظيفي، رسالة ماجستير غير منشورة، كلية العلوم التربوية، جامعة آل البيت، الأردن.

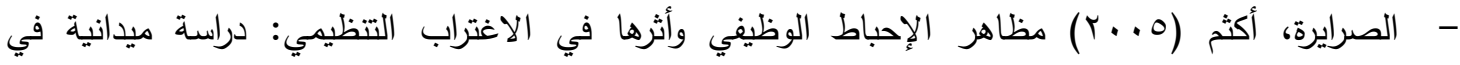

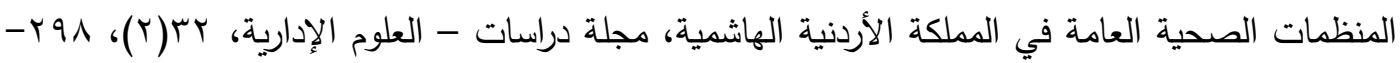
.TYV

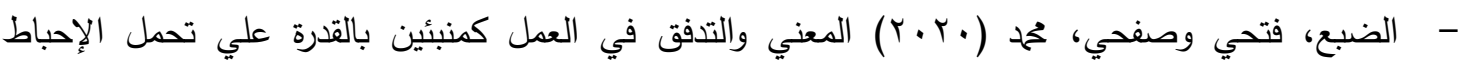

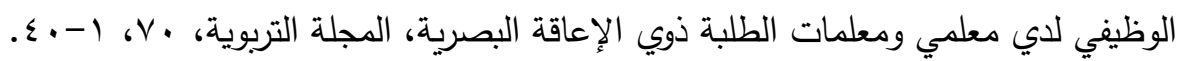

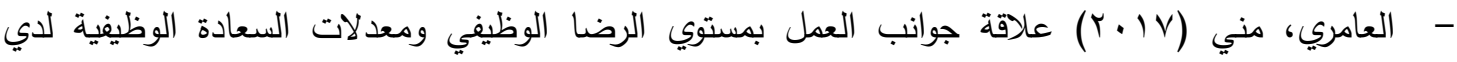
العاملين في المدارس الحكومية والخاصة: دراسة علي مجلس أبو ظبي للتعليم في العين، رسالة ماجستير غير منشورة، كلية العلوم الإنسانية والاجتماعية، جامعة الإمارات العربية المتحدة، الإمارات العربية المتحدة.

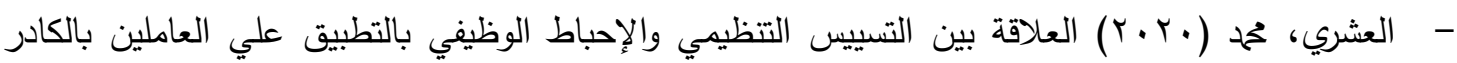

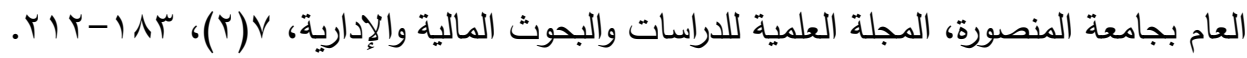

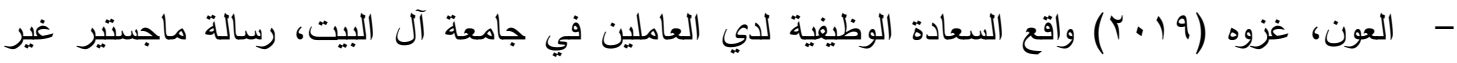
منشورة، كلية إدارة المال والأعمال، جامعة آل البيت، الأردون. - الفهداوي، بناء (9 (ب) درجة ممارسة مديري مدارس تربية لواء الجامعة للقيادة بالفضائل الإسلامية وعلاقتها بالسعادة الوظيفية، رسالة ماجستير غير منشورة، كلية العلوم التربوية، جامعة آل البيت، الأردن.

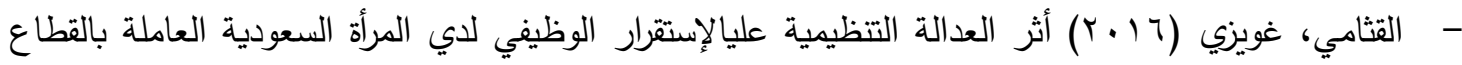

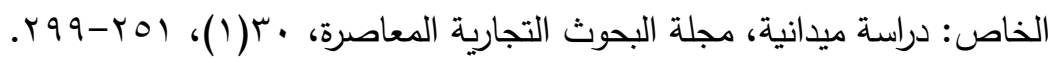

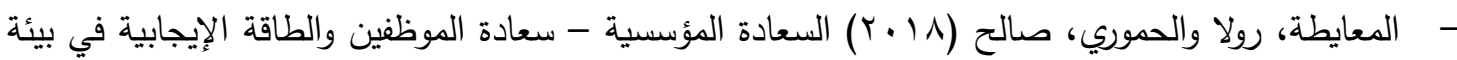
العمل، طس، دار قنديل للطباعة والنشر والتوزيع، الإمارات. 


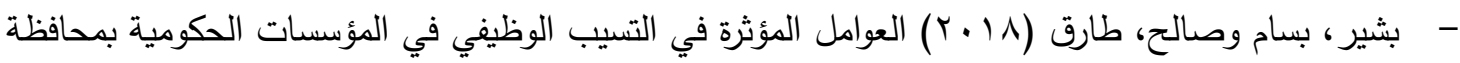

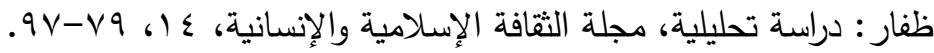

- - جمعة، محمود؛ ياسين، حمزة ونوري، حيدر (9 (19) تأثير تطبيقات الهندسة البشرية في السعادة الوظيفية عن طريق الرضا الوظيفي: بحث استطلاعي في كلية الهندسة الجامعة المستصرية، مجلة تتمية الرافدين،

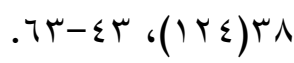

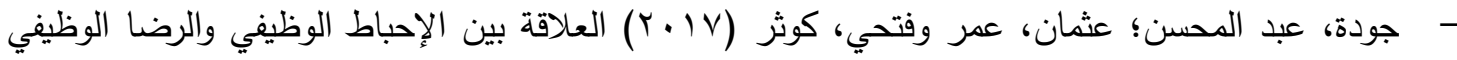
بالتطبيق علي المعلمين بالمدارس الحكومية بمدينة المنصورة، مجلة الدراسات والبحوث التجارية، VYس(ب)،

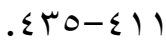

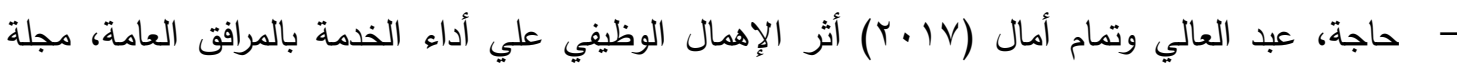

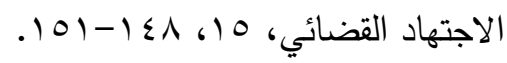
- - حمدان، سميرة (•r.r. درجة ممارسة القيادة التوزيعية لاي مديري مدارس التربية والتعليم لواء القويسمة وعلاقتها بالإستقرار الوظيفي للمعمين، رسالة ماجستير غير منشورة، كلية العلوم التربوية، جامعة آل البيت، الأردن.

حيدر، سنان وياسين، يوسف (Y (Y r) الروحانية الوظيفية وأثرها بتحقيق مؤشرات السعادة الوظيفية - دراسة ميدانية لآراء عينة من تدريسي عدد من الكليات الإنسانية في جامعة دهوك، مجلة جامعة دهوك، عب(Y)، סט

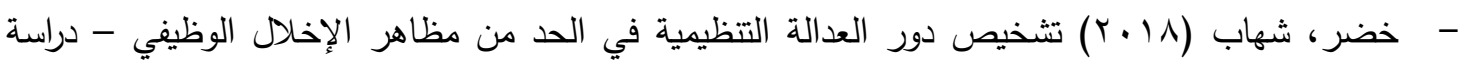
استطلاعية لآراء الكوادر الوظيفية في كليات جامعة دهوك التقنية، المؤتمر الدولي للجامعة الأردنية وجامعة القدس المفتوحة في عمان، الأردن. - - خلف، ياسر (Y.Y.r) السعادة في العمل ودورها في تعزيز الثقة التنظيمية: بحث استطلاعي لآراء العاملين

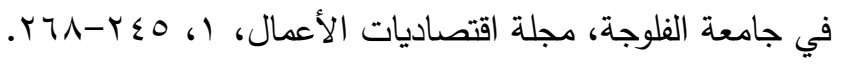

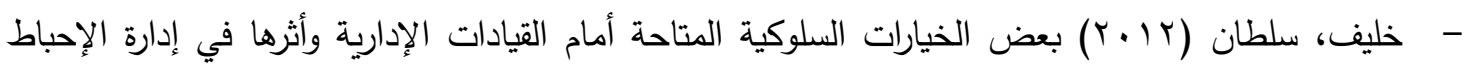
الوظيفي للعاملين - دراسة لآراء عينة من رؤساء الأقسام والثعب في معمل منت بادوش الجديد، مجلة

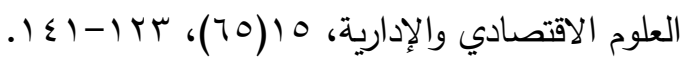
خوجة، زينة (•r.r. القيادة الخادمة ودورها في التقليل من الإخلال الوظيفي - دراسة ميدانية بكلية العلوم الإنسانية والاجتماعية بجامعة المسيلة، رسالة ماجستير غير منشورة، كلية العلوم الإنسانية والاجتماعية، جامعة محمد بوضياف بالمسيلة، الجزائر .

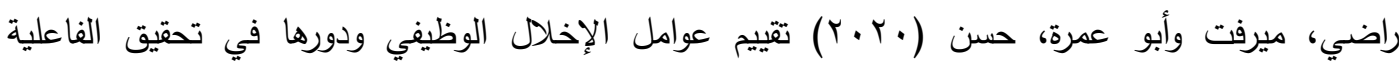

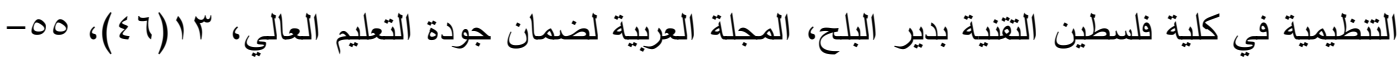
.$\wedge$. 
- ـ رشيد، فارس (11 (1) الإحباط الوظيفي وعلاقته بجودة حياة العمل لدي موظفات المؤسسات الحكومية في

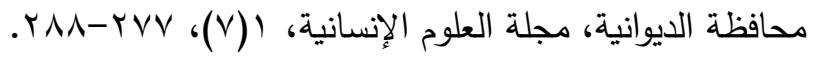

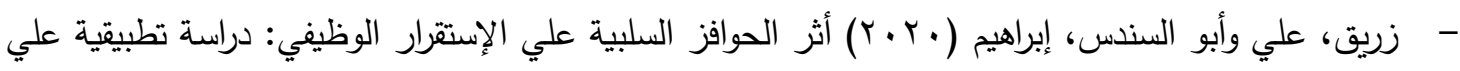

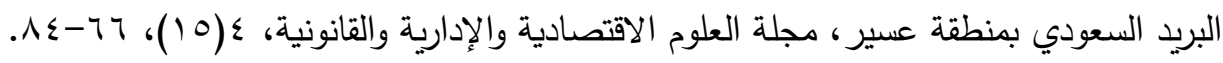

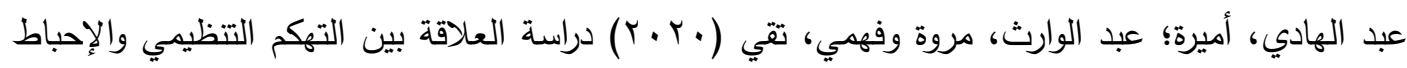

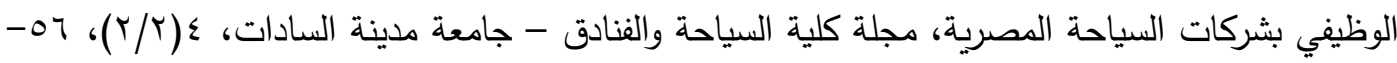

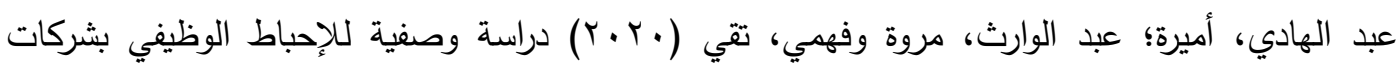

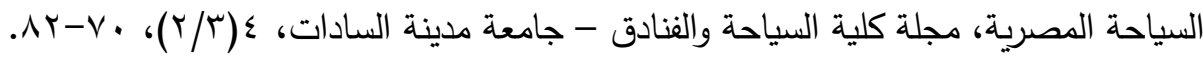

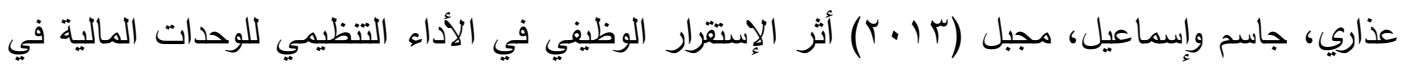

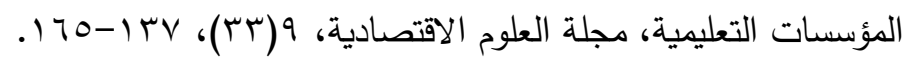

عذافة، رائد و محمد، نسرين (Y.Y.Y) القيادة المستدامة وتأثيرها في السعادة التتظيمية - بحث تحليلي في هيئة

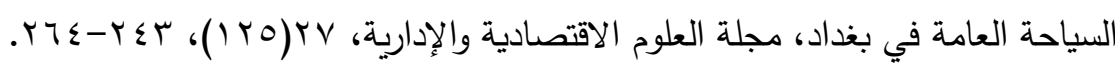

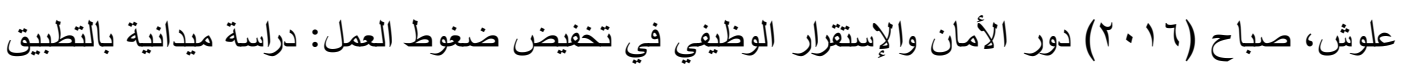

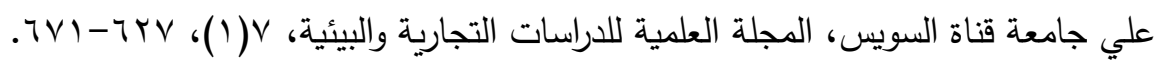

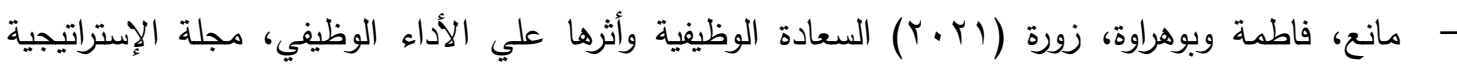
والتتمية، إع، (Y)؛

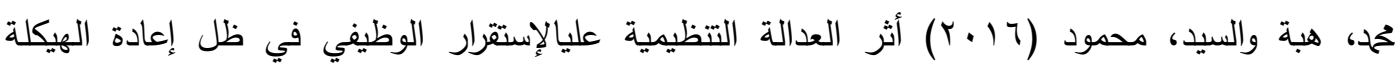

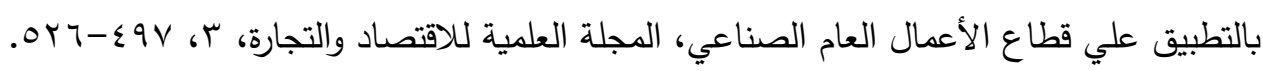
- محمود، خالد (r.r.r) الإحباط الوظيفي وعلاقته ببعض المتغيرات لدي المرشدين التربويين، مجلة دراسات

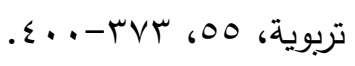

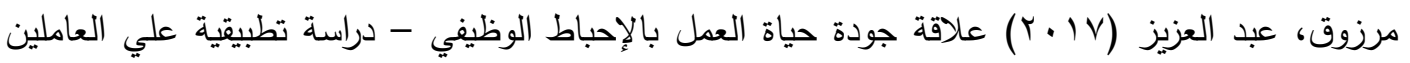

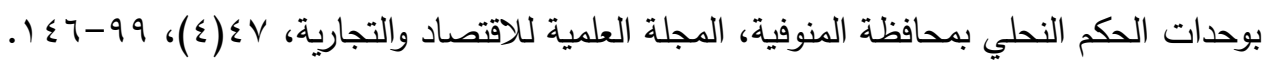

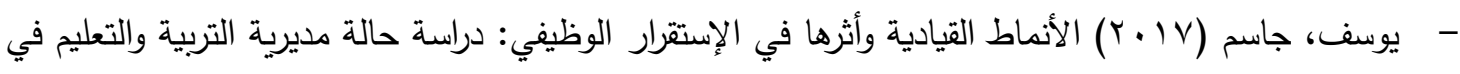
محافظة المفرق، رسالة ماجستير غير منشورة، كلية الاقتصاد والعلوم الإدارية، جامعة آل البيت، الأردن.

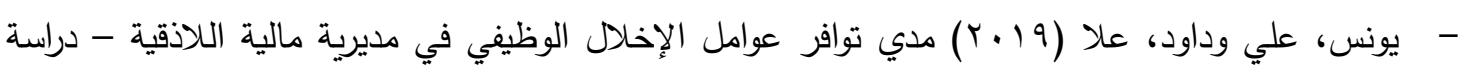

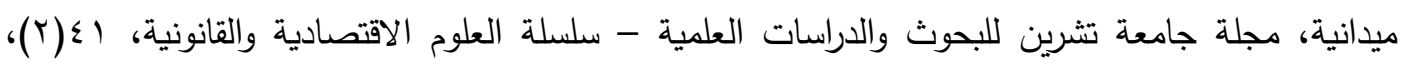

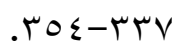

\section{ثانياً: المراجع الأجنبية}

Åhlin, J. K., Halonen, J. I., Madsen, I. E., Rugulies, R., Sørensen, J. K., \& Hanson, L. L. M. (2021). Interrelationships between job demands, low back pain and depression: A four-way decomposition analysis of direct and indirect effects 
of job demands through mediation and/or interaction. Journal of Affective Disorders, 282, 219-226.

- Al-Ali, W., Ameen, A., Isaac, O., Khalifa, G. S., \& Shibami, A. H. (2019). The mediating effect of job happiness on the relationship between job satisfaction and employee performance and turnover intentions: A case study on the oil and gas industry in the United Arab Emirates. Journal of Business and Retail Management Research, 13(4), 103-116.

- Ali, S. M. A. (2020). Impact of Salaries and Financial Incentives on Job Stability at Al-Basr International Foundation (Makkah Eye Hospital-Sudan). International Journal of Business and Social Science, 11(11), 41-48.

- Alserhan, H., Al-Adamat, A., \& Al-Adamat, O. (2021). The mediating effect of employee happiness on the relationship between quality of work-life and employee intention to quit: A study on fast-food restaurants in Jordan. Management Science Letters, 11(3), 933-938.

- Awang, Z. (2012). A handbook on structural equation modeling using AMOS. Universiti Technologi MARA Press, Malaysia.

- Bastos, W., \& Barsade, S. G. (2020). A new look at employee happiness: How employees' perceptions of a job as offering experiences versus objects to customers influence job-related happiness. Organizational Behavior and Human Decision Processes, 161, 176-187.

- Bui, A. T., Lambert, S., Phung, T. D., \& Reynolds, G. (2021). The Impact of Business Obstacles on Firm Growth and Job Stability in East Asia and Pacific Nations. Sustainability, 13(19), 10949.

- Butt, R. S., Wen, X., \& Hussain, R. Y. (2020). Mediated effect of employee job satisfaction on employees' happiness at work and analysis of motivational factors: evidence from telecommunication sector. Asian Business Research Journal, 5, 1927.

- Ganson, K. T., Tsai, A. C., Weiser, S. D., Benabou, S. E., \& Nagata, J. M. (2021). Job insecurity and symptoms of anxiety and depression among US young adults during COVID-19. Journal of Adolescent Health, 68(1), 53-56.

- Hair Jr., Hult, G., Ringle, C., \& Sarstedt, M. (2021). A primer on partial least squares structural equation modeling (PLS-SEM). Sage publications.

- Kamau, B. W. (2020). The Intervening Role of Employee's Awareness on the Relationship between the Adequacy of Welfare and Job Stability of University Catering Employees in Nairobi City County, Kenya. Journal of Hospitality and Tourism Management, 3(2), 1-24.

- Mérida- López, S., Extremera, N., Quintana- Orts, C., \& Rey, L. (2019). In pursuit of job satisfaction and happiness: Testing the interactive contribution of emotion- regulation ability and workplace social support. Scandinavian journal of psychology, 60(1), 59-66.

- Ministry of Tourism and Antiquities (2021). Tourism in Figures. Central department of information and decision support, general department of information and statistics, Egypt.

- Nitecki, R., Albright, B., \& Moss, H. (2021). Employment disruption in patients with gynecologic cancer: who is at risk?. Gynecologic Oncology, 162, S148. 
- Sánchez-Sánchez, N., \& Puente, A. C. F. (2021). Public versus private job satisfaction. Is there a trade-off between wages and stability?. Public Organization Review, 21(1), 47-67.

- Saquib, N., Zaghloul, M. S., Saquib, J., Alhomaidan, H. T., Al- Mohaimeed, A. \& Al- Mazrou, A. (2019). Association of cumulative job dissatisfaction with depression, anxiety and stress among expatriate nurses in Saudi Arabia. Journal of nursing management, 27(4), 740-748.

- Umeoji, I. C., \& Ugwu-Oju, A. (2019). Organizational frustration and selfenhancing humour as correlates of adherence to criminal investigation procedure. Zik Journal of Multidisciplinary Research, 2(1), 110-119. 


\title{
The Impact of Job Happiness and Job Stability on Employees in Egyptian Travel Agencies
}

\author{
Hebatullah Ali \\ Bassam Al-Romeedy
}

Faculty of Tourism and Hotels Tourism Studies Department University of Sadat City

\section{ARTICLE ABSTRACT INFO}

Keywords: job happiness; job stability; job frustration; job dysfunction; Egyptian travel agencies.

\section{(JAAUTH)} Vol. 23, No. 1, (December 2022), PP.105-150.
Recently, various companies have increased their interest in psychological aspects of work, such as employees' feeling of job happiness and job frustration, in addition to the interest of these companies in providing job stability in the work environment to ensure that there is no dysfunction at work. The study aimed to assess the impact of job happiness, job stability, and job frustration on job dysfunction in travel agents, to determine whether job happiness has a mediating role in the relationship between job stability and job dysfunction in these agents. The study also aimed to determine if there were statistically significant differences among respondents to the study variables represented in job happiness, job stability, job frustration, and job dysfunction, according to demographic data. To achieve the objectives of the study; 591 forms were distributed to a sample of employees in travel agents in Cairo (Category A). 461 questionnaires were analyzed using SPSS V. 26 and AMOS V.21 programs. The study concluded that job happiness plays a partial mediating role in the relationship between job stability and job dysfunction. The results also highlighted the absence of statistically significant differences in the responses of the sample members to job happiness, job stability, job frustration, and job dysfunction due to demographic and functional variables. The study recommended the importance of adopting supportive leadership styles represented in the charismatic and servant leadership to achieve a high level of stability and job happiness among employees in Egyptian travel agencies. 